\title{
BROOKHGUEN
}

NATIONAL LABORATORY

BNL-93715-2009-IR

\section{Performance Study of Swimming Pool Heaters}

\author{
Roger J. McDonald
}

January 2009

Energy Science and Technology Department/Energy Resources Division

Brookhaven National Laboratory

P.O. Box 5000

Upton, NY 11973-5000

www.bnl.gov

Notice: This manuscript has been authored by employees of Brookhaven Science Associates, LLC under Contract No. DE-AC02-98CH10886 with the U.S. Department of Energy. The publisher by accepting the manuscript for publication acknowledges that the United States Government retains a non-exclusive, paid-up, irrevocable, world-wide license to publish or reproduce the published form of this manuscript, or allow others to do so, for United States Government purposes. 


\section{DISCLAIMER}

This report was prepared as an account of work sponsored by an agency of the United States Government. Neither the United States Government nor any agency thereof, nor any of their employees, nor any of their contractors, subcontractors, or their employees, makes any warranty, express or implied, or assumes any legal liability or responsibility for the accuracy, completeness, or any third party's use or the results of such use of any information, apparatus, product, or process disclosed, or represents that its use would not infringe privately owned rights. Reference herein to any specific commercial product, process, or service by trade name, trademark, manufacturer, or otherwise, does not necessarily constitute or imply its endorsement, recommendation, or favoring by the United States Government or any agency thereof or its contractors or subcontractors. The views and opinions of authors expressed herein do not necessarily state or reflect those of the United States Government or any agency thereof. 


\title{
Performance Study of Swimming Pool Heaters
}

\author{
Brookhaven National Laboratory \\ Energy Sciences and Technology Department \\ Energy Resources Division
}

January 2009

Roger J. McDonald

Under Agreement with National Grid 


\section{Legal Note}

\section{United States Department of Energy}

This report was prepared as an account of work sponsored by an agency of the United States Government. Neither the United States Government nor any agency thereof, nor any of their employees, nor any of their contractors, subcontractors, or their employees makes any warranty, express or implied, or assumes any legal liability or responsibility for the accuracy, completeness, or usefulness of any information, apparatus, product, or process disclosed, or represents that its use would not infringe privately owned rights. Reference herein to any specific commercial product, process, or service by trade name, trademark, manufacturer, or otherwise, does not necessarily constitute or imply its endorsement, recommendation, or favoring by the United States Government or any agency, contractor or subcontractor thereof. The views and opinions of authors expressed herein do not necessarily state or reflect those of the United States Government or any agency, contractor, or subcontractor thereof.

\section{Acknowledgements}

The author would like to gratefully acknowledge Long Island homeowners, Garret Johnson and Joseph McCabe who allowed Brookhaven National Laboratory (BNL) to visit their homes in order to install data loggers, take photographs, to record information and monitor over several days the performance of their swimming pool heaters as discussed in the field survey section of this report. The author also gratefully acknowledges the valuable contributions of several other people who helped by reviewing and providing comments and edit corrections for this report, C.R. Krishna, Ph.D., Thomas A. Butcher, Ph.D., or who helped by providing technical support assistance in the setup and operation of the laboratory pool heater test facility, Yusuf Celebi, George Wei, Christopher Brown all from Brookhaven National Laboratory, also Matthew Brown a Clarkson University summer student. Of course, the author gratefully acknowledges the assistance of Richard Petraglia, Project Manager at National Grid. 


\section{Table of Contents}

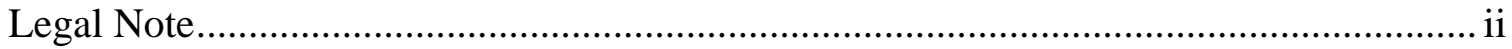

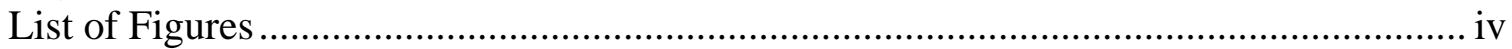

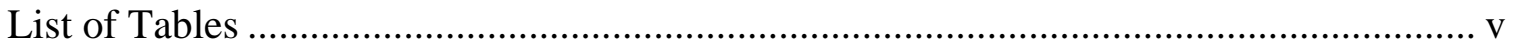

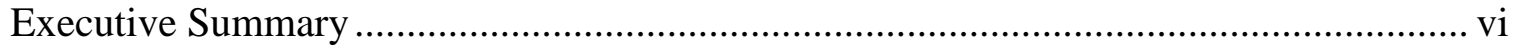

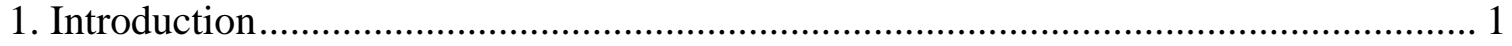

2. Field Study of Swimming Pool Heaters and Determination of Testing Protocol........... 2

Table 1 Flue gas emissions and stack gas efficiency data at Southold, NY test site ...... 4

3. Market Survey of Available Pool Heaters ............................................................... 10

4. Discussion of Market Survey Results and Selection of Units for Testing.................... 16

5. Measurement System to Determine Pool Heater Performance Characteristics............ 18

6. Gas Pool Heater Test Results.................................................................................... 23

6.1 Hayward H150 ........................................................................................... 23

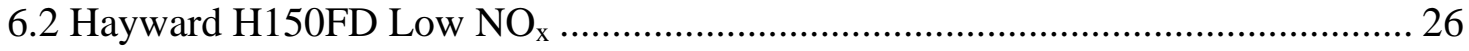

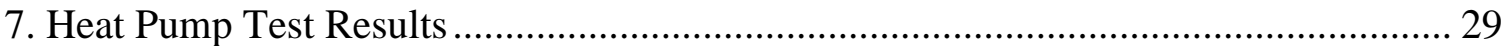

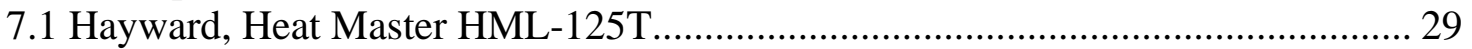

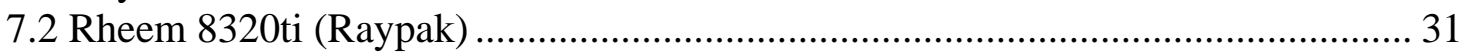

8. General Comments - All Heater Tests ................................................................. 33

9. Comparative Analysis of Costs, Energy Use and Environmental Emissions ............... 34

9.1 Initial Costs of Pool Heaters and Factors Associated with Sizing Capacity........... 34

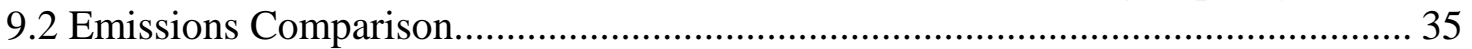

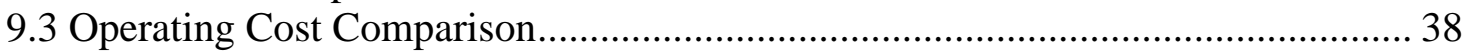

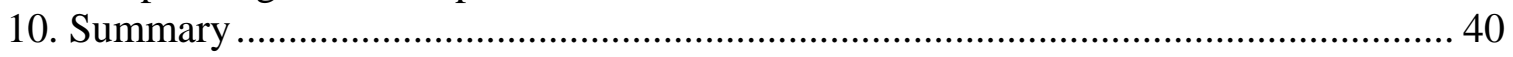




\section{List of Figures}

Figure EX-1 H150FD, cyclic measurement results of a low $\mathrm{NO}_{\mathrm{x}}$ gas-fired heater ... vii Figure EX-2 Model 8320ti, COP results for an electric heat pump heater .............. viii

Figure EX-3 Typical swimming pool heater installation............................................xi

Figure 1 Typical swimming pool heater installation ................................................ 1

Figure 2 Hayward H-400 pool heater at the Southold, NY field test site ................... 2

Figure 3 Swimming pool 38' by 18' located at site 1, Southold, NY ......................... 3

Figure 4 Stack temperature data from site in Southold, NY September 11, 2008...... 5

Figure 5 Hayward H-400 induced draft pool heater at the East Northport test site.. 7

Figure 6 Swimming pool 38' by 18' located at site 2, East Northport, NY................. 7

Figure 7 Stack temperature data for East Northport, NY site, September 13-14 ...... 8

Figure 8 Tightly finned copper low mass heat exchanger of a gas-fired heater ....... 13

Figure 9 Swimming pool load simulator ..................................................................... 19

Figure 10 AC-250 gas meter with pulser and readout.................................................. 20

Figure 11 Baseline gas-fired pool heater in the BNL test facility ............................. 20

Figure 12 Flow meter (brass body), RTD sensors (see blue/red tagged gray wires) 21

Figure 13 Testo 350XL Emissions analyzer system $\left(\mathrm{O}_{2}, \mathrm{NO}_{2}, \mathrm{NO}, \mathrm{SO}_{2}, \mathrm{CO}, \mathrm{CO}_{2}\right) . .22$

Figure 14 Hayward H150, pilot ignition .................................................................... 23

Figure $15 \mathrm{H150}$ with factory vent kit added....................................................................... 23

Figure $16 \mathrm{H150}$ - output rate as a function of input rate during cyclic operation ... 25

Figure $17 \mathrm{H150}$ - efficiency under cyclic operation as a function of input ............... 25

Figure 18 Hayward H150FD low $\mathrm{NO}_{\mathrm{x}}$ natural gas-fired pool heater ....................... 26

Figure 19 H150FD - output rate as a function of input rate for cyclic operation ..... 28

Figure 20 H150FD - efficiency under cyclic operation as a function of input .......... 28

Figure 21 Hayward Model: Heat Master HML-125T electric heat pump ................ 29

Figure 22 HML125L back end showing plumbing connections on the bottom ........ 30

Figure 23 COP results - Heat Master HML125L electric heat pump......................... 31

Figure 23 Rheem Model 8320ti electric heat pump being tested at BNL .................. 32

Figure 25 COP results for Rheem Model 8320ti electric heat pump .......................... 32 


\section{List of Tables}

Table EX-1 Pollutant emissions, pounds per million Btu as delivered to the load .... ix Table EX-2 Comparison of operating cost per MMBtu of heat supplied to load...... ix Table EX-3 Comparison, cost per 2.7 MMBtu of heat supplied, rise of $10 \mathrm{deg}$. F ......X Table 1 Flue gas emissions, stack gas efficiency data at Southold, NY test site ...........4 Table 2 Flue gas emissions, stack efficiency data at East Northport, NY test site.....10 Table 3 Natural gas swimming pool heater survey results ............................................13

Table 4 Heat pump swimming pool heater survey results ...........................................16

Table 5 Model H150, Steady State Efficiency Results ............................................25

Table 6 Model H150, Steady State Emission Results ....................................................25

Table 7 Model H150FD, Steady State Efficiency Results .........................................28

Table 8 Model H150FD, Steady State Emission Results .................................................28

Table 9 Model HML125L, Input-Output COP Results ...............................................31

Table 10 Model 8320ti, Input-Output COP Results .....................................................32

Table 11 Water flow rate and temperature rise data for all units tested ..................34

Table 12 Analysis of natural gas constituents in volume percentage .......................36

Table 13 Pollutant emissions from gas heaters due to gas consumption ....................37

Table 14 Pollutant emission in pounds per million Btu as delivered to the load ......38

Table 15 Comparison of operating cost per MMBtu of heat supplied to load............39

Table 16 Comparison of cost per 2.7 MMBtu supplied to load, rise of $10 \mathrm{deg}$. F ......40 


\section{Executive Summary}

Brookhaven National Laboratory (BNL) conducted a study, for National Grid to measure the performance factors associated with gas-fired and electric heat pump swimming pool heaters in order to assess the relative energy, environmental and economic consequences of using one technology in comparison to the other.

Prior to the laboratory measurements, a brief field investigation was conducted to obtain some basic functional knowledge with regard to how these appliances are actually used under real operating conditions. Two pool owners were identified by BNL and permission was granted to conduct a concise study of the operating characteristics of the gas-fired heaters installed at these locations. Temperature measurements and the cyclic operating characteristics were recorded by using portable data loggers. This provided BNL with a good understanding of the normal operation and use patterns for the pool heaters. This knowledge was then used to design and assemble a swimming pool load simulator along with a performance measurement test stand. The simulator was sized with a volume of 1,600 gallons of water to allow for up to three hours of full steady state operation. The simulator also allowed for up to 24 hours of cyclic operation. In either test mode draining the heated water in the tank and refilling it with cooler water recycled the simulator for use in the next test.

A survey of the various gas-fired and electric heat pump pool heaters was conducted including the manufacturer's efficiency or coefficient of performance (COP) ratings, output (used for heat pump units) or thermal input capacities (used for gas-fired units), unique design features and prices as found on Internet sites. This survey presented a wide array of different manufacturers and product lines of various designs. The capacities of gas-fired units ranged from a low 150,000 Btu per hour input to a high of 400,000 Btu per hour, retail prices varied from about $\$ 1,000$ to $\$ 2,000$ including low- $\mathrm{NO}_{\mathrm{x}}$ emission units. There was one exception and that was an ultra-high efficiency gas-fired unit with a condensing heat exchanger that had a listed efficiency rating of 95\% with a price of around \$5,000. Only heat pumps with listed output capacities greater than 100,000 Btu were included in the survey. These ranged from 100,000 to 140,000 Btu per hour with prices between $\$ 2,900$ and $\$ 4,600$. The majority of the heat pump units were equipped with scroll compressors but two manufacturers offer units with piston compressors. Heat pumps can be equipped with special optional features including an automatic defrost cycle for very cold weather conditions and even a reversing control with some product lines so that the heat pump can provide cooling of a pool in extremely hot summer climates. These were also omitted form the survey results. From the many designs included in the survey BNL selected four units for testing. The first gas-fired unit (Hayward H-150) was equipped with a standing pilot and millivolt control. It was considered to be representative of typical older designs still in use today. The second gas unit (Hayward H-150FD) incorporated an electric spark ignition control, low $\mathrm{NO}_{\mathrm{x}}$ combustion technology and a fully pre-mixed induced draft combustion system and a modestly higher efficiency rating. The two electric heat pumps selected (Rheem 8328ti 
and Hayward HML-125T) were both equipped with scroll type compressors. They were selected to be representative of the products currently being sold in the marketplace.

BNL has conducted a vast array of projects over many years associated with measuring the efficiency of residential hydronic boilers and more recently with absorption heat pump systems. This provided the starting point for this project in developing the test stand and test protocol. Efficiency can be determined by many methods but in its most basic definition it is the amount of useful output divided by the total amount of energy input to a system. BNL applied a thermal dynamic based input-output measurement technique for determining heater efficiency based on its many years of experience in measuring similar systems (residential boilers). This involves measuring the temperature rise and mass flow rate of water passing through the appliance as well as the energy inputs in terms of the fuel and/or electric power used to generate the heat input to the system. BNL has also amassed a great amount of experience in emissions measurements associated with all types of combustion appliances including oil, gas and wood fired systems. This was the basis of the techniques used in this project.

The data obtained from the field study and the first two units tested provided a good understanding of the operational characteristics of pool heaters. The most important was that the thermal mass and heat capacity of a pool heater is very small in comparison to a conventional residential boiler. The capacity for retaining any residual heat in the unit when the burner shuts down is almost non-existent. This is due to the very high water circulation rates and the effectiveness of the heat exchanger designs. Figure EX-1 is a plot of the efficiency characteristics of the H-150FD, a low- $\mathrm{NO}_{\mathrm{x}}$ gas-fired heater as a function of input percentage of the maximum rate. This very flat profile verifies that the heater exchanger has almost no thermal capacity. The high water circulation rate effectively purges any residual stored heat from the unit. The fall off in the outlet water temperature occurs in a mater of approximately 15-20 seconds after the burners shut off.

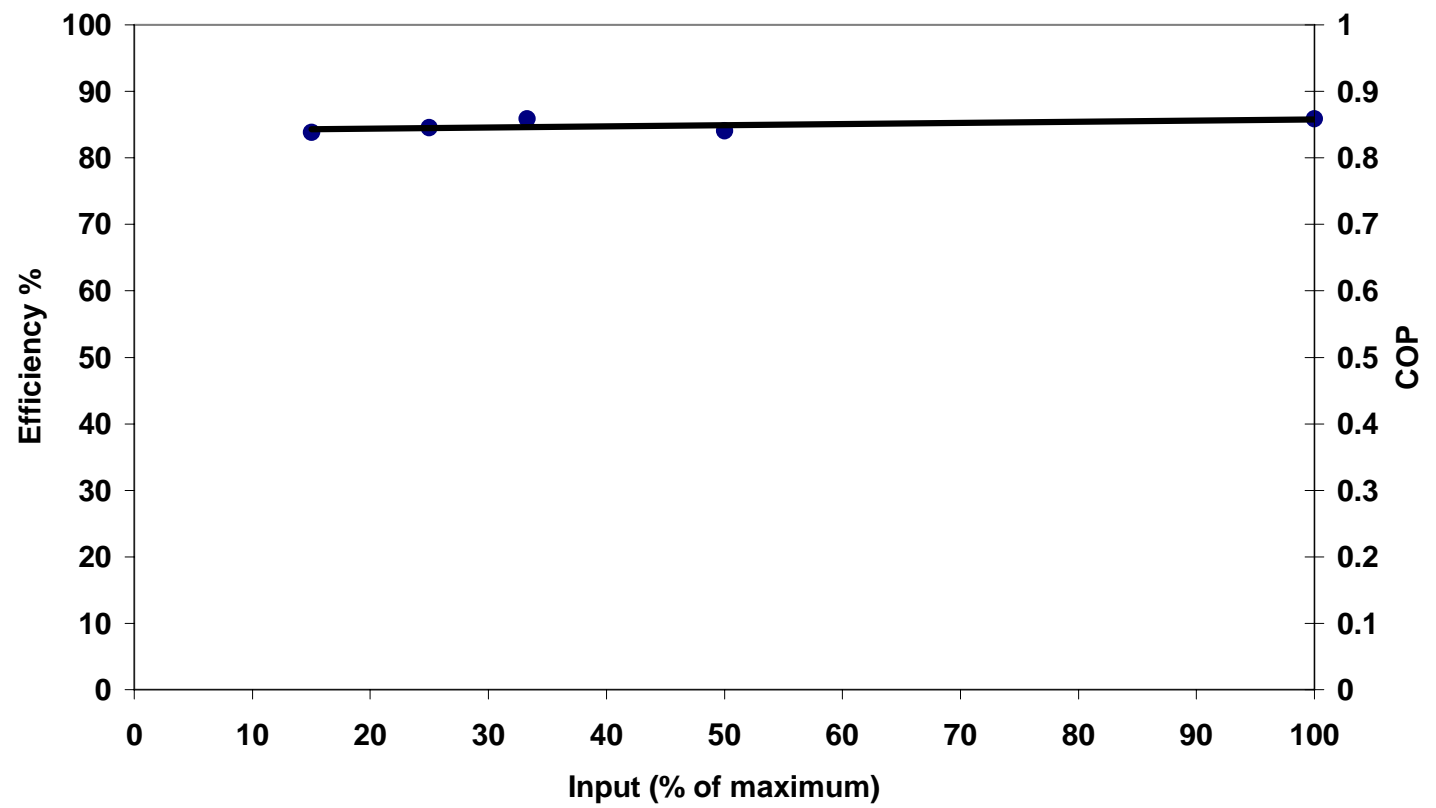

Figure EX-1 H150FD, cyclic measurement results of a low $\mathrm{NO}_{\mathrm{x}}$ gas-fired heater 
Given the design of the heat pump units and some early shake down test data, it became apparent that the heat pumps could also be characterized as having an extremely low thermal mass and heat capacity. These units were designed to operate with the same high rates of water flow and were almost instantly purged of any residual heat when the heat pumps were switched off. Heat pump capacity and associated performance are a function of the temperature of the heat source, which in this case is the ambient air. Based on these characteristics, BNL made the decision to only pursue measurement of heat pump COP as a function of ambient temperature variation. Figure EX-2 is a plot of the COP for the R-8328ti heat pump. It illustrates the expected typical fall off in performance as the heat source temperature, the ambient air, decreases.

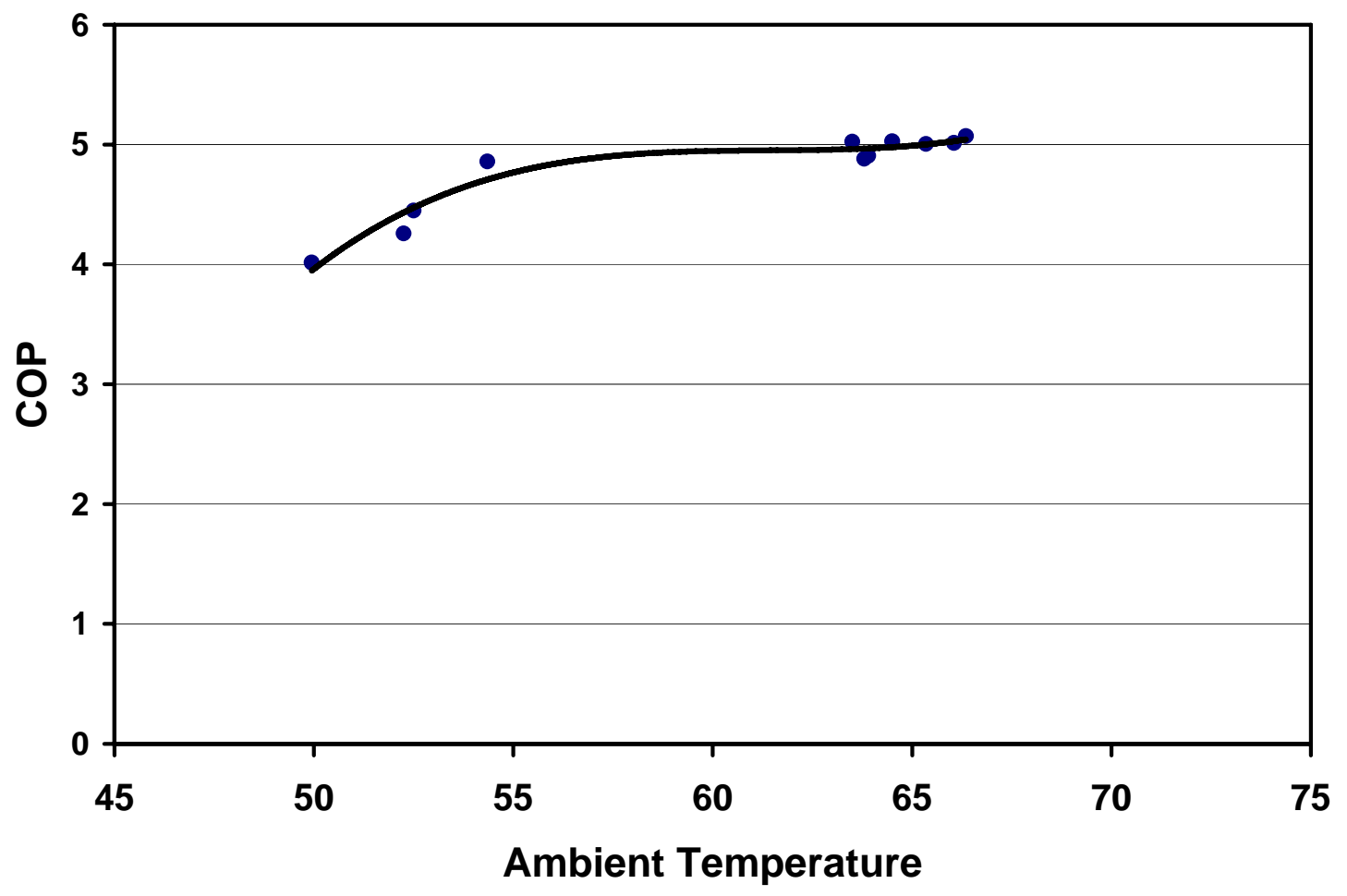

Figure EX-2 Model 8320ti, COP results for an electric heat pump heater

The specific emissions related to electric power generation used in this report are based on reported values available from 2005 as supplied by National Grid to the Federal Environmental Protection Agency (EPA) and available on the EPA eGRIDweb database. Knowing the emissions associated with the electric power generation used by the electric heat pumps as well as the emissions from the gas-fired units allowed for a direct comparison to be made as presented in Table EX-1. The emissions of carbon monoxide, $\mathrm{NO}_{2}$ and $\mathrm{NO}$ are not in this table because the eGRIDweb site provided no comparable data. The table contains the value for $\mathrm{NO}_{\mathrm{x}}$, the value when $\mathrm{NO}$ and $\mathrm{NO}_{2}$ emissions are combined. The results section of this report contains the more detailed emissions data as measured for the two gas-fired heaters. 
Table EX-1 Pollutant emission, pounds per million Btu as delivered to the load

\begin{tabular}{|c|c|c|c|c|}
\hline \multirow{2}{*}{ Pollutant } & \multicolumn{2}{|c|}{ Gas-fired Units } & \multicolumn{2}{c|}{ Heat Pump Units } \\
\cline { 2 - 5 } & Hayward & Hayward & Hayward & Rheem \\
\cline { 2 - 5 } Emitted & H-150 & H-150HD & HML125L & $8320 t$ \\
\cline { 2 - 5 } & Lbs/MMBtu & Lbs/MMBtu & Lbs/MMBtu & Lbs/MMBtu \\
\hline Carbon Dioxide & 143.8 & 136.1 & 99.8 & 90.0 \\
\hline Nitrogen Oxides & 0.1460 & 0.0224 & 0.1064 & 0.0960 \\
\hline Sulfur Dioxide & None Detected & 0.0050 & 0.2435 & 0.2198 \\
\hline
\end{tabular}

Operating cost comparisons calculated for two cases are presented in Tables EX-2 and EX-3. Table EX-2 presents the cost in terms of delivering one million Btu of heat without regard to the ancillary cost associated with the operation of the pool's water circulation pump. Given a 32,000-gallon pool this amount of heat would increase its temperature by about 3.7 degrees $\mathrm{F}$ assuming no losses are present. Table EX-3 presents the case when a 32,000-gallon pool is increased by 10 degrees F. In this example larger capacity gasfired units available with twice the output capacity were used. It was assumed and that they would have the same efficiency as the smaller units of the same product line design series. The heat pump units included are the same models as their capacity are already among the largest made and available in the market place. This example also includes the cost of using a typical pool pump while the pool heaters are operating to satisfy the heating load of 2.7 million Btu.

Table EX-2 Comparison of operating cost per MMBtu of heat supplied to load

\begin{tabular}{|l|c|c|c|c|c|}
\hline \multirow{2}{*}{\multicolumn{1}{c}{ Operating Cost Anaysis Results }} & \multicolumn{2}{c|}{ Gas-fired Units } & \multicolumn{3}{c|}{ Heat Pump Units } \\
\cline { 2 - 6 } & Hayward & Hayward & Hayward & Rheem & Rheem \\
\cline { 2 - 6 } & $\mathrm{H}-150$ & $\mathrm{H}-150 \mathrm{HD}$ & HML125L & $8320 \mathrm{ti}$ & $8320 \mathrm{ti}$ \\
\hline Thermal Efficiency & $80.3 \%$ & $85.9 \%$ & {$[450 \%]$} & {$[500 \%]$} & {$[425]$} \\
\hline Thermal COP & {$[0.803]$} & {$[0.859]$} & 4.5 & 5.0 & 4.25 \\
\hline Average Ambient Temperature & $65 \mathrm{~F}$ & $65 \mathrm{~F}$ & $70 \mathrm{~F}$ & $65 \mathrm{~F}$ & $52 \mathrm{~F}$ \\
\hline Btu Output Per Hour & 117,472 & 129,176 & 96,174 & 101,470 & 84,199 \\
\hline Hours to Output 1,000,000 Btu & 8.51 & 7.74 & 10.40 & 9.86 & 11.88 \\
\hline Energy Consumed Gas - Btu & $1,245,240$ & $1,163,940$ & 0 & 0 & 0 \\
\hline Natural Gas - Therms Used & 12.452 & 11.639 & 0 & 0 & 0 \\
\hline Btu Thermal Equivalent of Electric Used & 0 & 3,698 & 221,506 & 199,884 & 236,162 \\
\hline Electric Power Consumption KWh & 0 & 1.08 & 64.92 & 58.58 & 69.2 \\
\hline Natural gas \$ Cost Per Therm & $\$ 1.65$ & $\$ 1.65$ & $\$ 0.00$ & $\$ 0.00$ & $\$ 0.00$ \\
\hline Electric Power Cost \$ Per KWh & & $\$ 0.22$ & $\$ 0.22$ & $\$ 0.22$ & $\$ 0.22$ \\
\hline Total Cost Per MMBtu Pool Heat & $\$ 20.55$ & $\$ 19.44$ & $\$ 14.28$ & $\$ 12.89$ & $\$ 15.22$ \\
\hline
\end{tabular}

The gas-fired and electric heat pump units tested in this study had output rates that ranged from 96,129 to 117,472 Btu per hour as seen in Table EX-2. To heat a pool containing 32,000 gallons of water by 3.7 degrees $F$ it would require roughly 7.7 to 10.4 hours of operation for the specific units tested in this study. This is also based on ambient temperatures in the range of 65-70 degrees $\mathrm{F}$ for the heat pumps (as tested). If the ambient temperature were lower the output rate for the heat pumps would also be reduced 
as seen in Figure EX-2. In addition, a pool would certainly have thermal losses whenever heat is required. These could be to the ambient air by convection or to the ground soil from the buried pool piping (assuming the ground temperature is less then the circulating water) by conduction or by means of the pool's total radiant losses to the night sky. The resulting loss would require even longer periods of heater operation to make up the difference. This is why when selecting a pool heater; the unit is sized with sufficient capacity for the job. There are many large capacity gas-fired units available on the market but as stated the heat pump units selected for testing in this project are among the largest available.

Table EX-2 highlights the considerably lower operating costs associated with electric heat pumps in comparison to gas-fired units. The better of the two heat pumps operating at 65 degrees $\mathrm{F}$ would cost 33\% less to operate. If the temperature were to drop, for example to 52 degrees $\mathrm{F}$ the unit would still cost less to operate but at a reduced savings of about 22\%. This temperature condition is very low but would be representative of various days during the early spring or late fall swimming season.

Table EX-3 Comparison, cost per 2.7 MMBtu of heat supplied, rise of $10 \mathrm{deg}$. F

\begin{tabular}{|l|c|c|c|c|c|}
\hline \multirow{2}{*}{\multicolumn{1}{c}{ Operating Cost Anaysis Results }} & \multicolumn{2}{c|}{ Gas-fired Units } & \multicolumn{3}{c|}{ Heat Pump Units } \\
\cline { 2 - 6 } & Hayward & Hayward & Hayward & Rheem & Rheem \\
\cline { 2 - 6 } & $\mathrm{H}-300$ & $\mathrm{H}-300 \mathrm{HD}$ & $\mathrm{HML} 125 \mathrm{~L}$ & 8320 ti & 8320 ti \\
\hline Thermal Efficiency & $80.3 \%$ & $85.9 \%$ & {$[450 \%]$} & {$[500 \%]$} & {$[425]$} \\
\hline Thermal COP & {$[0.803]$} & {$[0.859]$} & 4.5 & 5.0 & 4.25 \\
\hline Average Ambient Temperature & $65 \mathrm{~F}$ & $65 \mathrm{~F}$ & $70 \mathrm{~F}$ & $65 \mathrm{~F}$ & $52 \mathrm{~F}$ \\
\hline Btu Output Per Hour & 234,944 & 258,352 & 96,174 & 101,470 & 84,199 \\
\hline Hours to Output 2,700,000 Btu & 11.49 & 10.45 & 28.07 & 26.61 & 32.07 \\
\hline Energy Consumed Gas - Btu & $3,362,148$ & $3,142,638$ & 0 & 0 & 0 \\
\hline Natural Gas - Therms Used & 33.62 & 31.43 & 0 & 0 & 0 \\
\hline Btu Thermal Equivalent of Electric Used & 0 & 9,985 & 598,066 & 539,687 & 637,637 \\
\hline Electric Power Consumption KWh & 0 & 2.93 & 175.28 & 158.17 & 186.84 \\
\hline Natural gas \$ Cost Per Therm & $\$ 1.65$ & $\$ 1.65$ & $\$ 0.00$ & $\$ 0.00$ & $\$ 0.00$ \\
\hline Electric Power Cost \$ Per KWh & $\$ 0.00$ & $\$ 0.22$ & $\$ 0.22$ & $\$ 0.22$ & $\$ 0.22$ \\
\hline Cost to Output 2,700,000 & $\$ 55.48$ & $\$ 52.50$ & $\$ 38.56$ & $\$ 34.80$ & $\$ 41.10$ \\
\hline Additional Pump Operating Cost & $\$ 3.79$ & $\$ 3.45$ & $\$ 9.26$ & $\$ 8.78$ & $\$ 10.58$ \\
\hline Total Cost Per MMBtu Pool Heat & $\$ 59.27$ & $\$ 55.30$ & $\$ 47.83$ & $\$ 43.58$ & $\$ 51.69$ \\
\hline
\end{tabular}

To avoid damage from over-heating, a pool heater cannot operate without water circulation. Table EX-3 illustrates the additional cost that is associated with the operation of a swimming pool's water circulation pump during the use of a pool heater. A reasonable power consumption estimate for an average sized pump with a two horsepower power pump is 1,500 watts and this was used in these calculations. In this case the pump was assumed to run only as long as it took to meet the heating demands. As can be seen the better heat pump unit will still operate at a cost advantage but the cost saving is now reduced to $21 \%$ at an ambient temperature of 65 degrees F. This cost advantage drops even further to $6.5 \%$ at an ambient temperature of 52 degrees F. It also points out the length of time that could be required to raise a sizeable pool's temperature by 10 degrees $\mathrm{F}$ even when ignoring normal heat loss mechanisms that would add to the load. These losses are variable based on many factors but are significant for most of the year. 
It is fairly obvious from the numbers in Table EX-3 that the capacity of an electric heat pump needs to be considered. Installing a larger heat pump is not an option as the largest units manufactured only have capacities of 120,000 to 140,000 Btu per hour even at the best of operating conditions ( 80 degrees F). As discussed the capacity drops measurably as the ambient outdoor temperature drops to levels that might be experienced on the front end or the back of the pool use season (60-70 degrees F). The only other option is to install multiple heat pump units at additional expense. This would double the purchase price and in all likelihood drastically increasing the electrician's installation bill to provide the electric power required. If the home's power distribution panel doesn't have the extra capacity to allow for multiple heat pumps to be installed this requires considerable extra costs to install a lager capacity electric service including at least a 200amp distribution circuit breaker panel.

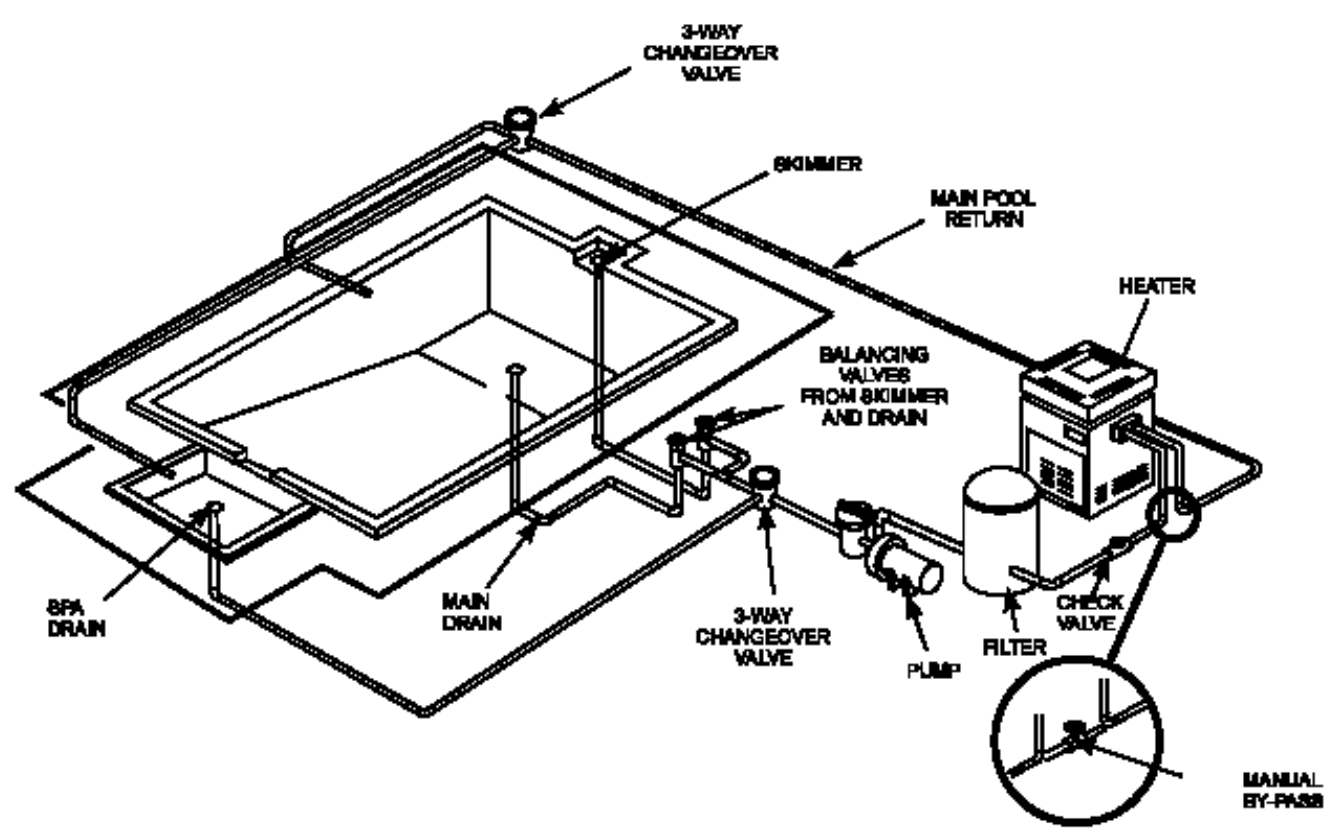

Figure EX-3 Typical swimming pool heater installation

This study has presented data on the performance of two generic types of swimming pool heaters (see Figure EX-3), natural gas-fired and electric heat pump units. It has illustrated the measurable operating energy cost reductions with the use of heat pumps in comparison to gas-fired units. In general the use of a heat pump also provides environmental reduction advantages with regard to $\mathrm{CO}_{2}$ and $\mathrm{NO}_{\mathrm{x}}$ emissions. Sulfur dioxide emissions with electric heat pump use are actually higher due to the mix of fuel used to produce the electric power, largely due to the use of oil in some of the power generation units. Measurements of fine particulate mater (PM 2.5) where not included in this study. However, the use of some fossil fuels like residual oil for power generation produces significant levels of primary PM 2.5 emissions. This is difficult to quantify absent any specific data for the mix of fuels used by National Grid. This mix also changes from year to year. Natural gas combustion produces almost insignificant 
amounts of primary PM 2.5 if used. This report has also pointed out the limitations of heat pump pool heaters. These include the lack of available product lines with medium to larger heating capacities. This can limit electric heat pump use to small and medium sized pool applications. It also precludes their use with larger sized pool loads unless multiple units are purchased and a very large investment is made to supply power to the units. The lower capacity limits the ability to satisfy the thermal demand in a timely fashion. The availability of larger capacity gas-fired pool heaters can easily satisfy the demand for rapid heating of a pool. This presents a tradeoff decision that the consumer and the pool heater installer need to address.

The heat pump option can provide lower operating costs and with modestly sized pools this may be a very reasonable choice. When the load is significantly larger, the heat pump units with their smaller capacity will require a much longer time to satisfy the demand for heat. These longer periods of operation increase the ancillary costs associated with operating the water filtration-circulation pump, which is required for any heater to function. The operating cost advantage would still favor the heat pump option but its relative savings are reduced. This is an option if the homeowner is willing to accept the much slower response to increasing the heater's set point for pool temperature. If the load is just too large and/or the consumer desires a more rapid response to increases in set point temperature, the heat pump option will not have sufficient capacity to meet these demands. In addition, as the ambient temperature gets colder the load increases just as the heat pump's performance (COP) is decreasing making it less able to satisfy the load demand and or response time. In comparison the capacity of the gas-fired heater will remain nearly the same regardless of changes in the ambient temperature. The availability of large capacity gas-fired heaters allows for satisfying larger loads and provides a much more rapid response to an increased temperature demand. 


\section{Introduction}

\section{Objective}

Perform a controlled laboratory study on the efficiency and emissions of swimming pool heaters based on a limited field investigation into the range of expected variations in operational parameters.

\section{Background}

Swimming pool heater sales trends have indicated a significant decline in the number of conventional natural gas-fired swimming pool heaters (NGPH). On Long Island the decline has been quite sharp, on the order of 50\%, in new installations since 2001. The major portion of the decline has been offset by a significant increase in the sales of electric powered heat pump pool heaters $(\mathrm{HPPH})$ that have been gaining market favor.

National Grid contracted with Brookhaven National Laboratory (BNL) to measure performance factors in order to compare the relative energy, environmental and economic consequences of using one technology versus the other. A field study was deemed inappropriate because of the wide range of differences in actual load variations (pool size), geographic orientations, ground plantings and shading variations, number of hours of use, seasonal use variations, occupancy patterns, hour of the day use patterns, temperature selection, etc. A decision was made to perform a controlled laboratory study based on a limited field investigation into the range of expected operational variations in parameters. Critical to this are the frequency of use, temperature selection, and sizing of the heater to the associated pool heating loads. This would be accomplished by installing a limited amount of relatively simple compact field data acquisition units on selected pool installations. This data included gas usage when available and alternately heater power or gas consumption rates were inferred from the manufacturer's specifications when direct metering was not available in the field. Figure 1 illustrates a typical pool heater installation layout.

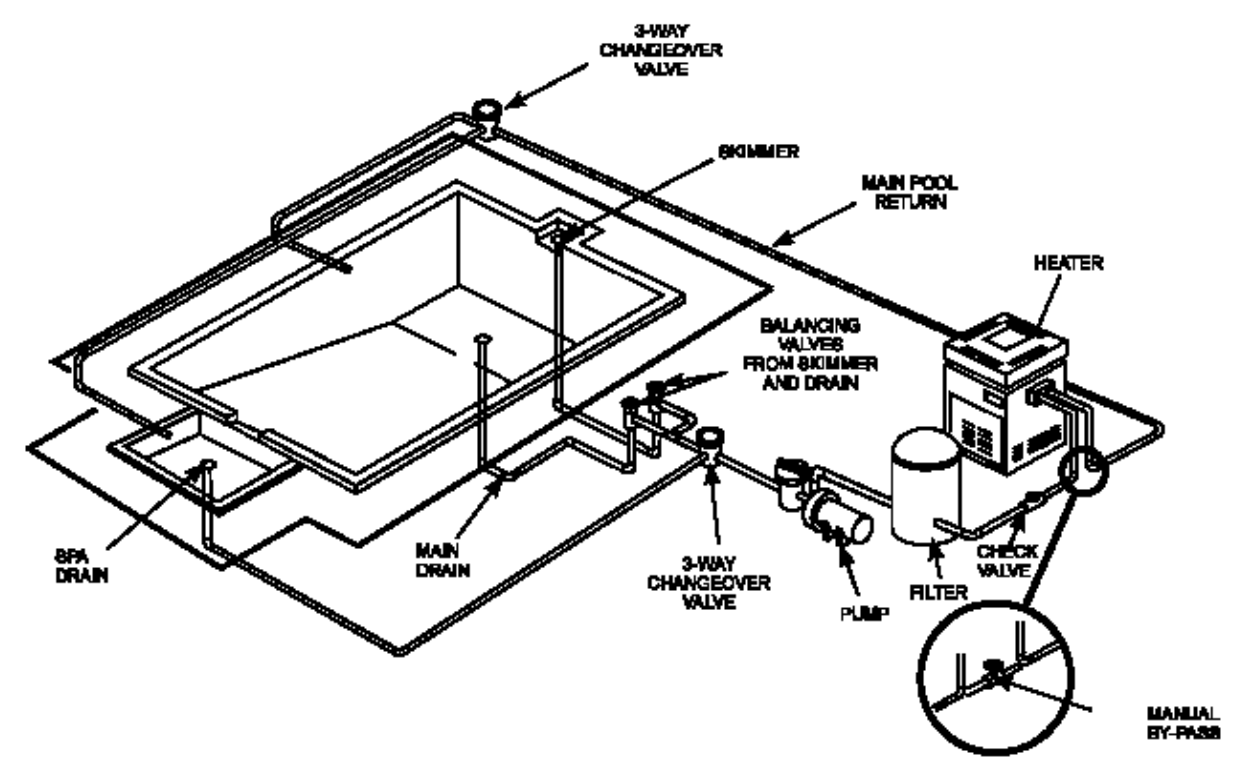

Figure 1 Typical swimming pool heater installation 


\section{Field Study of Swimming Pool Heaters and Determination of Testing Protocol}

This task addressed the need to develop a typical set of operating characteristics based on actual ranges of parameters encountered in the field during swimming pool heater operation. This included the size of the pool, sizing of pool heaters to the pool size, operating patterns, hours of operation, set-up or set-down of temperature, measurement of actual temperature rise across the pool heater, energy consumption where possible, gas flow, name plate data, geographic location of the pool, flow rate through the heater when possible and data logging using temperature loggers left at each location for a period of time.

Two swimming pools equipped with gas-fired pool heaters were identified and permission was granted to allow BNL to instrument the installations with temperature loggers to obtain operational emissions and efficiency data.

\section{Site One - Southold, NY}

Pool Size: 38’ L by 18’ W

Pool Heater: Hayward H-400 with pilot, milli-volt control, high wind vent

National Grid customer with separate gas meter for the pool heater

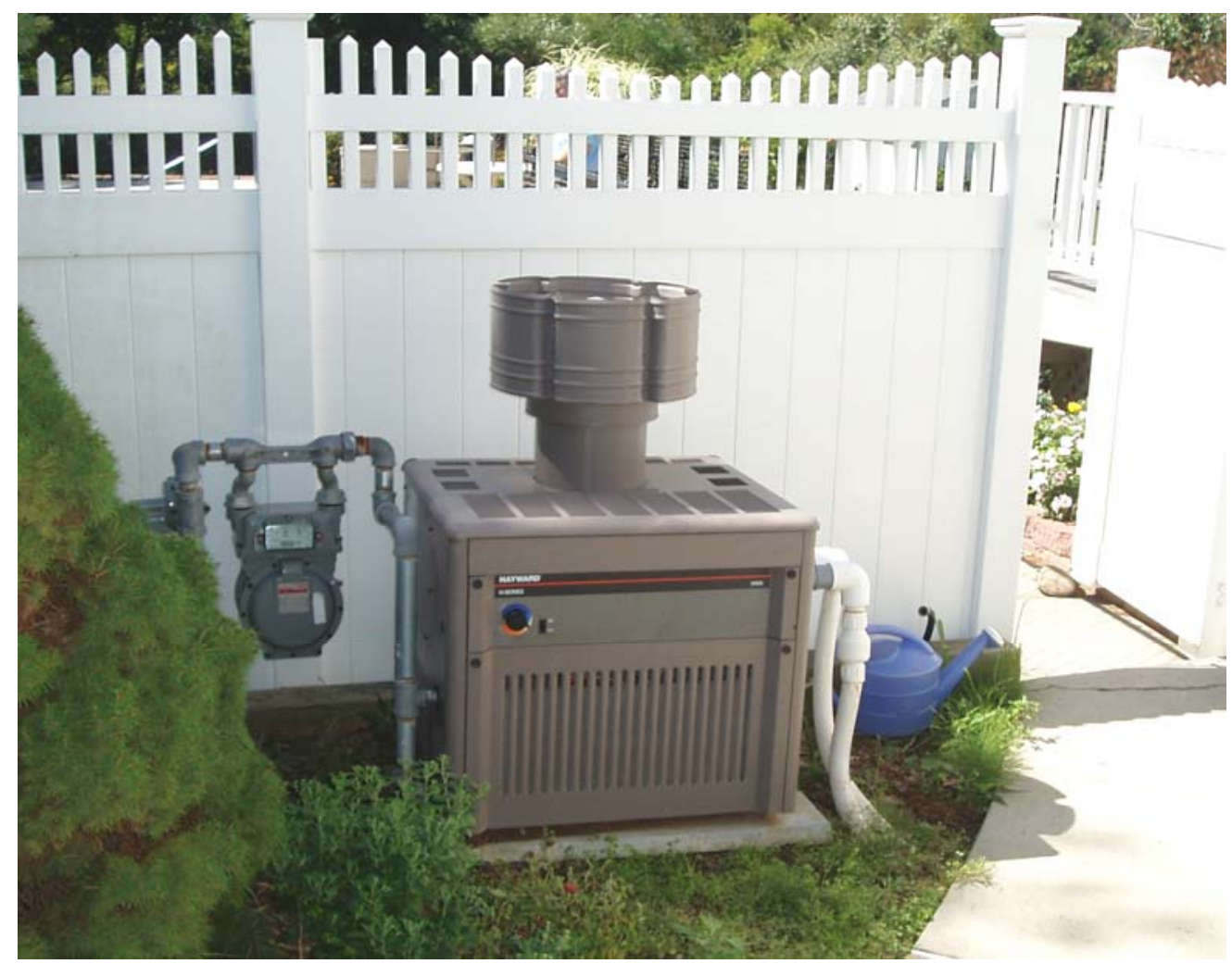

Figure 2 Hayward H-400 pool heater at the Southold, NY field test site 
The homeowner at this site uses the pool heater only for special occasions (like a family member's birthday party) due to the high fuel costs associated with its use. As a result they do not have a regular heater-operating pattern. For the purposes of gathering data, the homeowner agreed to operate the system for a two-day period. The pump for the pool is normally operated for a period of approximately eight hours during the day. Since the pool heater can only operate when the pump operates it too followed an 8-hour use period. Upon arriving at the site, the pool heater (Figure 2) had already been turned on and was operating under steady state condition. A series of flue gas measurements were performed measuring oxygen, $\mathrm{CO}, \mathrm{NO}, \mathrm{NO}_{2}$ and $\mathrm{SO}_{2}$ as well as a determination of "combustion efficiency" based on stack temperature and oxygen concentration in the stack, see Table 1 . The average efficiency based on the flue gas analysis was $83.3 \%$. The $400,000 \mathrm{Btu} / \mathrm{hr}$ rated unit was firing at an input of 345,000 Btu/hr based on timing the gas meter for the installation.

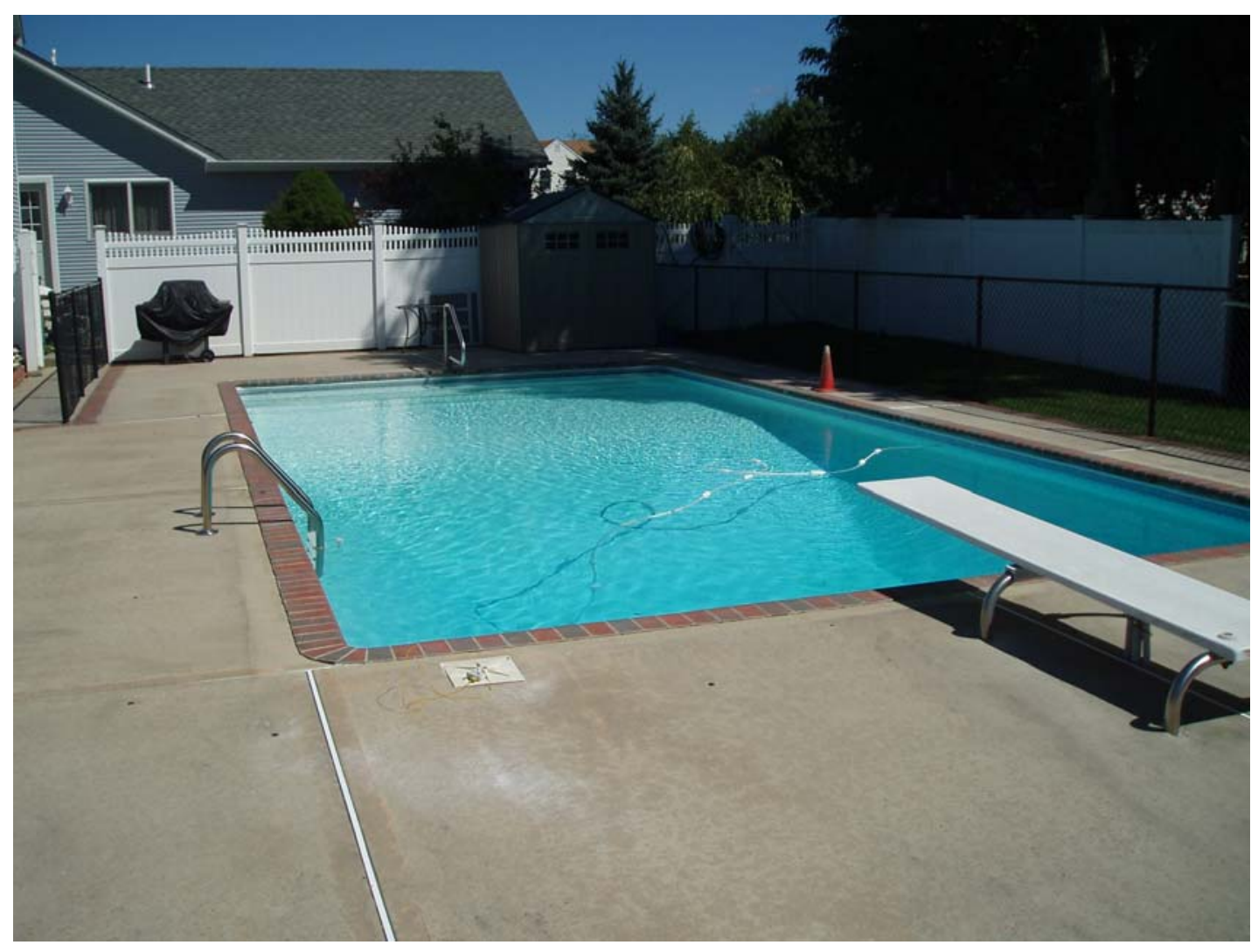

Figure 3 Swimming pool 38' by 18' located at site 1, Southold, NY

The pool temperature setting was approximately 80-82 degrees F. This unit was not equipped with a digital temperature setting and used a twist knob control to adjust the temperature manually. The ambient temperature for the one complete day where data was analyzed and found to be most consistent was between 68 and $69 \mathrm{~F}$. The heater provides heat for a fairly large pool, see figure 3, which measures 38 feet by 18 feet with an 8 -foot depth (deep end). Figure 4 is a plot of stack temperature illustrating the cyclic pattern that 
was observed for the second day of operation. The heater operated each day with an initial on-time burn lasting approximately 60 minutes followed by, on this day, ten much shorter periods of operation. The second burn period lasted for 26 minutes and the following nine burn periods averaged about 16-17 minutes. The off period between burns varied from 15 to 26 minutes lengthening as the day went on. This is an indication of the thermal gain by the pool from the warming air and solar gain. The temperature rise across the heater ranged from 9-11 degrees or about 10 degrees on average.

Table 1 Flue gas emissions and stack gas efficiency data at Southold, NY test site

\begin{tabular}{|c|c|c|c|c|c|c|c|}
\hline \multirow{3}{*}{$\begin{array}{c}\text { Dates: } \\
\text { 9/10-12/2008 } \\
\text { Steady State Data }\end{array}$} & \multicolumn{5}{|c|}{ Hayward H400 Gas Fired Pool Heater } & Fuel & \\
\hline & \multicolumn{5}{|c|}{ Site: Southold, NY } & Natural Gas & Average \\
\hline & Stack Gas & Stack Gas & Stack Gas & Stack Gas & Stack Gas & Avg. & Corrected \\
\hline Reading Number & 1 & 2 & 3 & 4 & 5 & Value & to $3 \% \mathrm{O} 2$ \\
\hline Stack Temp. Deg F & 319.7 & 323.3 & 325.3 & 326.4 & 321.1 & 323.2 & \\
\hline Oxygen \% & 9.5 & 9.4 & 9.44 & 9.55 & 9.5 & 9.5 & \\
\hline $\mathrm{CO} 2 \%$ & 6.4 & 6.45 & 8.8 & 6.36 & 6.9 & 7.0 & \\
\hline CO ppm & 8.8 & 9.1 & 8.8 & 9.7 & 8.9 & 9.1 & 14 \\
\hline NO ppm & 88.9 & 89.4 & 90.1 & 89.3 & 89.1 & 89.4 & 140 \\
\hline NOx ppm & 96.3 & 98.9 & 99.9 & 99.5 & 97.3 & 98.4 & 154 \\
\hline NO2 ppm & 7.4 & 9.5 & 9.8 & 10.2 & 8.2 & 9.0 & 14 \\
\hline SO2 ppm & 0 & 1 & 0 & 0 & 0.4 & 0.3 & 0 \\
\hline Efficiency & 83.4 & 83.4 & 83.2 & 83.2 & 83.4 & 83.3 & \\
\hline Excess Air & 72.7 & 71.4 & 71.9 & 73.5 & 72.7 & 72.4 & \\
\hline Loss $\%$ & 16.6 & 16.6 & 16.8 & 16.8 & 16.6 & 16.7 & \\
\hline \multirow{3}{*}{\multicolumn{3}{|c|}{$\begin{array}{l}\text { Gas flow rate data: } \\
10 \mathrm{cu} f \mathrm{ft} \text { in } 1 \text { minute } 44 \text { seconds } \\
\text { Input rate: } 345,000 \mathrm{Btu} / \mathrm{hr}\end{array}$}} & \multicolumn{2}{|c|}{ Gas Meter at finish: } & 928 & \multicolumn{2}{|c|}{ 9/12/2008 13:00 } \\
\hline & & & \multicolumn{2}{|c|}{ Gas Meter at start: } & 894 & \multicolumn{2}{|c|}{ 9/10/2008 13:20 } \\
\hline & & & \multicolumn{2}{|c|}{ Net Gas Usage = } & 34 & & \\
\hline
\end{tabular}


Site 1 Stack Temperature - 9/11/2008 8:30 AM - 4 PM

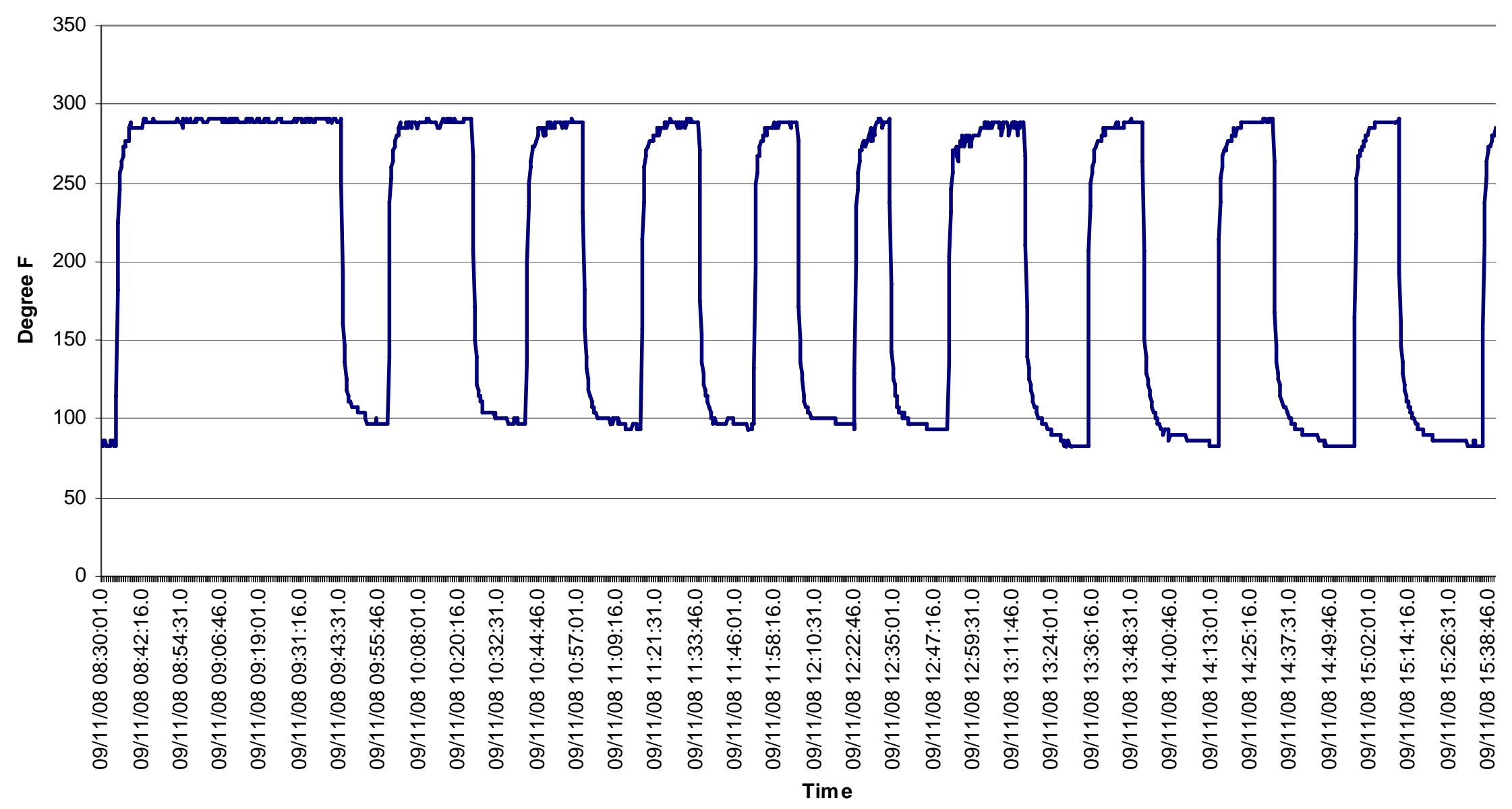

Figure 4 Stack temperature data from site in Southold, NY September 11, 2008 


\section{Site Two - East Northport, NY}

Pool Size: 36’ L by 18’ W

Pool Heater: Hayward H-400 with hot surface, digital control, and induced draft vent

Fuel: liquid propane gas (no gas meter)

Again the homeowner at this site was not a frequent user of the pool heater due to the high cost of fuel. As a result the heater was only used on rare occasions. The heater unit in Figure 5 was fired with propane. The homeowner identified that the propane tanks were low and that he would not be refilling them until next year. The pump for the pool at this second location is normally operated for a period of approximately twelve hours during the day. On the day the site was first visited, the weather was unusually warm for September and the expectation for gathering any useful data during daylight hours was low. The homeowner agreed to operate the heater for a 24-hour period to see what data could be gathered including the overnight period. Upon arriving at the site, the pool heater was found to be turned on and had been operating under steady state conditions for a period of thirty minutes prior to any emissions and stack tests. A series of flue gas measurements were performed measuring $\mathrm{CO}, \mathrm{NO}, \mathrm{NO}_{2}$ and $\mathrm{SO}_{2}$ as well as stack temperature and oxygen concentration in the stack as seen in Table 2. The average efficiency based on the flue gas analysis was $86.5 \%$. This can be compared to the manufacturer's data of $84 \%$ efficiency for this model. The 400,000 Btu/hr rated unit was not equipped with any gas metering capability. The pool temperature digital control was set to $78 \mathrm{~F}$. The heater provides heat for a fairly large pool as seen in Figure 6. It measured 36 feet by 18 feet with an 8-foot depth (deep end).

The unusually warm day of the tests had followed a period of quite cool weather during which the pool heater was not operational. The initial heater burn period lasted for 80 minutes. The unit then exhibited an on-off cycle pattern that can be characterized by a series of short periods of burner operation 2-2.5 minutes and brief off periods of about one minute. This is hard to explain and may be suggestive of a control with a very narrow dead-band or a heater that was oversized for the load found on that day. The warm ambient temperatures experienced during the daylight hours may have been a factor. This went on for a period of about six hours after which the unit seemed to settle into a quite regular cycle pattern overnight and some useful information was obtained. During this overnight period the unit fired eight times with an average burn time of 7.69 minutes. Figure 7 is a plot of stack temperature, illustrating the cyclic pattern that was observed during this nighttime operating period. A second attempt was made to obtain data from this site but unfortunately, shortly after the monitoring equipment was placed on the unit, it shut down as the fuel had run out and propane tanks were empty.

From these field measurements made at both sites it is the judgment that a laboratory test operating cycle should follow a load pattern similar to that generally observed in the field. That is a system that only operates for a fixed time period each day, with an initial large load forcing a steady period of operation followed by a consistent load, hopefully emulating the on-off cyclic patterns observed at the first test site. One obvious issue that came to mind was that heat pump type pool heaters are relatively small in capacity 
$(85,000-150,000 \mathrm{Btu} / \mathrm{hr})$ so if it was replacing a conventional gas-fired unit of higher capacity it will take a lot longer to satisfy the load if it were even possible or else two or three units would be required.

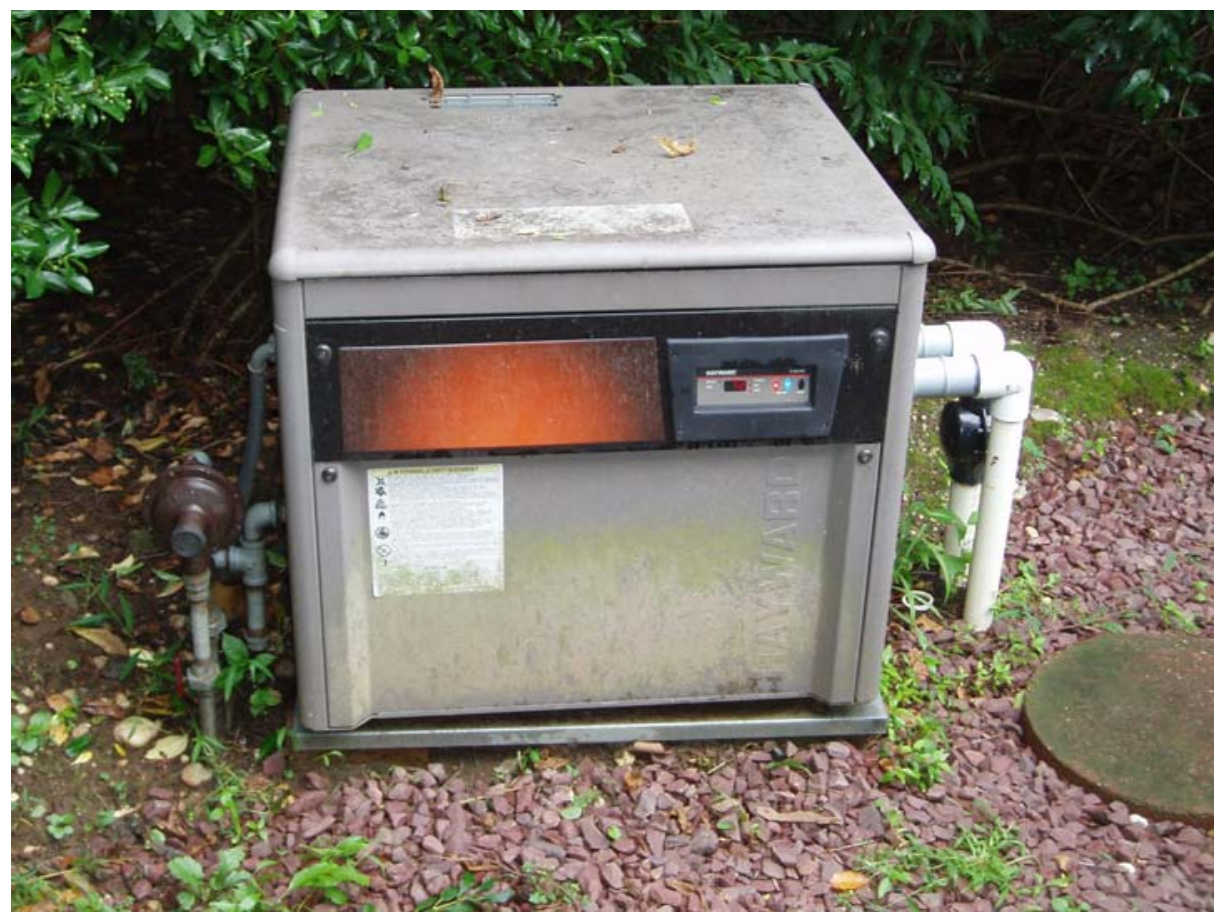

Figure 5 Hayward H-400 induced draft pool heater at the East Northport test site

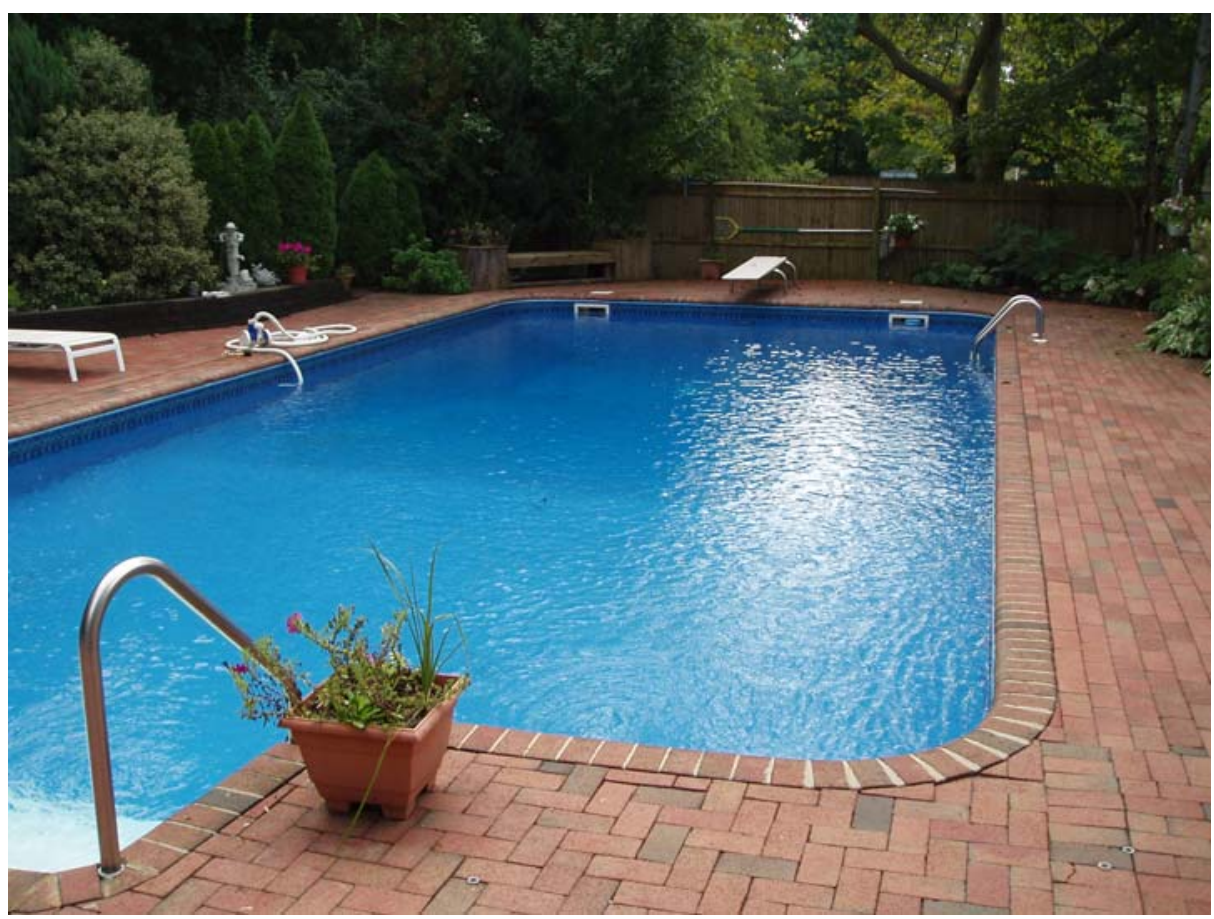

Figure 6 Swimming pool 38' by 18' located at site 2, East Northport, NY 
Stack Temp 9-13-08 to 9-14-08

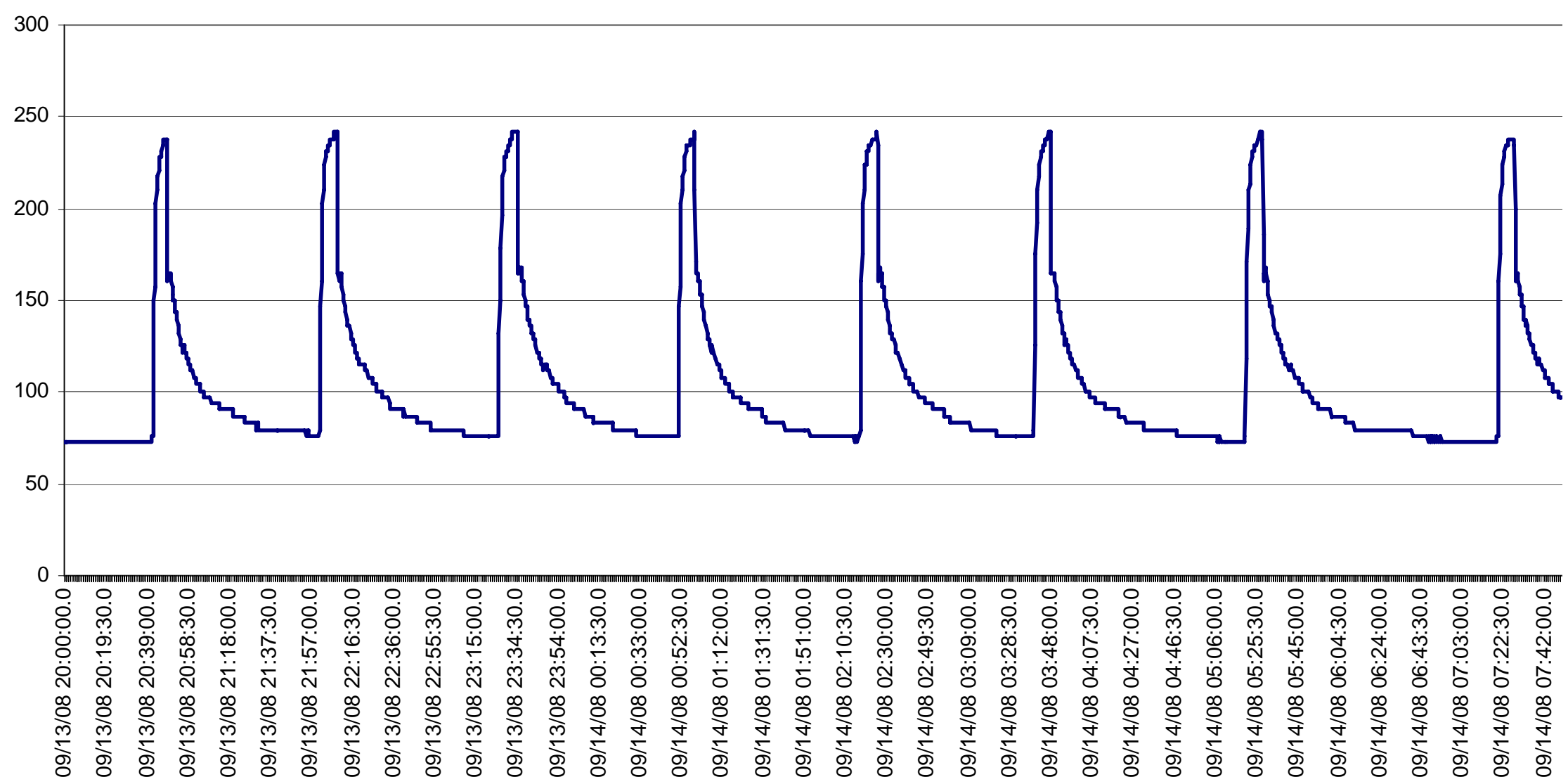

Figure 7 Stack temperature data for East Northport, NY site, September 13-14 
Table 2 Flue gas emissions, stack efficiency data at East Northport, NY test site

\begin{tabular}{|c|c|c|c|c|c|c|c|}
\hline $\begin{array}{l}\text { Test Dates } \\
\text { 9/13-14/2008 }\end{array}$ & \multicolumn{6}{|c|}{$\begin{array}{l}\text { Hayward H400 Induced Draft Gas Fired Pool Heater } \\
\text { with electronic control and digital temperature display }\end{array}$} & $\begin{array}{l}\text { Fuel: } \\
\text { Propane }\end{array}$ \\
\hline \multicolumn{7}{|c|}{ Emissions Measurements - Site: East Northport, NY, Set Point 78 F, Hot Humid Day } & \multirow{3}{*}{$\begin{array}{l}\text { Average } \\
\text { Corrected } \\
\text { to } 3 \% \mathrm{O} 2\end{array}$} \\
\hline Steady State Data & Stack Gas & Stack Gas & Stack Gas & Stack Gas & Stack Gas & Avg. & \\
\hline Reading Number & 1 & 2 & 3 & 4 & 5 & Value & \\
\hline Stack Temp. Deg F & 248.7 & 253.1 & 242.5 & 251.6 & 252 & $\overline{249.6}$ & \\
\hline Oxygen \% & 9.17 & 9.02 & 12.93 & 8.94 & 8.9 & 9.79 & \\
\hline $\mathrm{CO} 2 \%$ & 8.49 & 8.6 & 5.78 & 8.66 & 8.69 & 8.04 & \\
\hline CO ppm & 101.3 & 112.9 & 96.7 & 112.9 & 104 & 105.6 & 170.1 \\
\hline NO ppm & 61.5 & 58.7 & $\overline{40.6}$ & 60 & 61 & 56.4 & 90.8 \\
\hline NOx ppm & $\overline{66.1}$ & $\overline{66.9}$ & $\overline{47.4}$ & 70.3 & $\overline{72.6}$ & 64.7 & 104.2 \\
\hline NO2 ppm & 4.6 & 8.2 & 6.8 & 10.3 & 11.6 & 8.3 & 13.4 \\
\hline SO2 ppm & 1 & 1 & 0 & 0 & 0 & 0.4 & 0.6 \\
\hline Efficiency & 86.9 & 86.8 & 84.8 & 86.9 & 86.9 & 86.5 & \\
\hline Excess Air & 70.9 & 68.9 & 145.6 & 67.8 & 67.3 & $\overline{84.1}$ & \\
\hline Loss \% & 13.1 & 13.2 & 15.2 & 13.1 & 13.1 & 13.5 & \\
\hline
\end{tabular}




\section{Market Survey of Available Pool Heaters}

Natural Gas Pool Heater (NGPH) Survey

The NGPH results including eight brands are presented in Table 3. These brands include those models sold by Hayward, Jandy, Lochinvar - EnergyRite, Pentair, Raypak (which also makes models under the Rheem and Rudd brands) and Sta-Rite.

The NGPH can be grouped into four classifications. The first is equipped with conventional natural draft burners using a standing pilot light for ignition and a very basic but reliable analog temperature control based on a millivolt powered design. These designs do not require any electrical hookup for the heater. The control operates using power generated by the thermal electric conversion principle (the Seebeck effect) using heat supplied by the pilot light. This control type was also used with older designs of gasfired water heater storage tanks where installation was simplified by not needing a 120volts AC circuit for operation.

The second type is similar to the first but is equipped with an AC (120-volt) powered control that allows for the elimination of the standing pilot. This type of control system additionally allows for the selection of the temperature set point(s) by using a digital readout. It usually monitors and displays the water temperature during operation and can provide on-board diagnostic capabilities in the event of an operational failure. In this product class the atmospheric burners are ignited using either a direct spark or hot surface igniter. Most are capable of using dual set points for both a pool and a spa provided remote temperature sensors and three-way control valves are used.

The third class of heaters includes all of the features of the second group but uses a premixed combustion system using a forced draft blower in place of atmospheric natural draft burners. These units normally have somewhat higher efficiencies and exhibit much lower $\mathrm{NO}_{\mathrm{x}}$ emissions. They were developed to satisfy low $\mathrm{NO}_{\mathrm{x}}$ emissions requirements as first imposed by the South Coast Air Quality Management District in California. They are currently marketed nation wide based on their higher efficiency and cleaner emissions. These units typically have a control that uses a hot surface igniter, digital temperature setting(s) and have enhanced onboard diagnostic capabilities monitoring multiple sensors associated with the water circulation and the combustion systems.

The fourth type of gas heater is designed with a condensing heat exchanger to achieve an efficiency of 95\%. These units have all of the capabilities of the third group but are more complex to install. In addition to providing electrical hookup and plumbing the gas line these units must have a provision for handling the condensate from the heat exchanger. This is slightly acidic and must be passed through a neutralizer prior to disposal down a drain. The heat exchanger must also be fabricated using materials designed for the corrosive environment of the condensate in the condensing unit. The heat exchangers used in this type of heater must be fabricated from a material with properties that will resist this corrosive environment while providing reasonable longevity over a period of many years of use. The materials of choice used for condensing heat exchangers are 
much more expensive than conventional materials and have a significant impact on the initial cost of a unit that incorporates a condensing heat exchanger.

All prices mentioned in this report are based on a survey of Internet pricing. They do not include installation or setup costs at the pool site. The range of prices for the different types varies considerably. The units equipped with pilot lights and millivolt controls are the least expensive to purchase and would also be less costly to install as they do not require any electric power connection. They range from roughly $\$ 1,000$ to $\$ 2,000$ depending on the make and heating capacity. The prices for the second group increase only slightly (\$30-50 per unit). This reflects an upgrade to a different control system using either a direct spark or hot surface igniter. The third type, those with fully premixed combustion systems and low NOx emissions are in the range of \$180-250 more when compared to the first type and $\$ 150-\$ 200$ more than the second type. It is important to remember that an electric 120 -volt AC circuit is required for the second and third groups. There was only one United States manufacturer of the fourth class. The condensing heat exchanger type has a selling price depending on the vendor from about \$5,000-5,500 for a heater with a capacity of 350,000 Btu per hour. This is a cost premium of roughly $\$ 3,000$ above that for a low $\mathrm{NO}_{\mathrm{x}}$ pool heater. Again this unit is more complex to install and maintain, requiring an AC line, plumbing and a condensate neutralizer and drain. 


\section{Table 3 Natural gas swimming pool heater survey results}

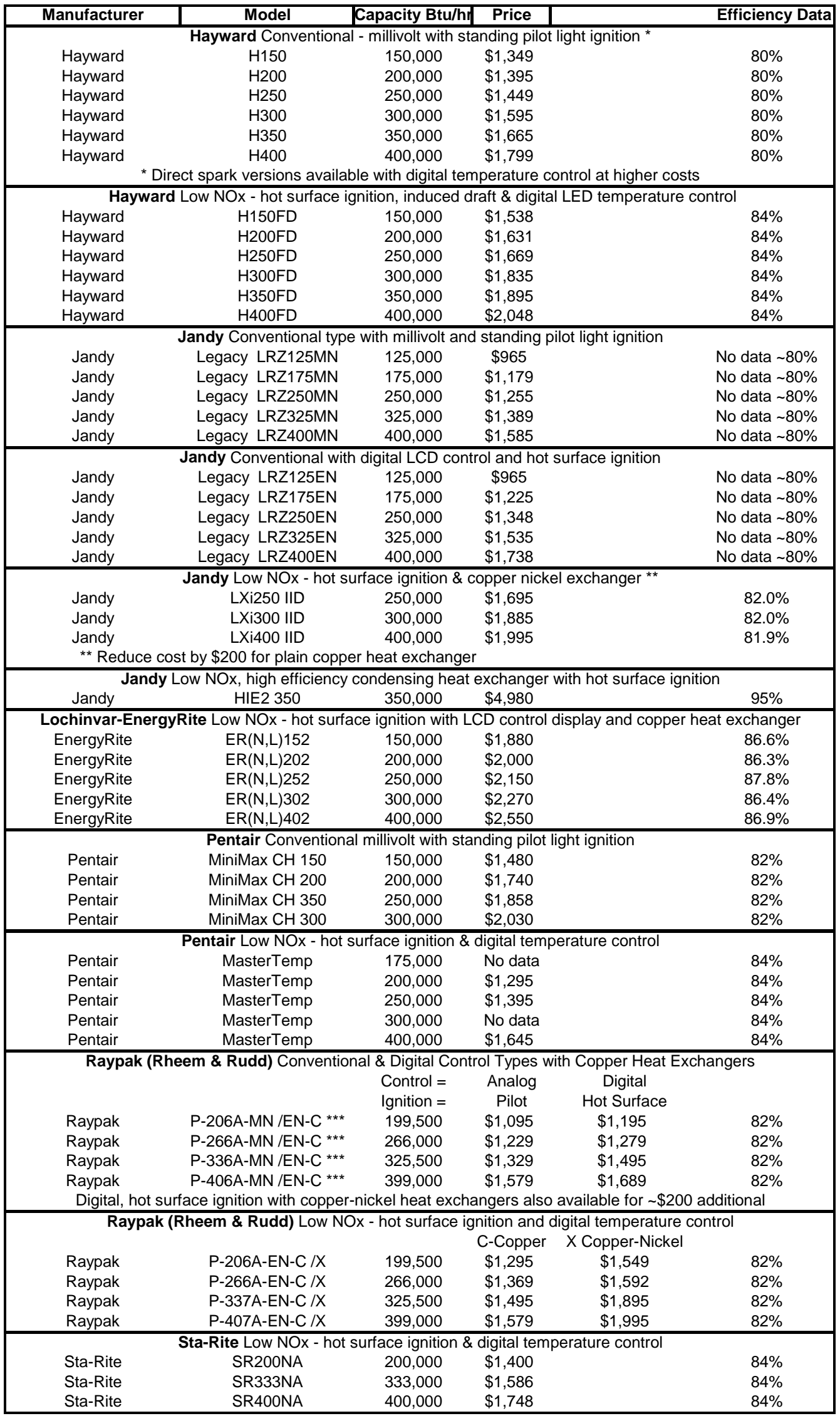


To go over the main points for NGPH, there are a significant number of models with various features available in the United States as manufactured by six companies and sold under eight brand names. They range in cost from roughly $\$ 1,700$ to $\$ 5,000$ (assuming a $350,000 \mathrm{Btu} / \mathrm{hr}$ size) and have efficiencies as low as $80 \%$ and as high as $\$ 95 \%$ based on Federal Trade Commission energy rating labels. The vast bulk of the designs are noncondensing and fall in the range of $80-88 \%$ efficiency and cost between $\$ 1,700$ and $\$ 2,550$, for units with a 400,000 Btu/hr capacity. The relatively small cost differential between a small capacity NGPH unit $(150,000 \mathrm{Btu} / \mathrm{hr})$ and a large capacity model $(400,000 \mathrm{Btu} / \mathrm{hr})$ creates a market demand skewed towards the larger sized units. The larger the capacity the faster it can elevate the pool's water temperature. Pool heaters have in general very low mass heat exchangers and a vast ability to purge any stored heat to the load (pool). The thermal performance characteristics, which will be discussed in more detail in the Sections 6 and 7 of this report supports the concept that there is no real efficiency penalty related to buying a larger capacity unit.

A typical gas-fired pool heater's heat exchanger can be seen in Figure 8. This is from the viewpoint looking down from above taken during the conversion for inside installation using a factory optional kit replacing the baffle and grill that originally covered the heat exchanger. The heat exchanger is fabricated from tightly finned copper tubing with the burners mounted below the heat exchanger tubes.

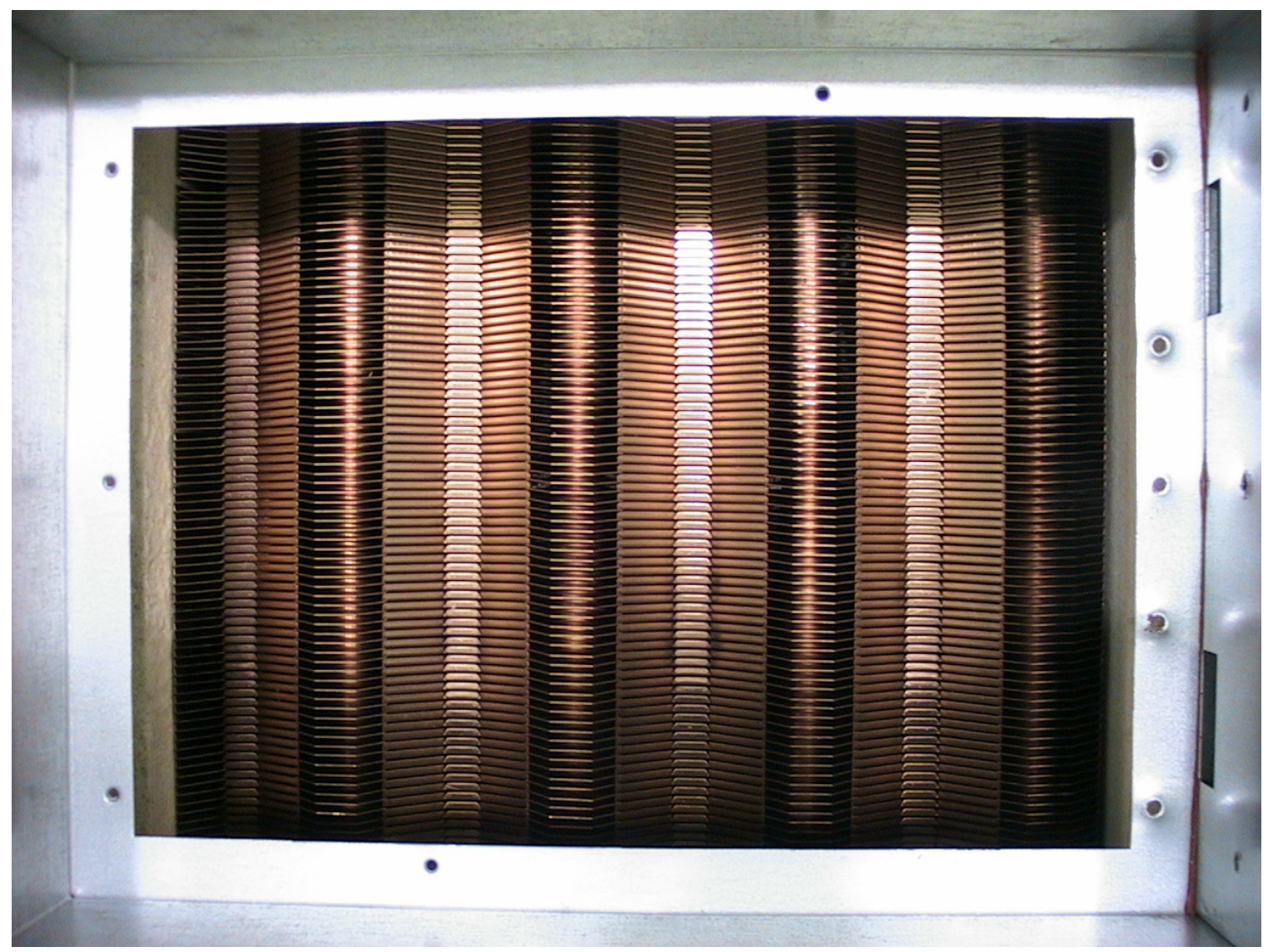

Figure 8 Tightly finned copper low mass heat exchanger of a gas-fired heater 


\section{Electric Heat Pump Pool Heater (HPPH) Survey}

There are at least 13 manufacturers of electric heat pump swimming pool heaters. The major pool product manufactures produce a full array of equipment types including pool pumps, water filters, heaters, cleaners and chlorinators. As a result most manufacturers of NGPH also produce and market HPPH systems. In addition there are manufacturers that primarily built HVAC equipment including forced warm air heating furnaces and residential heat pump heating systems that also build swimming pool heat pumps. Table 4 contains the survey results found for all HPPH made in the United States with capacities greater than 100,000 Btu per hour based on the manufacture's product descriptions.

There are two basic types of compressors used. The most frequently used is a scroll type and the other used is a piston driven compressor. The scroll type is the predominant type used in the industry today. Like any heat pump the compressor pumps the working refrigerant fluid around a closed loop. First the compressor pushes the hot highly pressurized gas through the condenser where heat is rejected to the circulating pool water by means of a tube in shell heat exchanger. The condenser cools the hot high-pressure gas until it condenses into a high-pressure moderate temperature liquid. The condensed refrigerant then goes through a pressure-reducing device (for example an expansion valve) where it becomes a low-pressure (almost) liquid refrigerant gas. It then enters the evaporator. In the evaporator it absorbs heat from the ambient air, which continues to fully evaporate the refrigerant gas expanding it into warm vapor prior to it entering the compressor where it is compressed back to the hot high-pressure gaseous state. The cycle then repeats. To simplify, the heat pump's evaporator is used to remove heat from the source, the warm ambient air and absorb it into the refrigerant. The heated refrigerant then enters the compressor. Here it is compressed and pumped next to the condenser where the heat is transferred it to the circulating pool water, the heat sink.

The HPPH like any pool heater is often sold as a means for extending the swimming season by providing a heating function during the cooler months that bracket the summer season. To extend this even more some models are equipped with automatic defrost controls that allow for operation at colder temperatures. The HPPH is primarily a heater but with the addition of a reversing valve it can also be used to cool a pool in very hot climates. These were not considered in the context of this project because cooling is not a requirement given the regional areas served by National Grid.

A scroll compressor can provide about a 12-15\% efficiency advantage, which translates to a higher COP rating. The piston compressors can provide about a $4-12 \%$ increase in output capacity for a compressor with the same horsepower rating. As a result a few manufacturers continue to make both types. In the larger picture it is apparent that the scroll compressor has gained in popularity based on its reduced energy consumption. All modern HPPH designs use a Titanium heat exchanger for fabrication of the condenser, as in many NGPH designs this is the preferred material due to its corrosion resistant qualities when exposed to water containing chlorine and other pool water chemicals. However it is more expensive to fabricate a heat exchanger when using this material. The Titanium tube is usually housed inside a PVC shell so that the rapidly circulating pool 
water surrounds it. This again provides for excellent heat transfer and a very low mass heat exchanger that can be quickly purged of any residual heat.

Table 4 Heat pump swimming pool heater survey results

\begin{tabular}{|c|c|c|c|c|c|}
\hline \begin{tabular}{|l|} 
Brand \\
Product Line
\end{tabular} & Model & Price & Capacity & COP & $\begin{array}{c}\text { Compressor } \\
\text { Type }\end{array}$ \\
\hline \multirow[t]{2}{*}{ AquaPro } & PRO1300 & $\$ 3,280$ & 125,000 & 5.8 & Scroll \\
\hline & PRO1100 & $\$ 2,900$ & 109,000 & 5.9 & Scroll \\
\hline Fibro Pool & FH109 & $\$ 2,825$ & 109,000 & 5.8 & Scroll \\
\hline \multirow[t]{2}{*}{ Gulfstream } & GS1500 & $\$ 3,500$ & 130,000 & 5.6 & Scroll \\
\hline & GS1000 & $\$ 3,000$ & 113,000 & 6.2 & Scroll \\
\hline Hayward & HP21203T & $\$ 3,535$ & 125,000 & 5.2 & Scroll \\
\hline Heat Pro & HP11003T & $\$ 3,095$ & 116,000 & 5.0 & Scroll \\
\hline HeatMaster & HML125T & $\$ 3,699$ & 125,000 & No data & Scroll \\
\hline HeatMaster & MML110T & $\$ 3,499$ & 110,000 & No data & Scroll \\
\hline \multirow[t]{2}{*}{ Heat Siphon } & DHP5.0 & $\$ 3,295$ & 122,000 & 6.2 & Piston \\
\hline & DX5.0 & $\$ 3,195$ & 109,000 & 7.6 & Piston \\
\hline \multirow[t]{3}{*}{ Jandy } & AE3000 & $\$ 3,755$ & 135,000 & 5.9 & Scroll \\
\hline & AE2500 & $\$ 3,255$ & 118,000 & 5.4 & Scroll \\
\hline & AE2000 & $\$ 2,895$ & 103,000 & 5.3 & Scroll \\
\hline Kopec & 700TI & $\$ 3,795$ & 136,000 & 6.0 & Scroll \\
\hline Enterprises & $600 \mathrm{TI}$ & $\$ 3,495$ & 115,000 & 5.6 & Scroll \\
\hline \multirow[t]{3}{*}{ Nirvana } & M40 & $\$ 3,595$ & 140,000 & 6.3 & Piston \\
\hline & M35 & $\$ 3,395$ & 125,000 & 6.4 & Piston \\
\hline & M30 & $\$ 3,195$ & 105,000 & 6.3 & Piston \\
\hline Pentair & UT 120 & $\$ 4,295$ & 125,000 & 5.5 & Scroll \\
\hline UltraTemp & UT 110 & $\$ 3,895$ & 108,000 & 5.8 & Scroll \\
\hline Thermal Flow & HP1200 & $\$ 3,995$ & 125,000 & 4.2 & Piston \\
\hline Thermal Flow & HP900 & $\$ 3,595$ & 117,000 & 4.4 & Piston \\
\hline Thermal Flow & HP700 & $\$ 3,495$ & 109,000 & 4.1 & Piston \\
\hline \multirow[t]{2}{*}{ RayPak } & R8320ti & $\$ 3,995$ & 121,000 & 5.3 & Scroll \\
\hline & R63101ti & $\$ 3,595$ & 108,000 & 5.6 & Scroll \\
\hline \multicolumn{6}{|c|}{ (also sold as Rheem \& Rudd) } \\
\hline Rome & 150Ti & $\$ 4,595$ & 142,500 & 6.3 & Piston \\
\hline \multirow[t]{3}{*}{ Industries } & 130Ti & $\$ 3,595$ & 130,000 & 6.5 & Piston \\
\hline & $105 \mathrm{Ti}$ & $\$ 3,195$ & 105,000 & 6.3 & Piston \\
\hline & & so sold as & Solarium) & & \\
\hline \multirow[t]{2}{*}{ Summit } & SUM7 & $\$ 3,595$ & 125,000 & 5.2 & Scroll \\
\hline & SUM5 & $\$ 3,295$ & 110,000 & 5.5 & Scroll \\
\hline Waterco & IMK101T & $\$ 2,795$ & 101,000 & No Data & Scroll \\
\hline AquaHeat & AQX101TI & $\$ 2,995$ & 101,000 & No Data & Scroll \\
\hline ElectroHeat & EPX150T & $\$ 3,995$ & 150,000 & No Data & Scroll \\
\hline ElectroHeat & EPX125T & $\$ 3,595$ & 125,000 & No Data & Scroll \\
\hline ElectroHeat & EPX105T & $\$ 3,295$ & 105,000 & No Data & Scroll \\
\hline
\end{tabular}

Note: most manufacturers make models less than 100,000 Btu but are not listed here 


\section{Discussion of Market Survey Results and Selection of Units for Testing}

There are significant differences in both price and heating capacity when comparing NGPH to HPPH options. The smallest capacity NGPH units are sized at 150,000 Btu per hour fuel input or about 120,000 Btu/hr in thermal output. Under the best test conditions the output of the largest HPPH is in the same range. Larger capacity heat pump units are not available nor would they be possible for residential installation. A heat pump capacity of $121,000 \mathrm{Btu} / \mathrm{hr}$ requires an electric circuit rated for 60 -amp at 220-volt AC. Many houses only have an electric service with a power distribution panel sized for $100 \mathrm{amps}$ and at most 200 amps. In other words $30-60 \%$ of the capacity of the home's AC power would be required for a HPPH with a capacity of 121,000 Btu per hour. The impact of this must be taken into account if the current electric service is undersized for a HPPH. In addition the initial cost of a HPPH is much higher than a NGPH. For example, the cost of a 120,000 Btu per hour gas-fired pool heater would be $\$ 1,500$ compared to $\$ 4,000$ for a heat pump of the same capacity (even at an air temperature of 80 degrees F).

The federal appliance labeling program does not have an applicable standard or requirement for labeling HPPH units. As a result the figures of merit for capacity and the coefficient of performance (COP) are not reported under any standard conditions. The capacity and COP of any heat pump that uses ambient air as a heat source is dependent on the air temperature, the humidity and the pool water temperature at which the COP was determined. The data found in Table 4 is from the manufacturer or seller's literature and do not represent a good basis for comparison. Most of these numbers are for ambient air conditions of 80 degrees $\mathrm{F}$ and at either $63 \%$ or $80 \%$ humidity with a pool water temperature of 80 degrees F. The 80/63/80 is a voluntary standard (AHRI 1160) but not one that every manufacturer follows. One manufacturer (Pentair) did list COPs for their products at three sets of conditions. For example for one specific model the first COP given at the $80 / 80 / 80$ condition was 5.8 with a capacity of 108,000 Btu then at 80/63/80 it was 5.5 with a capacity of 101,000 Btu and finally at 50/63/80 the COP was 4.0 (at 50 degrees F air temperature) and the capacity was given as 72,000 Btu (all Btu per hour).

In summary, the survey of HPPH units made in the United States included thirteen manufacturers offering several models with heating capacities in the range of 101,000 to $142,500 \mathrm{Btu} / \mathrm{hr}$ and the price range of $\$ 2,999-\$ 4,595$. This survey omitted units with a capacity below 100,000 Btu per hour. Common to most HPPH brands is the use of a scroll compressor and for all brands a Titanium heat exchanger for the refrigerant flow within the condenser, which is in turn enclosed by a PVC outer shell through which the circulating pool water flows. The flow rate of water is typically in the range of 20-60 gallons per minute and this flows continuously regardless of the heater cycling on or off.

\section{Units Selected for Testing}

The decision of what units to evaluate in the laboratory was made after doing some initial phone interviews with various pool product companies and vendors. It became rather clear that the Hayward brand of heater products currently dominate the Long Island marketplace. Additional consideration was also given to the fact that the two random 
Long Island pool heater installations evaluated during the field study both had units manufactured by Hayward. Long Island represents the major portion of the market supplied by National Grid's natural gas distribution network. Also, a vast majority of National Grid's electric power production is in turn delivered to consumers on Long Island by the Long Island Power Authority (LIPA). The testing of product lines typically sold in this local market was a significant factor in the decision process. Other candidates were equally acceptable but for reasons of convenience, local availability and matching National Grid's market territory a decision was made to go with the models selected.

The specific models selected for laboratory testing at BNL were much smaller in heating capacity than those was found during the field evaluations. There were two concerns that caused BNL to select the heating capacity in the range of 125,000 to 150,000 Btu per hour. The first was that unlike NGPH that can have much higher capacities, up to 400,000 Btu per hour, HPPH models top out in capacity at roughly the 125,000 to 130,000 Btu per hour. This is partly due to the heat pump design and electric power requirements. An electric heat pump with a capacity of 125,000 Btu per hour requires an AC circuit rated at 220 volt and 60 amps. Gas fired pool heaters have capacities that start at 150,000 Btu per hour and range up to 400,000 Btu per hour. In an attempt to make the results more directly comparable BNL selected units with similar capacities. As will be discussed in a next section of this report BNL also required a swimming pool simulator for loads sized to the expected capacities of the units. This was to allow for reasonable operating periods and conditions. This provided a strong criterion from a practical viewpoint that helped drive the decision to test units with a smaller capacity.

The four pool heaters selected for testing at BNL are the following models:

1) Hayward Model: H150 - natural gas with pilot light ignition

2) Hayward Model: H150FD - natural gas Universal H-Series Low $\mathrm{NO}_{\mathrm{x}}$ heater

3) Hayward Model: Heat Master HML-125T electric heat pump

4) Rheem Model: 8320ti (Raypack Model: R8230ti made by Raypak) electric heat pump

The H150 with its simple control and standing pilot was selected as a baseline unit representative of older existing pool heaters that have been in use for many years. The $\mathrm{H} 150 \mathrm{HD}$ is a more modern unit with a higher efficiency and lower $\mathrm{NO}_{\mathrm{x}}$ rating. This is presumed to be the normal type of new unit selected by most pool owners. The decision was made to omit the one available condensing pool heater, as it is much more expensive to purchase and more complex to install and maintain. The HML-125T heat pump replaced a different model made by Hayward based on statements by a representative of a major national pool equipment supplier with many retail outlets on Long Island. This model was made by Hayward but a year after it was purchased it still does not appear on the Hayward website. It is suspected that this model might be an exclusive model line made just for sale by the national pool equipment dealer. The Rheem 8020ti heat pump was selected as a second unit for evaluation. It was purchased separately almost nine months after the other units had been acquired. Although sold and labeled under the Rheem brand the product has a warranty provided by Rakpak. 


\section{Measurement System to Determine Pool Heater Performance Characteristics}

The definition of thermodynamic efficiency is the ratio of energy output divided by the energy input from a device. In testing swimming pool heaters, BNL began to develop a test method based on years of experience with measuring the efficiency of residential hydronic heating units (boilers) based on this definition. Residential boilers do operate in a somewhat similar manner as gas fired swimming pool heaters. There are some significant differences that were discovered in the course of this investigation. One is that the flow through the heat exchanger is at least an order of magnitude higher with pool heaters (25-70 gallons per minute) as compared to hydronic boilers (2-4 gallons per minute). Another factor is that the water temperatures are at the most 85-95 degrees $\mathrm{F}$ versus 170-200 degrees $\mathrm{F}$ with a residential boiler system. This translates into a test facility with capabilities for a much large volume of water but at much lower working temperatures.

Pool Load Simulation and Test Rig Assembly

A pool simulator with sufficient capacity to allow for at least several hours of operation was desired. The water flow capacity of the hydronic boiler-testing laboratory was not even close to the flow rates used by swimming pool heaters. Using the water supply and drain capacities on a once through basis was not possible either as the maximum flow rate was only 15 gallons per minute. The use of a large volume buffer tank made from high-density polyethylene (HDPE) and used in a closed loop was then considered. These tanks are sold for agricultural uses and are relatively inexpensive to purchase.

The calculated heat input to the pool simulator was determined based on the baseline H150 gas-fired heater operating at $80 \%$, an output of 120,000 Btu per hour. At an acceptable flow rate of 35 gallons this would mean that a tank with a volume of 2,100 gallons would increase the water temperature by 6.8 degrees $\mathrm{F}$ per hour. If the initial temperature of the 2,100-gallon tank were 70 degrees $\mathrm{F}$ it would be heated to about 90 degrees F in approximately three hours. A search for a suitable tank of this approximate size resulted in a somewhat smaller tank of 1,600 gallons. The tank was sized based on the available space on a concrete pad adjacent to the laboratory where it was to be located and its immediate availability for purchase. Based on the prior calculation, this tank would allow for roughly two and a half hours of steady operation. This was also deemed sufficient for cyclic operation that was also part of the test plan. The operating strategy was to initially fill the tank with cold tap water (65 degrees $\mathrm{F}$ at the time the tests were performed) and then run a series of tests as the capacity allowed and then dump the hot water outside to an area drain used for rainwater runoff. The cycle could then be repeated. This tank was plumbed using 2-inch PVC piping common to pool installations along with a $3 / 4$ horsepower pool pump purchased for this project. The plumbing also included a water flow meter and temperature sensors. The tank is shown in Figure 9. 


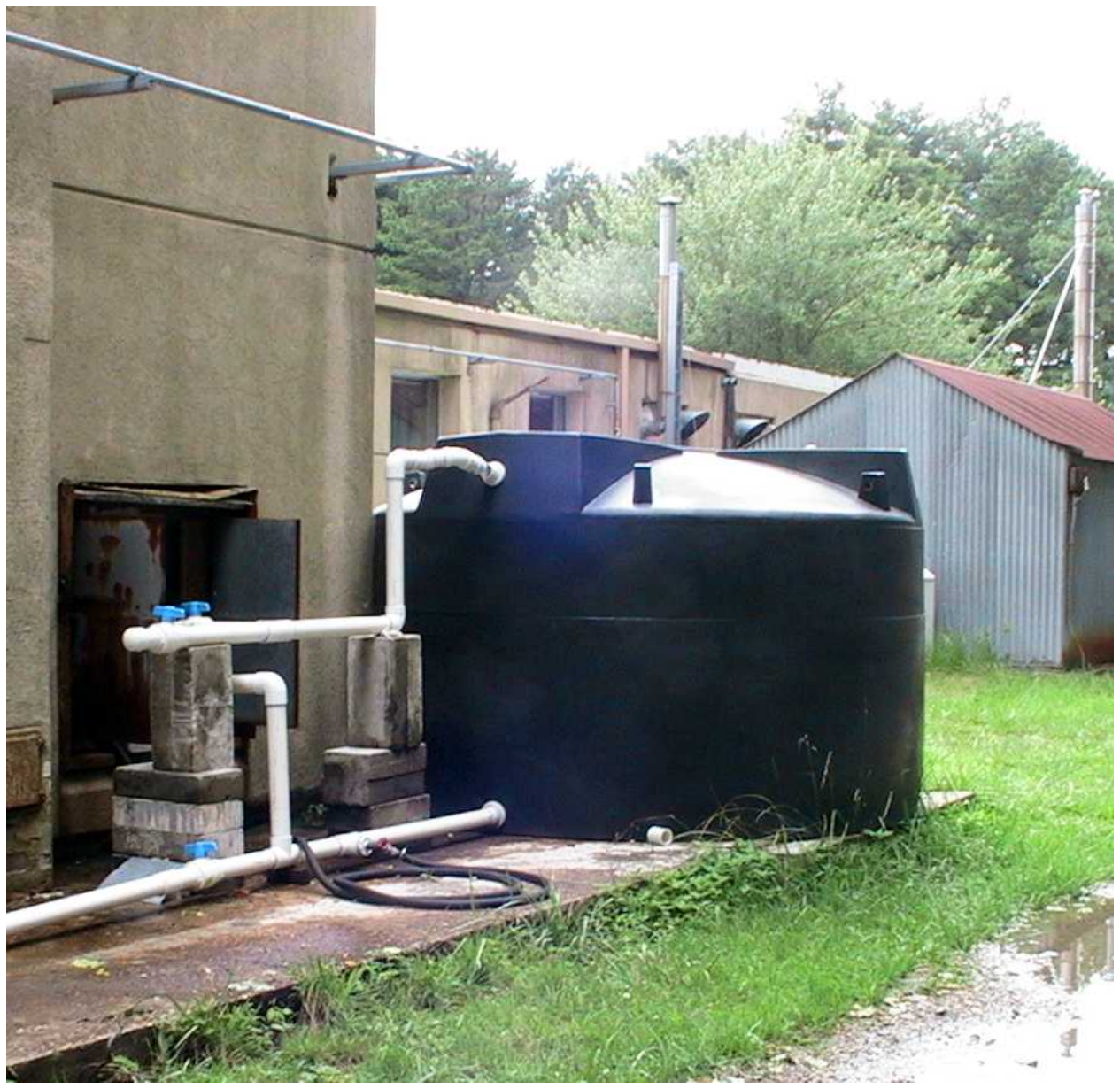

Figure 9 Swimming pool load simulator

The heating units were located indoors using factory conversion kits for the gas-fired pool heaters. These conversion kits are used for inside installations typical when a structure (like a pool cabana) allows for the unit to be hidden from view. This option allowed for accurate measurement of emissions at a location in the venting system downstream of the unit's vent connection. The units are more typically installed outdoors in open locations as found in the field investigation. However the units normally do not have a vent stack or if they do it is an option consisting of a very short stack used for high wind locations with a baffled passageway for the hot gases to travel. Neither of these outdoor vents would allow for a proper measurement of the flue gas emissions. It was decided to also test the HPPH in the laboratory so as to allow for some control of the ambient temperature conditions. Another factor included in this decision was that the desirable to test all of the units with as little change in the installation plumbing as possible so that there was no experimental bias introduced by using a different physical setup. 
The next part of the measurement system involved the instrumentation used for measuring the energy inputs and thermal output. This includes the flow meter, temperature sensors and the capability to measure the emissions associated with the gasfired units.

\section{Energy Input - Natural Gas, Electric}

The natural gas consumption was metered using an AC250 , a temperature compensated diaphragm type, gas meter equipped with a pulse senor pickup used with a digital read out (see Figures 10 and 11). The readout was carefully monitored with a stopwatch to measure the elapsed time period of gas consumption only starting and stopping the watch at the moment the counter "clicked" over a digit. The meter is the same type as used for billing purposes and considered to be very accurate with a proof curve of almost $100 \%$ at the flow rate used (+/- less than $0.20 \%)$.

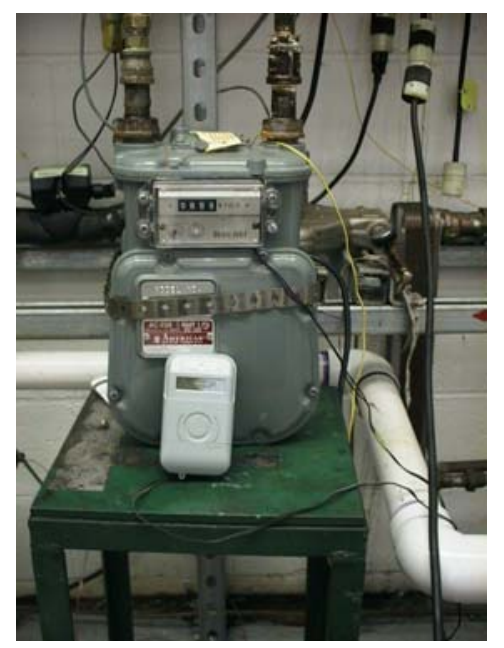

Figure 10 AC-250 gas meter with pulser and readout

The large levels of electric consumption of the HPPH units was measured using a brand new 220-volt single phase AC Model I-120 GE-Energy 5 digit electric meter with an accuracy of $0.2 \%$ or better. This is similar to other billing meters used by electric utilities. This meter had a KWH resolution and the readout was again carefully monitored with a stopwatch to measure the elapsed time period of electric consumption only starting and stopping the watch at the moment the counter "clicked" over a digit. In the case of heat pump testing this required that someone sit with the stopwatch and monitor the meter, as

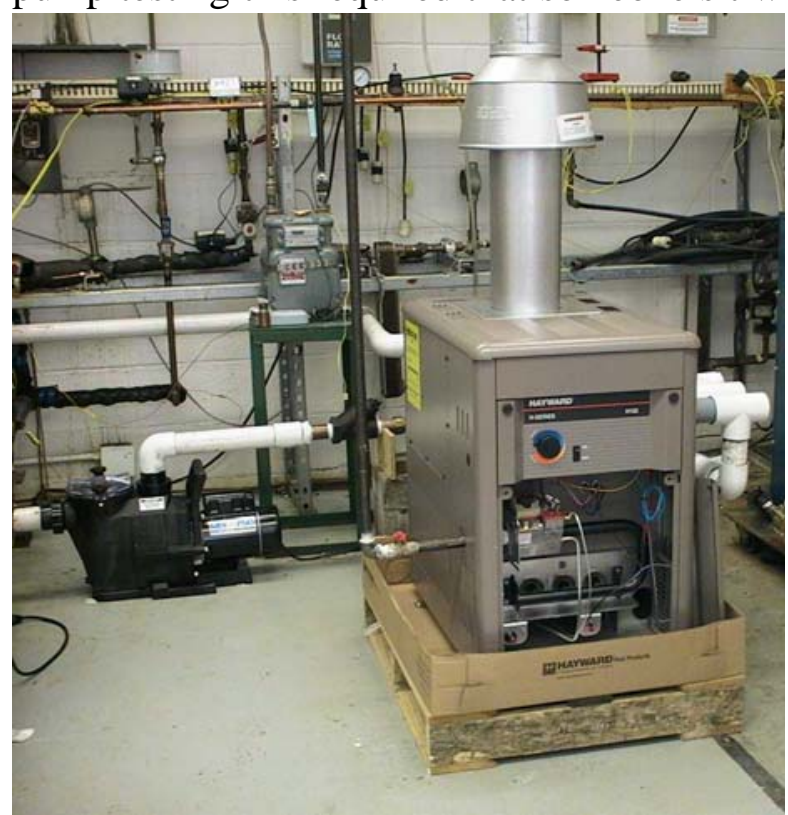

it would take about 10 minutes to use a single kilowatt-hour of electric power. Smaller levels of electric power consumption were determined by using a 110-volt AC Brand Electronics power meter with an accuracy of better than $2 \%$ of the reading or +/- 2 in the least significant reading of the measurement. This meter is designed for a maximum power level of 1800 watts.

Figure 11 Baseline gas-fired pool heater in the BNL test facility 
A commercially available Btu metering system, Model 4003 with Model 1732 flow meter manufactured by the ISTEC Corporation (Figure 12) was selected for measuring the thermal energy output to the load simulator. A Btu meter measures energy usage by multiplying flow rate and temperature difference. As the water (or other liquid) passes through the flow meter, the meter's turbine rotates and sends flow impulses to the electronic calculating unit, which determines the volumetric flow rate. Two RTD type temperature sensors measure the inlet and outlet temperatures and the signal outputs go to the electronic calculating unit to determine the water temperature differential. The cold temperature sensor is also used to automatically compensate for water density changes as a function of water temperature to accurately calculate the mass flow. The Btu meter accumulates the signals, processing the Btu input rate and accumulating the net Btu delivered to the load. The total Btu accumulation is displayed on an LCD readout and is also stored in a non-resettable electronic counter. The Btu meter's display can also be used to indicate the momentary energy rate, momentary flow rate, total flow, temperatures, etc. The accuracy of this system is specified as $+/-1.5 \%$ in the continuous flow range, which was selected based on the desired nominal 25-35 GPM flow rate required in this experiment.

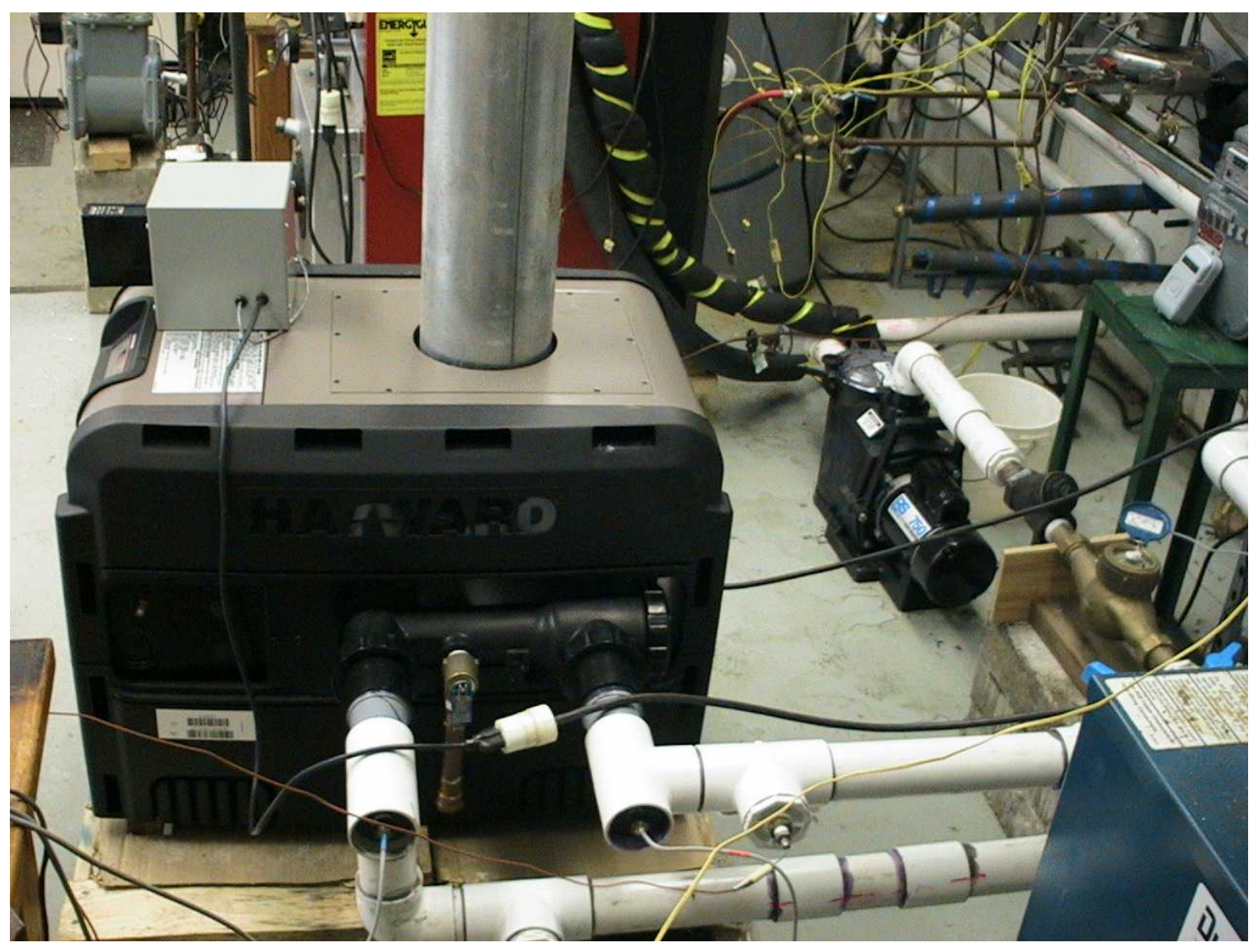

Figure 12 Flow meter (brass body), RTD sensors (see blue/red tagged gray wires) 


\section{Emissions Measurements}

The flue gas emissions data was obtained using an electro-chemical sensor based analyzer capable of measuring oxygen, $\mathrm{CO}, \mathrm{NO}, \mathrm{NO}_{2}$ and $\mathrm{SO}_{2}$ as well as measuring stack gas temperature and determining the so-called "steady state efficiency." It also determines a percent $\mathrm{CO}_{2}$ emission value that is calculated by the analyzer and based on the oxygen reading and the selected fuel setting, natural gas in this instance. The acceptance of portable electrochemical-based analyzers by state and federal environmental agencies has grown significantly over the past decade. Numerous third party organizations have tested and evaluated the technology and found that not only does it satisfy the accuracy requirements of many compliance-testing programs, but also it offers a more affordable and better time managed solution. Coupled with great cross utilization capability that can identify improvements in the combustion, process and product quality, these analyzers make a valuable asset to many types of combustion research. The specific analyzer used in this project was a Testo Model 350 equipped with low range $\mathrm{CO}$ and $\mathrm{NO}_{\mathrm{x}}$ capabilities. This specific device was evaluated, tested and its performance verified under the US EPA's Environmental Technology Verification Program (ETV) by the Advanced Monitoring Systems (AMS) Center, one of six technology areas under ETV and operated by Battelle (Columbus, OH) in cooperation with the EPA's National Exposure Laboratory. The Testo 350 unit is capable of measuring with an accuracy of better than $0.05 \%$ for oxygen $\left(\mathrm{O}_{2}\right)$, better than $5 \mathrm{ppm}$ for sulfur dioxide $\left(\mathrm{SO}_{2}\right)$, better than $2 \mathrm{ppm}$ for $\mathrm{NO}$, better than $5 \mathrm{ppm}$ for $\mathrm{NO}_{2}$, and better than 5 ppm for CO measurements.

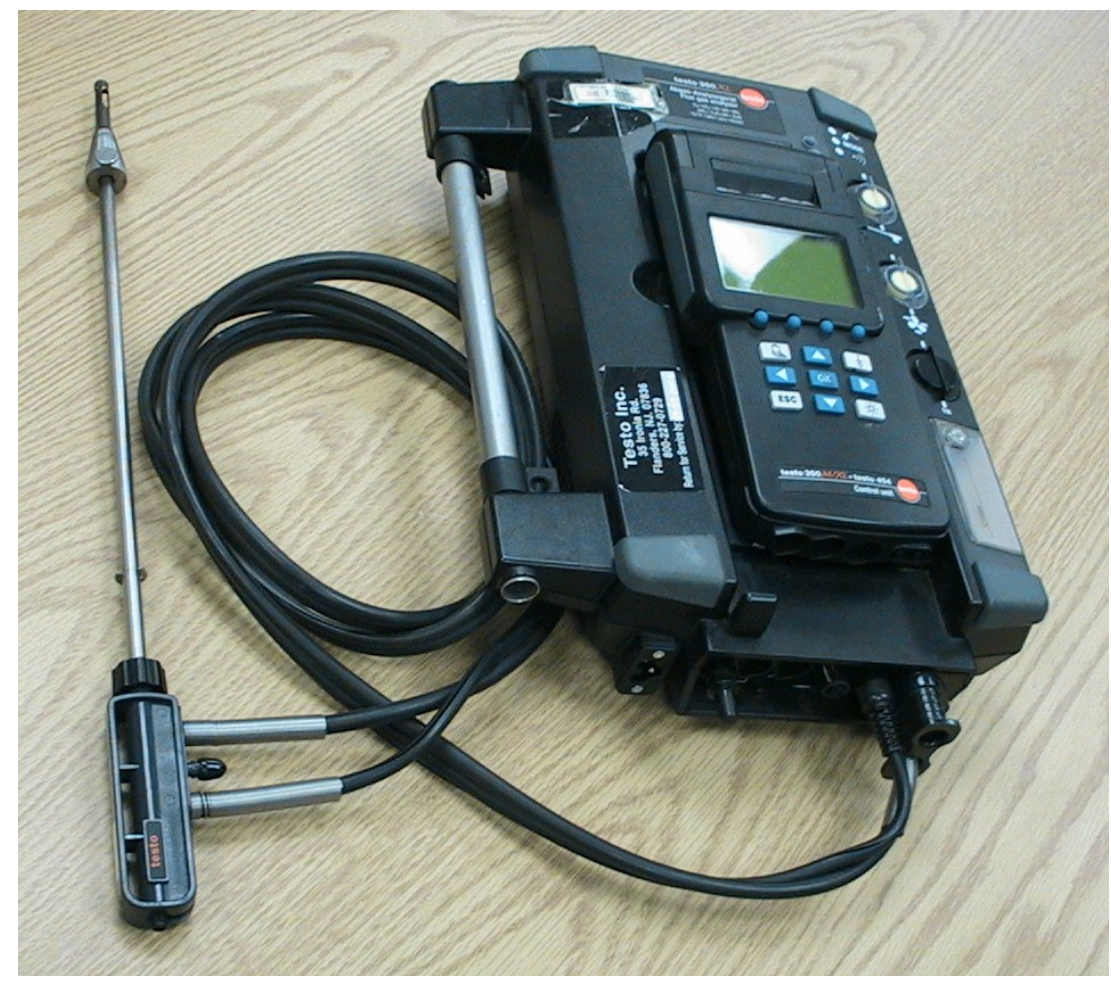

Figure 13 Testo 350XL Emissions analyzer system $\left(\mathrm{O}_{2}, \mathrm{NO}_{2}, \mathrm{NO}, \mathrm{SO}_{2}, \mathrm{CO}, \mathrm{CO}_{2}\right)$ 


\section{Gas Pool Heater Test Results}

\subsection{Hayward H150}

The Hayward Model H150 was the first gas-fired unit evaluated and is considered to be a representative baseline model typical of many older pool heaters still in use. The test plan included a series of tests under a full load during steady state operation followed by a number of cyclic load tests mimicking the type of on-off cycle observed in the field study. The unit was installed in the BNL test laboratory as seen in Figures 14 and 15. A series of shake down tests were conducted to gain some operating experience with the heater as well as the new testing setup and load simulator. Then a series of steady state tests were performed including measuring the thermodynamic efficiency and emissions performance.

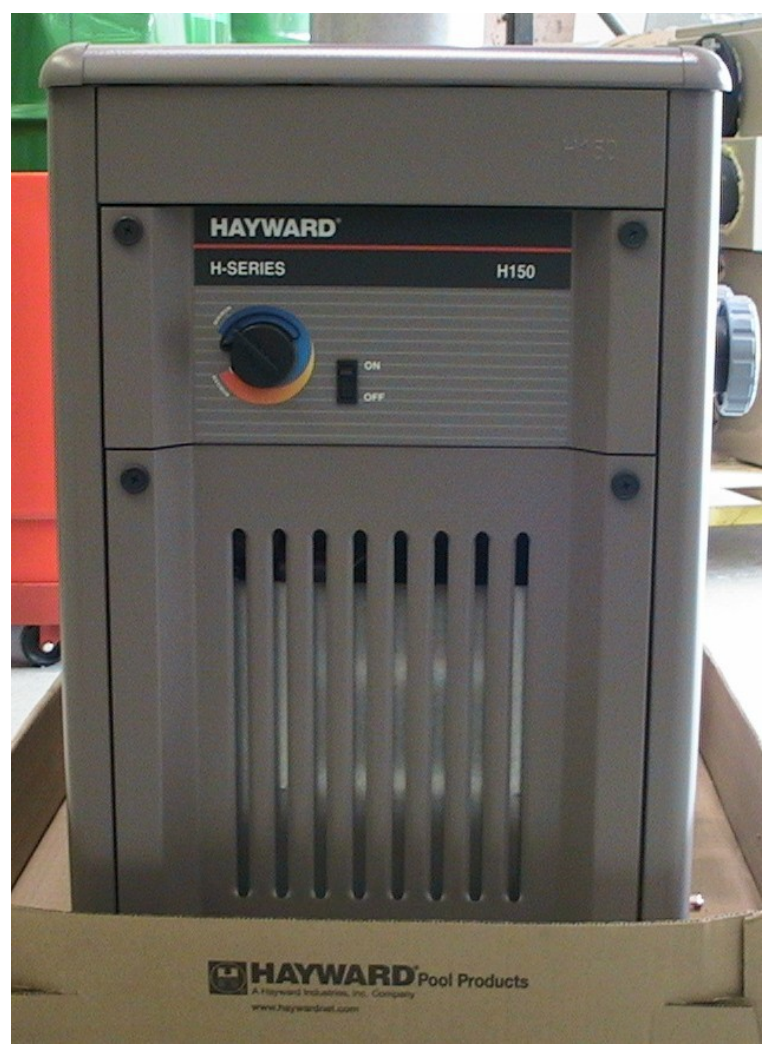

Figure 14 Hayward H150, pilot ignition

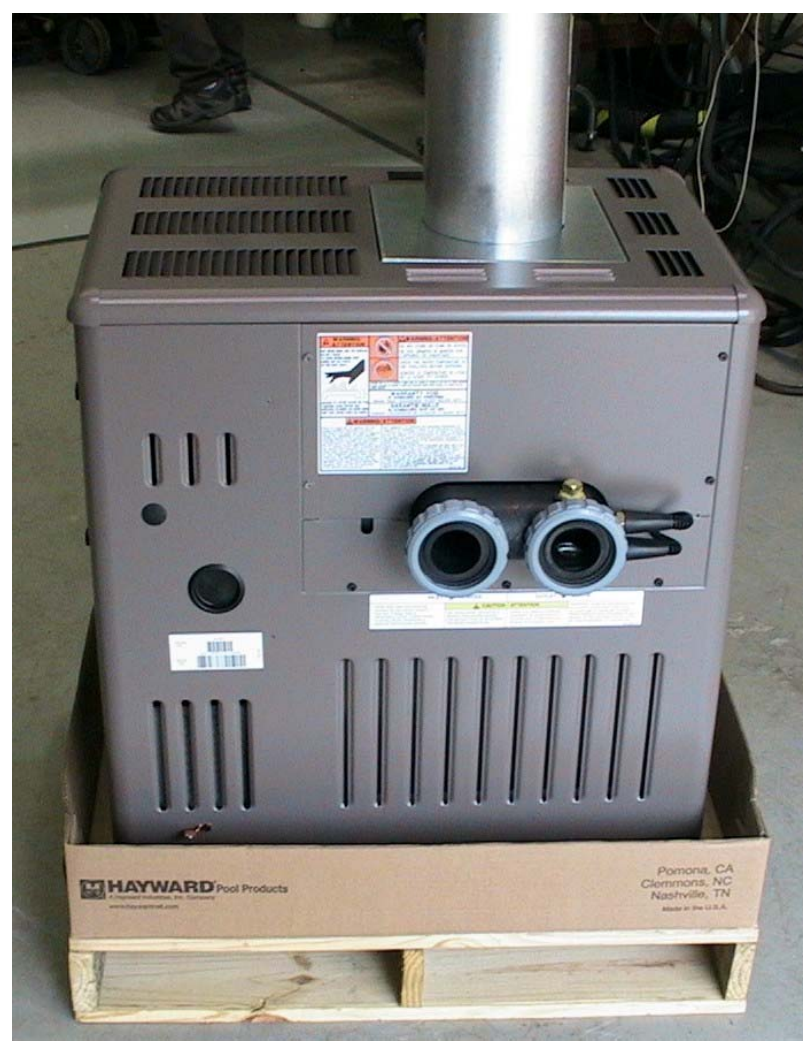

Figure 15 H150 with factory vent kit added

Table 5 presents the efficiency performance including a summary of the data recorded and the results for the H150 (baseline unit). Table 6 contains the emission measurement data obtained during steady state and the flue gas efficiency, the so called "combustion efficiency'. The difference between the input-output results when compared to the flue gas efficiency results would indicate that the jacket losses associated with this system is approximately $4.2 \%$. The average thermal efficiency matches very closely with the Federal Energy Label rating of 80\% for this model. 
Table 5 Model H150, Steady State Efficiency Results

\begin{tabular}{|l|c|c|c|c|c|c|c|}
\hline \multicolumn{6}{|c|}{ Input-Output Efficiency Results - Hayward Model H-150 Natural Gas-fired Pool Heater } \\
\hline $\begin{array}{l}\text { Test } \\
\text { Date }\end{array}$ & $\begin{array}{c}\text { Btu In } \\
\text { Accumulated }\end{array}$ & $\begin{array}{c}\text { Time } \\
\text { Period }\end{array}$ & $\begin{array}{c}\text { Btu Out } \\
\text { Accumulated }\end{array}$ & $\begin{array}{c}\text { Time } \\
\text { Period }\end{array}$ & $\begin{array}{c}\text { Btu/hr } \\
\text { Input }\end{array}$ & $\begin{array}{c}\text { Btu/hr } \\
\text { Output }\end{array}$ & $\begin{array}{c}\text { Thermal } \\
\text { Efficiency }\end{array}$ \\
\hline $6 / 19 / 2009$ & 148000 & 1.00472 & 118000 & 1.02472 & 147304 & 115153 & 78.2 \\
\hline $6 / 22 / 2009$ & 115500 & 0.78514 & 88000 & 0.76931 & 146957 & 114251 & 77.7 \\
\hline $6 / 23 / 2009$ & 146500 & 1.00278 & 117000 & 1.01097 & 146051 & 115731 & 79.2 \\
\hline $6 / 24 / 2009$ & 147500 & 1.00986 & 122500 & 1.01250 & 146050 & 120972 & 82.8 \\
\hline $6 / 25 / 2009$ & 147000 & 1.01347 & 125500 & 1.03500 & 145038 & 121252 & 83.6 \\
\hline \multicolumn{96}{|c|}{} & & & Average & $\mathbf{8 0 . 3}$ \\
\hline
\end{tabular}

Table 6 Model H150, Steady State Emission Results

\begin{tabular}{|l|c|c|c|c|c|c|c|}
\hline \multicolumn{6}{|c|}{ Emission Test Results- Hayward Model H-150 Natural Gas-fired Pool Heater } \\
\hline Test Date & $6 / 19 / 2009$ & $6 / 22 / 2009$ & $6 / 23 / 2009$ & $6 / 24 / 2009$ & $6 / 25 / 2009$ & Average & Avg. @ 3\% O2 \\
\hline Stack Temp. Deg F & 277.5 & 275.5 & 269.2 & 277.6 & 277.0 & 275.4 & $* * * *$ \\
\hline Oxygen \% & 9.67 & 9.66 & 9.61 & 9.50 & 9.64 & 9.62 & $* \star * *$ \\
\hline CO2 \% & 6.30 & 6.31 & 6.33 & 6.40 & 6.32 & 6.33 & 10.0 \\
\hline CO ppm & 10.4 & 9.8 & 10.4 & 9.5 & 10.3 & 10.1 & 16.0 \\
\hline NO ppm & 66.1 & 67.0 & 75.3 & 74.3 & 76.5 & 71.8 & 114.0 \\
\hline NOx ppm & 79.4 & 81.2 & 90.6 & 90.0 & 92.1 & 86.7 & 137.5 \\
\hline NO2 ppm & 13.3 & 14.2 & 15.3 & 15.7 & 15.7 & 14.8 & 23.5 \\
\hline SO2 ppm & 0 & 0 & 0 & 0 & 0 & 0 & 0.0 \\
\hline Efficiency & 84.5 & 84.4 & 84.7 & 84.5 & 84.4 & 84.5 & $* * * *$ \\
\hline Excess Air & 75.1 & 75.0 & 74.4 & 72.8 & 74.8 & 74.4 & $* * * *$ \\
\hline
\end{tabular}

The evaluation of the unit under cyclic on-off operation followed the full load steady state tests. A repeating cycle pattern of 15 minutes of heater operation followed by an associated off period for each load was established. For example a test with the unit cycling 15 minutes on and 30 minutes off represents a burner fractional on time of 33\%. This means that the unit operates at this percentage of its maximum capacity over the cycle, $33.33 \%$ for the example described. Tests at 50\%, 33.33\%, 25\% and 15\% run time were used to characterize the cyclic performance of the heater. The results can be presented in two ways. The first is presented in Figure 16 and is a linear plot of the energy output to the pool as a function of the energy input to the burners. The second shown in Figure 17 is a plot of efficiency as a function of burner fraction on time. It's important to note that the pilot flame $(1,080 \mathrm{Btu} / \mathrm{hr})$ contributes to the heater's output if the pool pump is operating. When the pump is off the energy consumed by the pilot flame will not contribute to the thermal output at all. In this study it was assumed that the pool's pump would operate 12 hours a day. The gas consumed by the pilot flame was assumed to only contribute $50 \%$ of the time. The results from the first field evaluation found that with an 80-82 degree F pool temperature setting the heating unit (a Hayward, Model H400) operated with an on period of roughly 16 minutes and a corresponding off period of $15-26$ minutes. This is $44 \%$ of the time, $44 \%$ of its maximum input heating capacity was used. Given the cyclic characteristics measured in the laboratory for a very 
similar (but smaller) unit at the $44 \%$ point the unit would be expected to be operating with an efficiency level almost identical to its measured steady state level of $80 \%$.

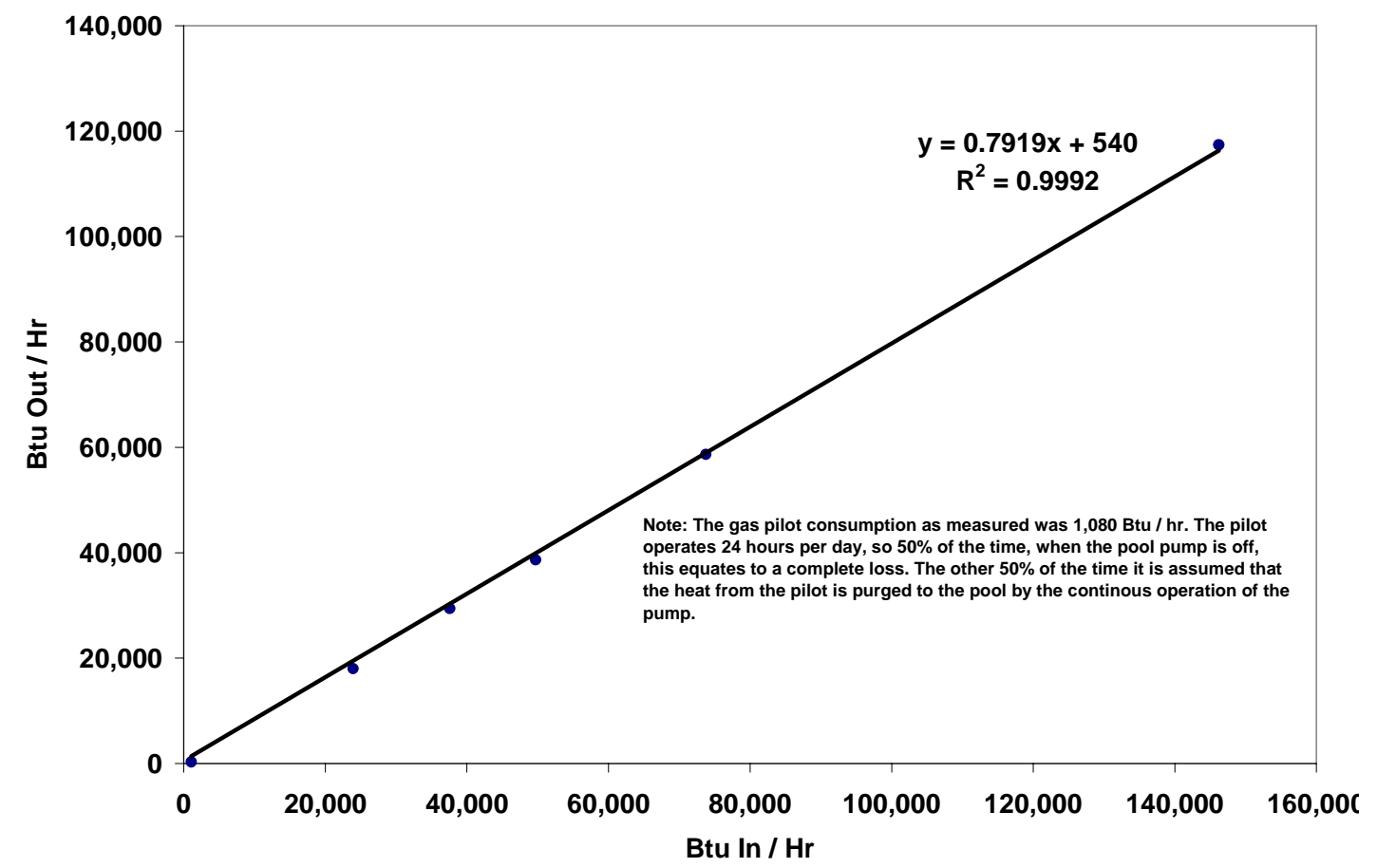

Figure $16 \mathrm{H150}$ - output rate as a function of input rate during cyclic operation

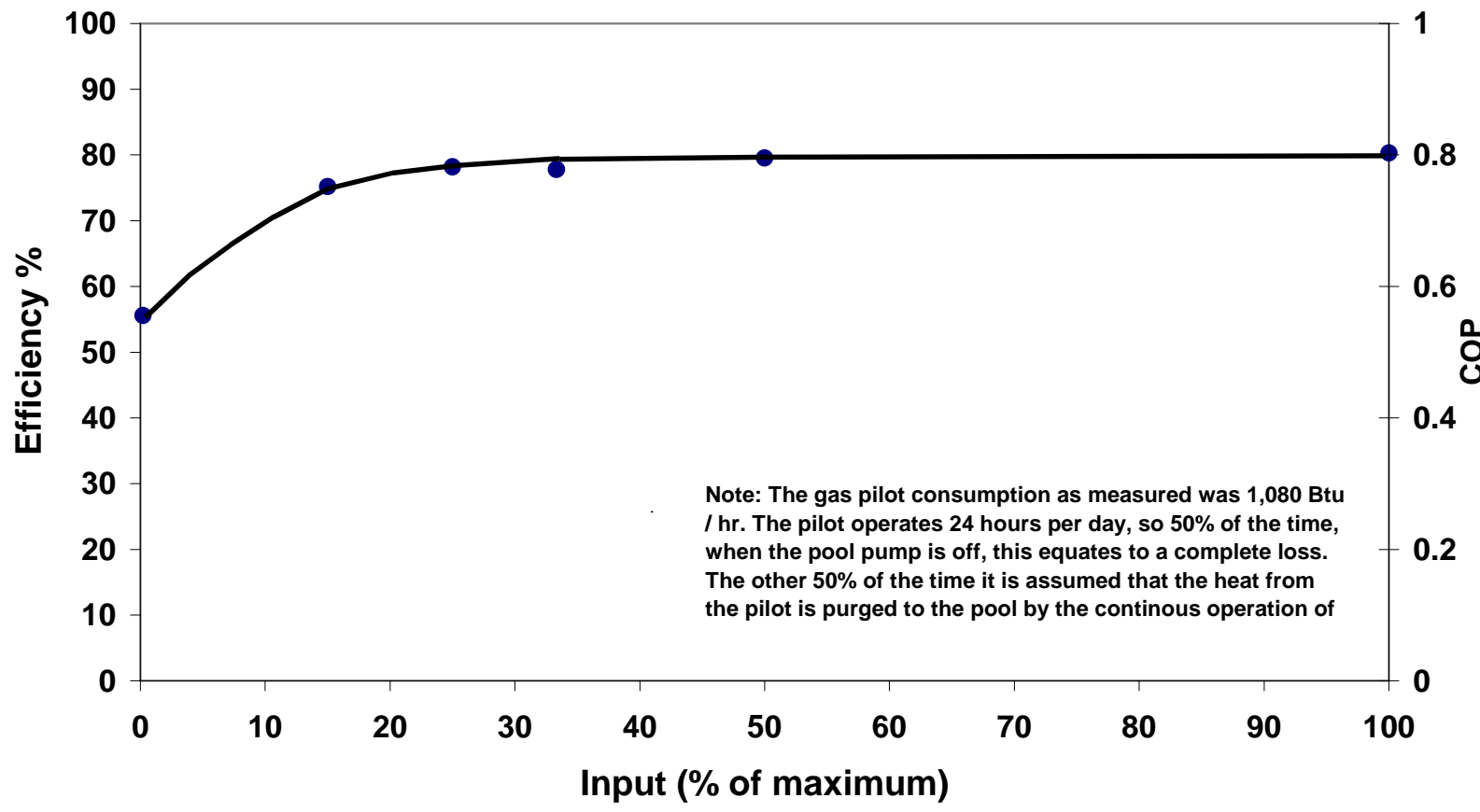

Figure $17 \mathrm{H150}$ - efficiency under cyclic operation as a function of input 


\subsection{Hayward H150FD Low $\mathrm{NO}_{\mathrm{x}}$}

The second unit evaluated was the Hayward H150FD low $\mathrm{NO}_{\mathrm{x}}$ gas-fired pool heater with a fully premixed air-fuel burner as shown in Figure 18. The tests again included a series of steady state runs followed by a number of cyclic load tests mimicking the type of onoff cycle observed in the field study. The steady state tests also included measuring the emissions performance.

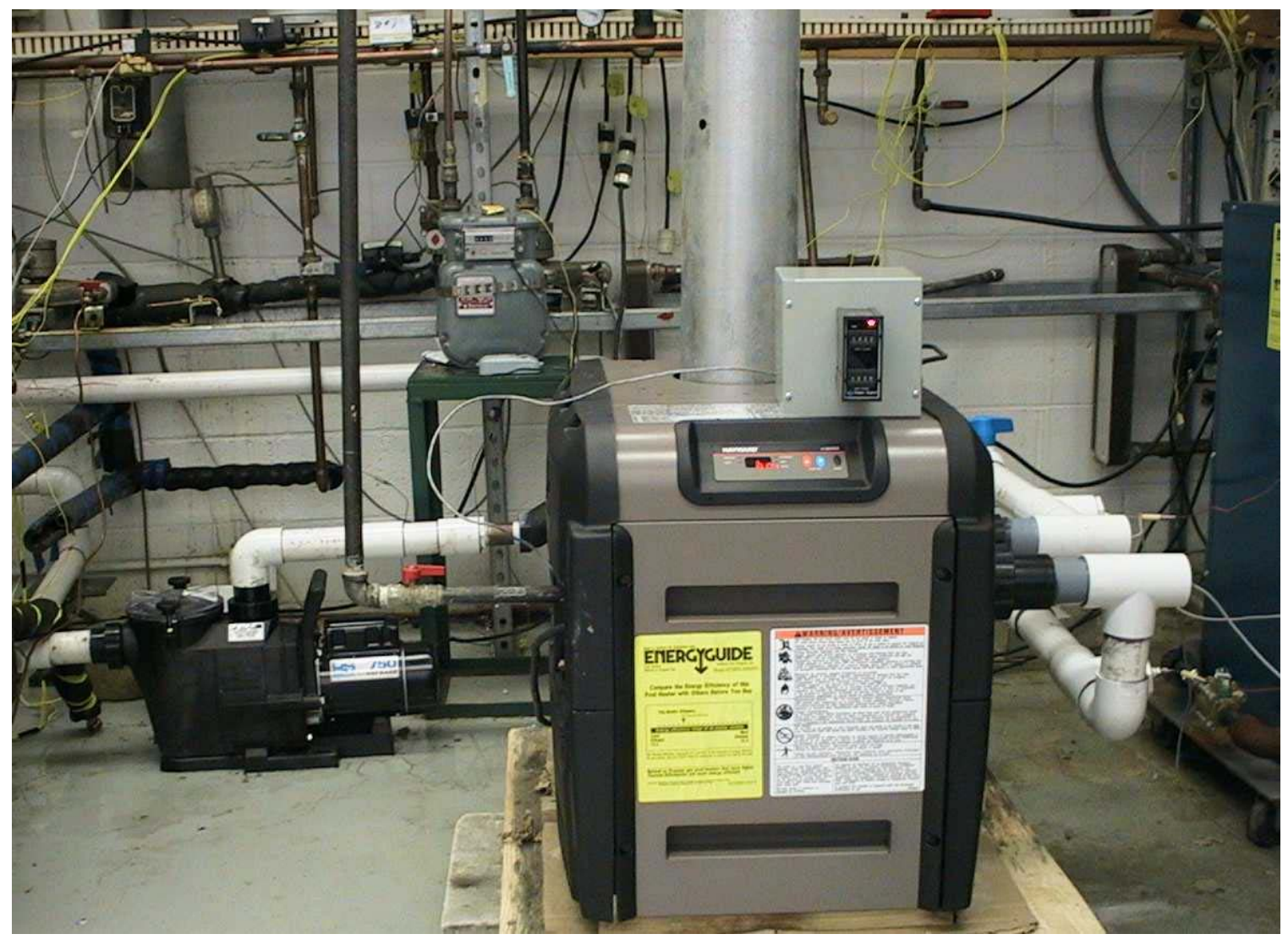

Figure 18 Hayward H150FD low $\mathrm{NO}_{\mathrm{x}}$ natural gas-fired pool heater

Table 7 presents the data measured and the efficiency performance results for the H150FD (low $\mathrm{NO}_{\mathrm{x}}$ unit). Table 8 contains the emission measurement data obtained during steady state along with the flue gas efficiency, the "combustion efficiency'. The jacket loss associated with this system was approximately $0.3 \%$. The average thermal efficiency matches very closely with the Federal Energy Label rating of $84 \%$ for this model. 


\section{Table 7 Model H150FD, Steady State Efficiency Results}

\begin{tabular}{|l|c|c|c|c|c|c|c|}
\hline \multicolumn{8}{|c|}{ Input-Output Efficiency Results - Hayward Model H-150FD Low NOx Gas Fired Pool Heater } \\
\hline $\begin{array}{l}\text { Test } \\
\text { Date }\end{array}$ & $\begin{array}{c}\text { Btu In } \\
\text { Accumulated }\end{array}$ & $\begin{array}{c}\text { Time } \\
\text { Period }\end{array}$ & $\begin{array}{c}\text { Btu Out } \\
\text { Accumulated }\end{array}$ & $\begin{array}{c}\text { Time } \\
\text { Period }\end{array}$ & $\begin{array}{c}\text { Btu/hr } \\
\text { Input }\end{array}$ & $\begin{array}{c}\text { Btu/hr } \\
\text { Output }\end{array}$ & $\begin{array}{c}\text { Thermal } \\
\text { Efficiency }\end{array}$ \\
\hline $7 / 14 / 2009$ & 154,000 & 1.0008 & 134,000 & 1.0197 & 153,872 & 131,408 & 85.4 \\
\hline $7 / 15 / 2009$ & 150,000 & 1.0056 & 134,000 & 1.0400 & 149,171 & 128,846 & 86.4 \\
\hline $7 / 16 / 2009$ & 150,000 & 1.0011 & 132,000 & 1.0231 & 149,834 & 129,025 & 86.1 \\
\hline $7 / 17 / 2009$ & 148,000 & 1.0058 & 128,000 & 1.0064 & 147,142 & 127,187 & 86.4 \\
\hline $7 / 20 / 2009$ & 152,000 & 1.0017 & 132,000 & 1.0200 & 151,747 & 129,412 & 85.3 \\
\hline \multicolumn{70}{|c|}{} \\
\hline
\end{tabular}

\section{Table 8 Model H150FD, Steady State Emission Results}

\begin{tabular}{|l|c|c|c|c|c|c|c|}
\hline \multicolumn{7}{|c|}{ Emission Test Results - Hayward Model H-150FD Low NOx Natural Gas Fired Pool Heater } \\
\hline Test Date & $7 / 14 / 2009$ & $7 / 15 / 2009$ & $7 / 16 / 2009$ & $7 / 17 / 2009$ & $7 / 20 / 2009$ & Average & Avg. @ 3\% O2 \\
\hline Stack Temp. F & 232.6 & 237.1 & 238.2 & 239.3 & 240.3 & 237.5 & $\star \star \star \star$ \\
\hline Oxygen \% & 7.80 & 7.94 & 7.94 & 7.72 & 7.77 & 7.834 & $\star \star \star \star$ \\
\hline CO2 \% & 7.34 & 7.27 & 7.27 & 7.39 & 7.37 & 7.328 & 10.0 \\
\hline CO ppm & 13.2 & 9.7 & 8.4 & 8.5 & 7.7 & 9.5 & 13.0 \\
\hline NO ppm & 9.9 & 9.8 & 9.5 & 10.3 & 10.2 & 9.9 & 13.6 \\
\hline NOx ppm & 14.4 & 14.3 & 13.1 & 14.4 & 14.8 & 14.2 & 19.5 \\
\hline NO2 ppm & 4.6 & 4.5 & 3.6 & 4.1 & 4.6 & 4.28 & 5.9 \\
\hline SO2 ppm & 1 & 0 & 0 & 1 & 1 & 0.6 & 0.8 \\
\hline Efficiency & 86.4 & 86.2 & 86.2 & 86.2 & 86.2 & 86.24 & $\star \star \star \star$ \\
\hline Excess Air & 52.2 & 53.6 & 53.6 & 51.3 & 51.8 & 52.5 & $\star \star \star \star$ \\
\hline
\end{tabular}

The evaluation of the unit under cyclic on-off operation followed the full load steady state tests. Tests at 50\%, 33.33\%, 25\% and 15\% run time were used to characterize the cyclic performance of the heater. The results are again presented in two ways. The first is presented in Figure 19 and is a linear plot of the energy output to the pool as a function of the energy input to the burners. The second shown in Figure 20 is a plot of efficiency as a function of burner fraction on time. This unit used a hot surface igniter in place of the gas-fueled pilot light. The low $\mathrm{NO}_{\mathrm{x}}$ pool heater consumed 140 watts of electric power during operation. This was used to power the hot surface igniter during light off, the combustion fan during running conditions and the electronic controls. There was a tiny but constant draw of 11-12 watts during stand-by periods when the system was not operating. A good estimate is that roughly half of this electric power during operation is lost as heat. This power "loss" is estimated to be $50 \%$ of the 140 watts consumed or about 240 Btu per hour. It is assumed that this "lost" heat (240 Btu/hour) would be absorbed by the circulating pool water. Given the cyclic characteristics as measured for this unit in the laboratory it would at a point of $44 \%$ of its maximum input capacity have an efficiency of roughly $85.8 \%$ which is again is almost identical to the steady state value of $85.9 \%$. 


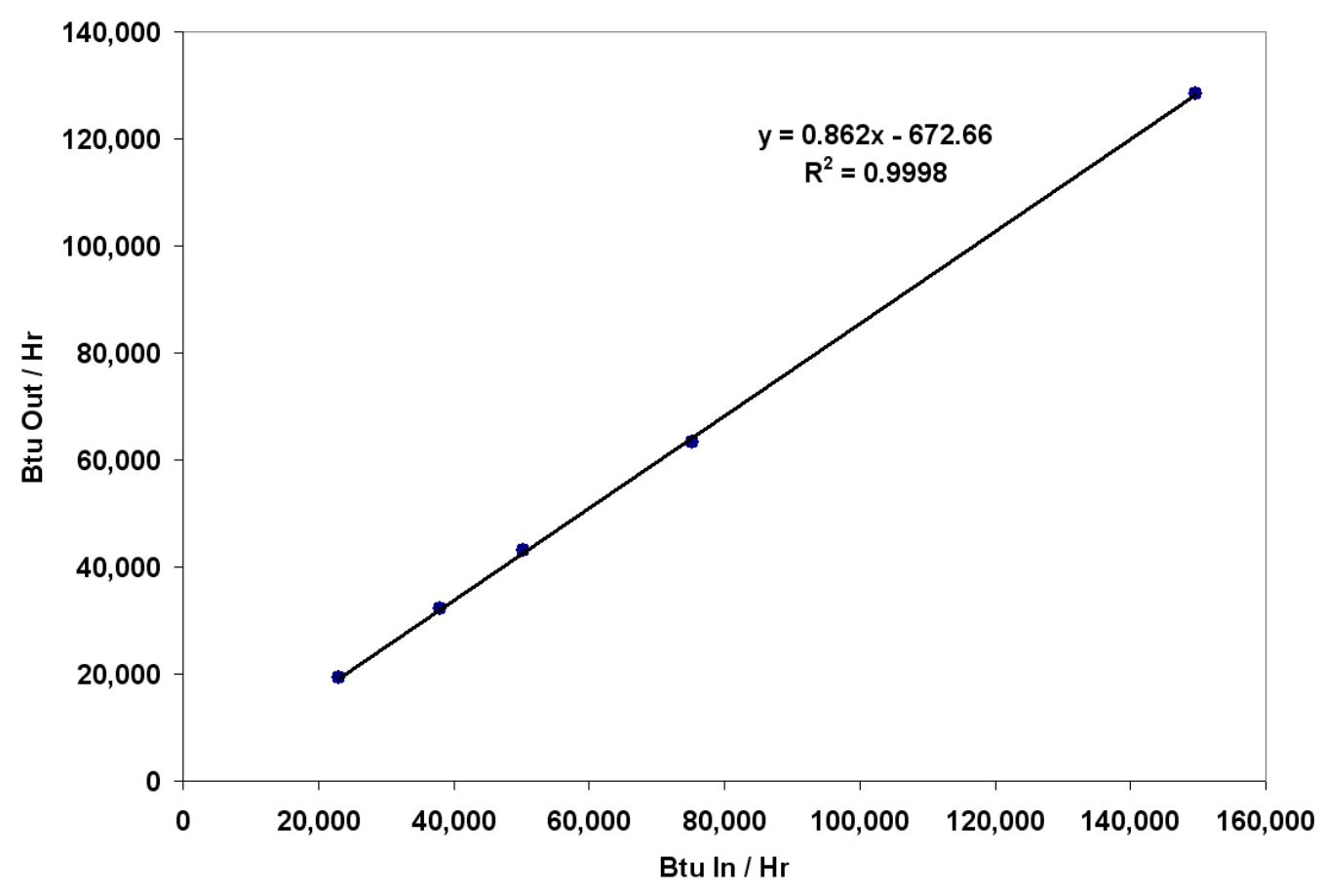

Figure 19 H150FD - output rate as a function of input rate for cyclic operation

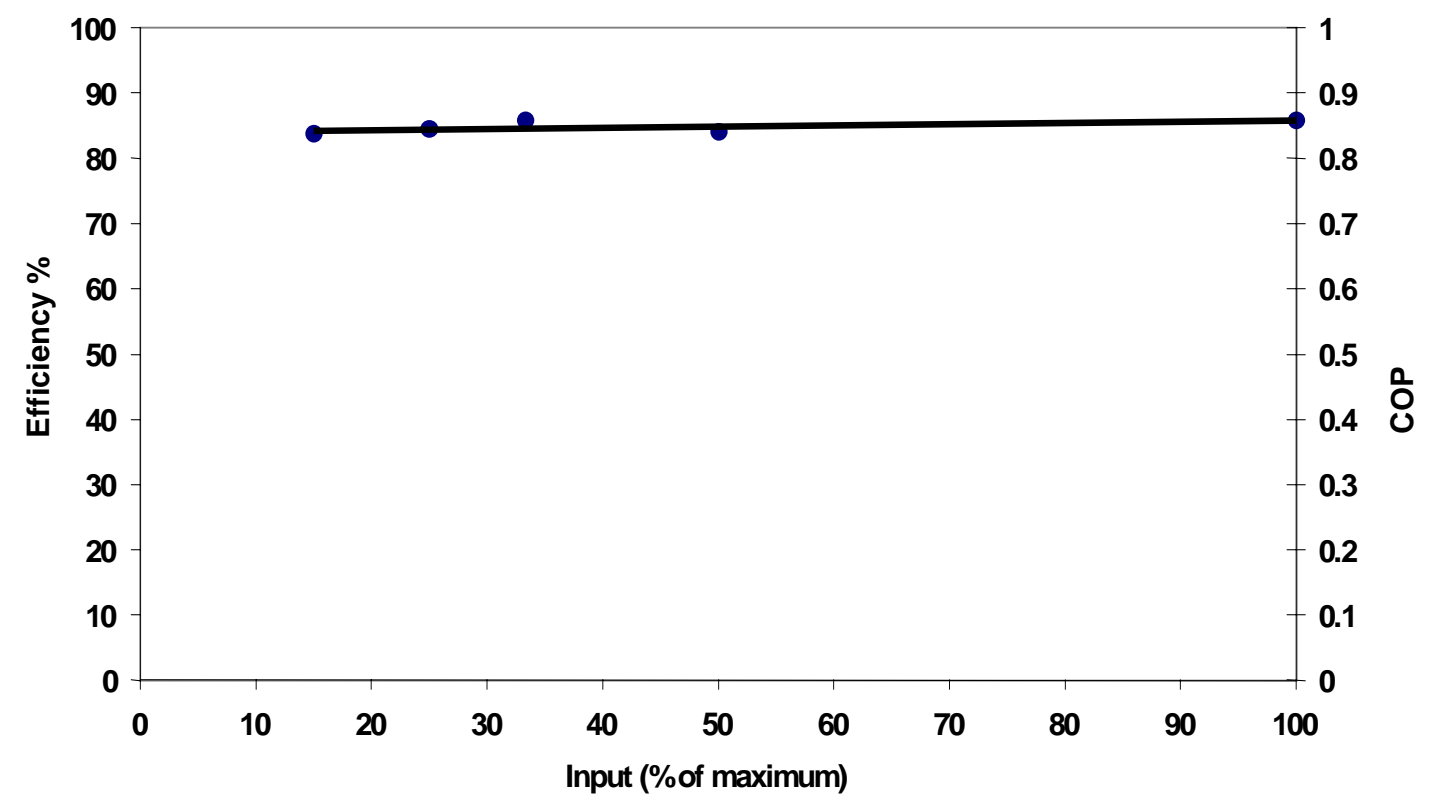

Figure 20 H150FD - efficiency under cyclic operation as a function of input

After having tested the two gas-fired pool heaters it had become obvious that there was little point in attempting to measure the cyclic characteristics due to the extremely low thermal mass of the heaters and the almost instant purge of residual heat by the high flow rate of circulating water (30 gallons per minute) through the heat exchanger. This simplified the test plan for the heat pump units that had even less thermal storage capacity. 


\section{Heat Pump Test Results}

\subsection{Hayward, Heat Master HML-125T}

The third unit tested was an electric heat pump, Model HML-125T made by Hayward. This unit was installed in the BNL test facility in a similar manner as the gas-fired units except for replacing the gas supply with electric power supplied at 208 volts single-phase for the heat pump's scroll compressor and other power consuming components. The manufacturer's literature claimed a heat capacity of 125,000 Btu per hour. No COP data is available for this model. The unit is pictured in Figures 21 and 22 (front and rear views) just after it was removed form the BNL test stand. The unit was designed to draw ambient air from the side and back of the unit to warm the refrigerant in the evaporator heat exchanger and then exhaust the cold air out the top. Using the laboratory's airconditioning heating and cooling system the ambient temperature was controlled to simulate different outdoor temperature ambient temperatures. However, the laboratory was not controlled for humidity.

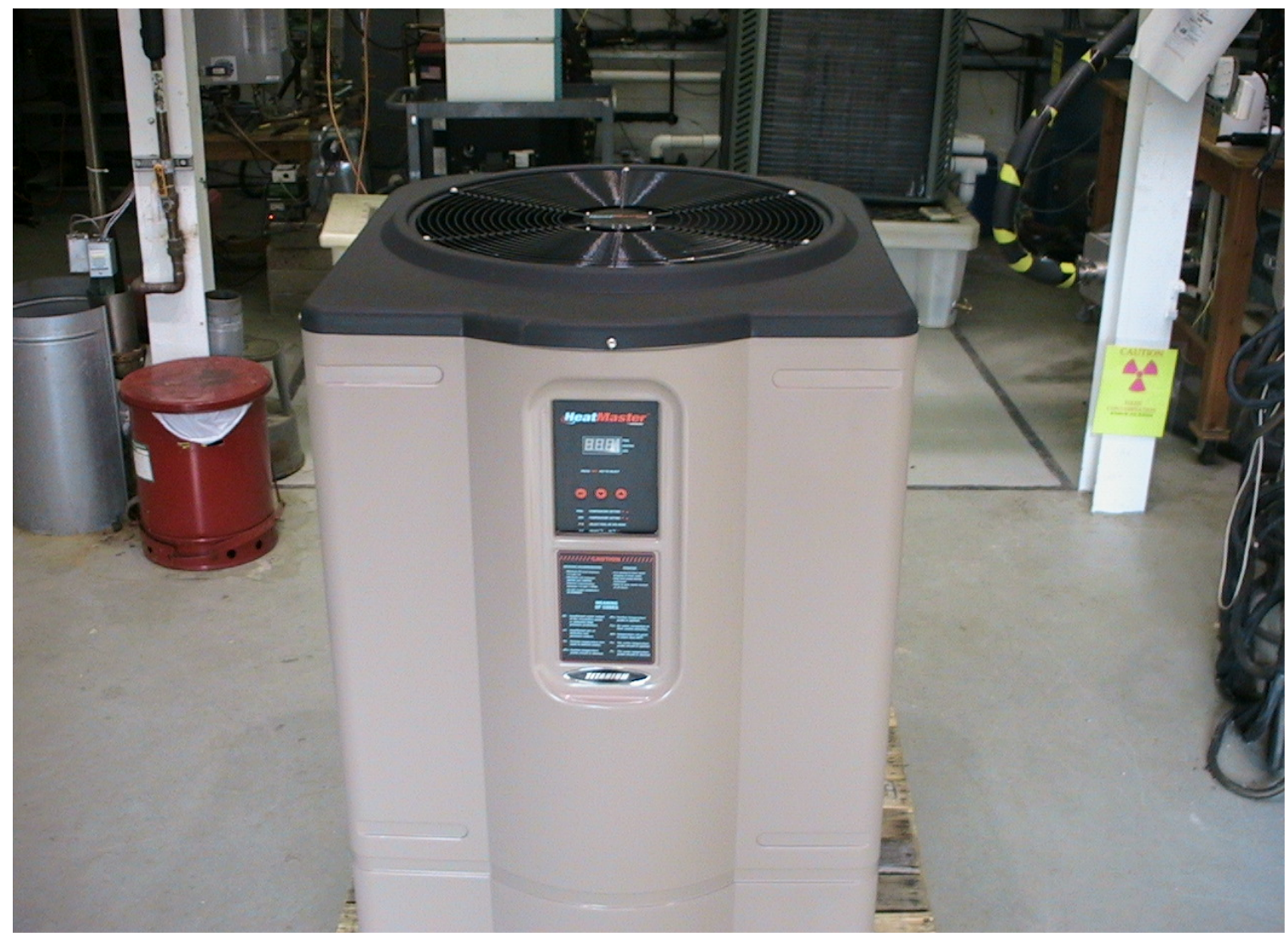

Figure 21 Hayward Model: Heat Master HML-125T electric heat pump 
The results of the evaluations performed are presented in Table 9 and Figure 23. The average COP determined was 4.5 at an ambient temperature of 70 degrees F. Note that in Table 9 power consumption has been converted to the equivalent Btu per hour rating. The COP ranged form a high of 4.8 to a low of 4.3 over the span of temperatures as measured. As can be seen the results had quite a bit of scatter as a function of ambient temperature but do indicate a slight decrease with decreasing ambient temperature. The data scatter makes any conclusion with regard to this trend rather weak but this is the expected trend for a curve of COP as temperatures decrease (a colder source temperature). The explanation for the data scatter may be the inability to control humidity in the test facility and lack of precise temperature control on temperature. An effort was made to control temperature to the best degree possible. These variations in tests conditions would have been worse if the units had been tested outside where conditions can change minute by minute. The value for the COP can best be stated as 4.5 at an average ambient temperature of 70 degrees $\mathrm{F}$ based on the tests performed. The power consumption during operation averaged $6.24 \mathrm{~kW}$. It was not possible to determine the idle consumption of electric power without the compressor operating as the heat pump was hooked up to the larger GE-Energy I-120 power meter, which could only be read to the single $\mathrm{kWh}$ level. It is assumed that the power draw when the heat pump is not operating would be on the same minimal level as that determined for the low $\mathrm{NO}_{\mathrm{x}}$ gas-fired unit (11-12 watts), which had a similar electronic control system.

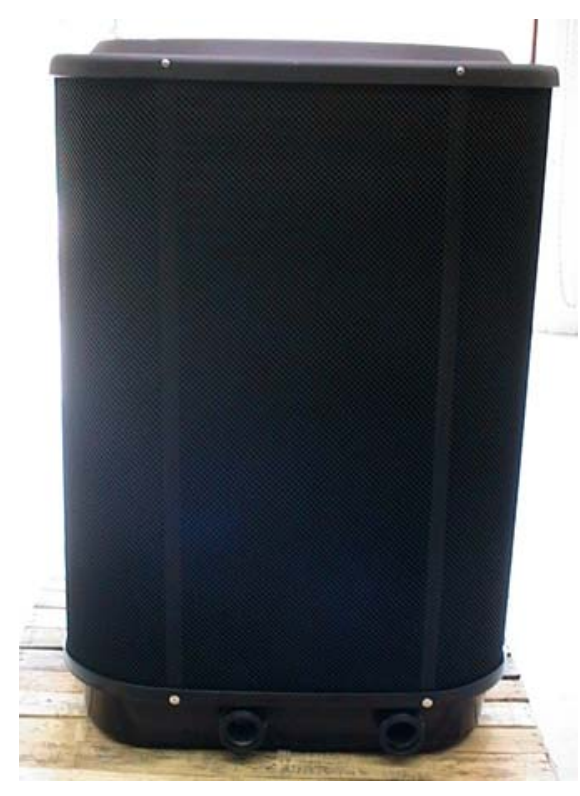

Figure 22 HML125L back end showing plumbing connections on the bottom

Table 9 HML125L, Input-Output COP Results

\begin{tabular}{|l|c|c|r|r|r|r|r|c|}
\hline \multicolumn{7}{|c|}{ Input Output COP Results - Hayward Model Heat Master HML125L Electric Heat Pump } \\
\hline $\begin{array}{l}\text { Test } \\
\text { Date }\end{array}$ & $\begin{array}{c}\text { Btu In } \\
\text { Accumulated }\end{array}$ & $\begin{array}{c}\text { Time } \\
\text { Period }\end{array}$ & $\begin{array}{c}\text { Btu Out } \\
\text { Accumulated }\end{array}$ & $\begin{array}{c}\text { Time } \\
\text { Period }\end{array}$ & $\begin{array}{c}\text { Btu/Hr } \\
\text { Input }\end{array}$ & $\begin{array}{c}\text { Btu / Hr } \\
\text { Output }\end{array}$ & $\begin{array}{c}\text { Ambient Deg F } \\
\text { Temperature }\end{array}$ & COP \\
\hline $9 / 8 / 2009$ & 27297 & 1.28917 & 122000 & 1.29861 & 21174 & 93947 & 67.9 & 4.44 \\
\hline $9 / 9 / 2009$ & 20473 & 0.97306 & 96000 & 0.98000 & 21040 & 97959 & 67.9 & 4.66 \\
\hline $9 / 10 / 2009$ & 27297 & 1.31278 & 118000 & 1.31361 & 20793 & 89829 & 61.2 & 4.32 \\
\hline $9 / 14 / 2009$ & 58006 & 2.76639 & 277000 & 2.77278 & 20968 & 99900 & 68.0 & 4.76 \\
\hline $10 / 5 / 2009$ & 58006 & 2.68333 & 256000 & 2.58833 & 21617 & 98905 & 74.4 & 4.58 \\
\hline $10 / 6 / 2009$ & 51182 & 2.36583 & 233000 & 2.41333 & 21634 & 96547 & 73.9 & 4.46 \\
\hline $10 / 7 / 2009$ & 64831 & 2.96111 & 289000 & 3.00639 & 21894 & 96129 & 74.1 & 4.39 \\
\hline
\end{tabular}




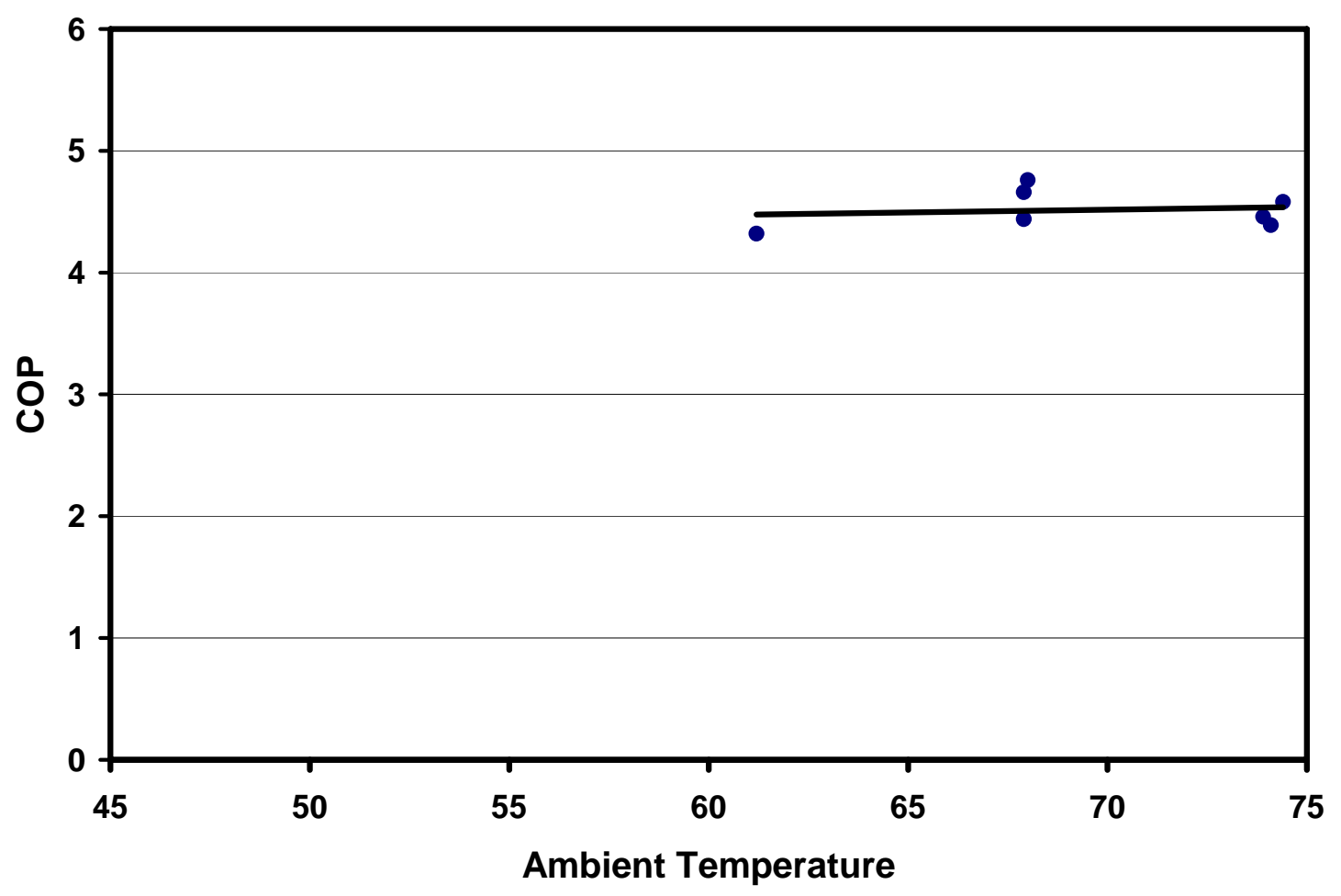

Figure 23 COP results - Heat Master HML125L electric heat pump

\subsection{Rheem 8320ti (Raypak)}

The fourth and last unit tested was the Rheem Model 8320ti electric heat pump manufacturer by Raypak (also sold as Raypak R8320ti and also under the Rudd brand). The unit as tested on the BNL test stand can be seen in Figure 24. This unit was listed with a heating capacity of 121,000 Btu per hour with a COP of 5.3 under AHRI-1160 standard conditions of 80/63/80 (ambient temperature, humidity and pool temperature). The results are presented in Table 10 and Figure 25.

Table 10 Model 8320ti, Input-Output COP Results

\begin{tabular}{|l|c|c|c|c|c|c|c|c|}
\hline \multicolumn{8}{|c|}{ Input Output COP Results - Rheem Model 8320ti (Raypak R8320ti) Electric Heat Pump } \\
\hline $\begin{array}{l}\text { Test } \\
\text { Date }\end{array}$ & $\begin{array}{c}\text { Btu In } \\
\text { Accumulated }\end{array}$ & $\begin{array}{c}\text { Time } \\
\text { Period }\end{array}$ & $\begin{array}{c}\text { Btu Out } \\
\text { Accumulated }\end{array}$ & $\begin{array}{c}\text { Time } \\
\text { Period }\end{array}$ & $\begin{array}{c}\text { Btu / Hr } \\
\text { Input }\end{array}$ & $\begin{array}{c}\text { Btu / Hr } \\
\text { Output }\end{array}$ & $\begin{array}{c}\text { Ambient Deg F } \\
\text { Temperature }\end{array}$ & \begin{tabular}{c} 
COP \\
\hline $10 / 9 / 2009$
\end{tabular} \\
\hline 40946 & 2.01833 & 211000 & 2.07056 & 20287 & 101905 & 63.5 & 5.02 \\
\hline $10 / 13 / 2009$ & 40946 & 2.05528 & 205000 & 2.04667 & 19922 & 100163 & 64.5 & 5.03 \\
\hline $10 / 14 / 2009$ & 64831 & 3.20917 & 324000 & 3.20361 & 20202 & 101136 & 65.4 & 5.01 \\
\hline $10 / 15 / 2009$ & 68243 & 3.37500 & 346000 & 3.37472 & 20220 & 102527 & 66.4 & 5.07 \\
\hline $10 / 16 / 2009$ R1 & 58006 & 2.79083 & 283000 & 2.78972 & 20785 & 101444 & 63.8 & 4.88 \\
\hline $10 / 16 / 2009$ R2 & 75067 & 3.70194 & 376000 & 3.69917 & 20278 & 101645 & 66.1 & 5.01 \\
\hline $10 / 16 / 2009$ RO & 17061 & 0.91111 & 93000 & 0.90944 & 18725 & 102260 & 68.1 & 5.46 \\
\hline $11 / 3 / 2009$ & 51182 & 2.86639 & 246000 & 2.83556 & 17856 & 86755 & 54.4 & 4.86 \\
\hline $11 / 4 / 2009$ R1 & 34121 & 1.64389 & 138000 & 1.65583 & 20757 & 83342 & 50.0 & 4.02 \\
\hline $11 / 4 / 2009$ R2 & 75067 & 3.78917 & 320000 & 3.79361 & 19811 & 84352 & 52.3 & 4.26 \\
\hline $11 / 4 / 2009$ RC & 40946 & 2.14528 & 182000 & 2.14361 & 19086 & 84903 & 52.5 & 4.45 \\
\hline Note: R1=Run 1, R2 Run 2 and RO=Run Overall when 1 and 2 are combined. & Averages & $\mathbf{6 1}$ & $\mathbf{4 . 8}$ \\
\hline
\end{tabular}




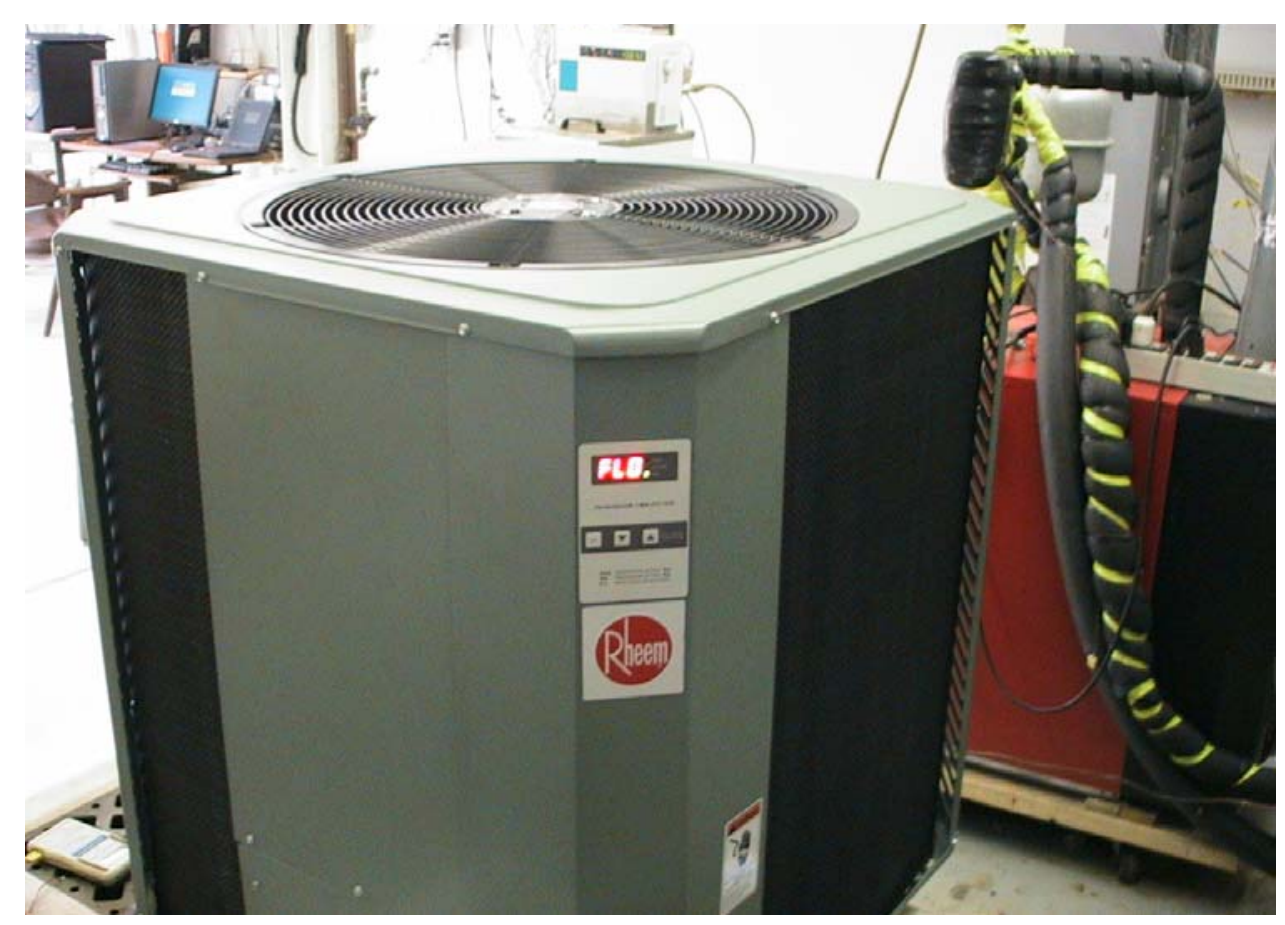

Figure 23 Rheem Model 8320ti electric heat pump being tested at BNL

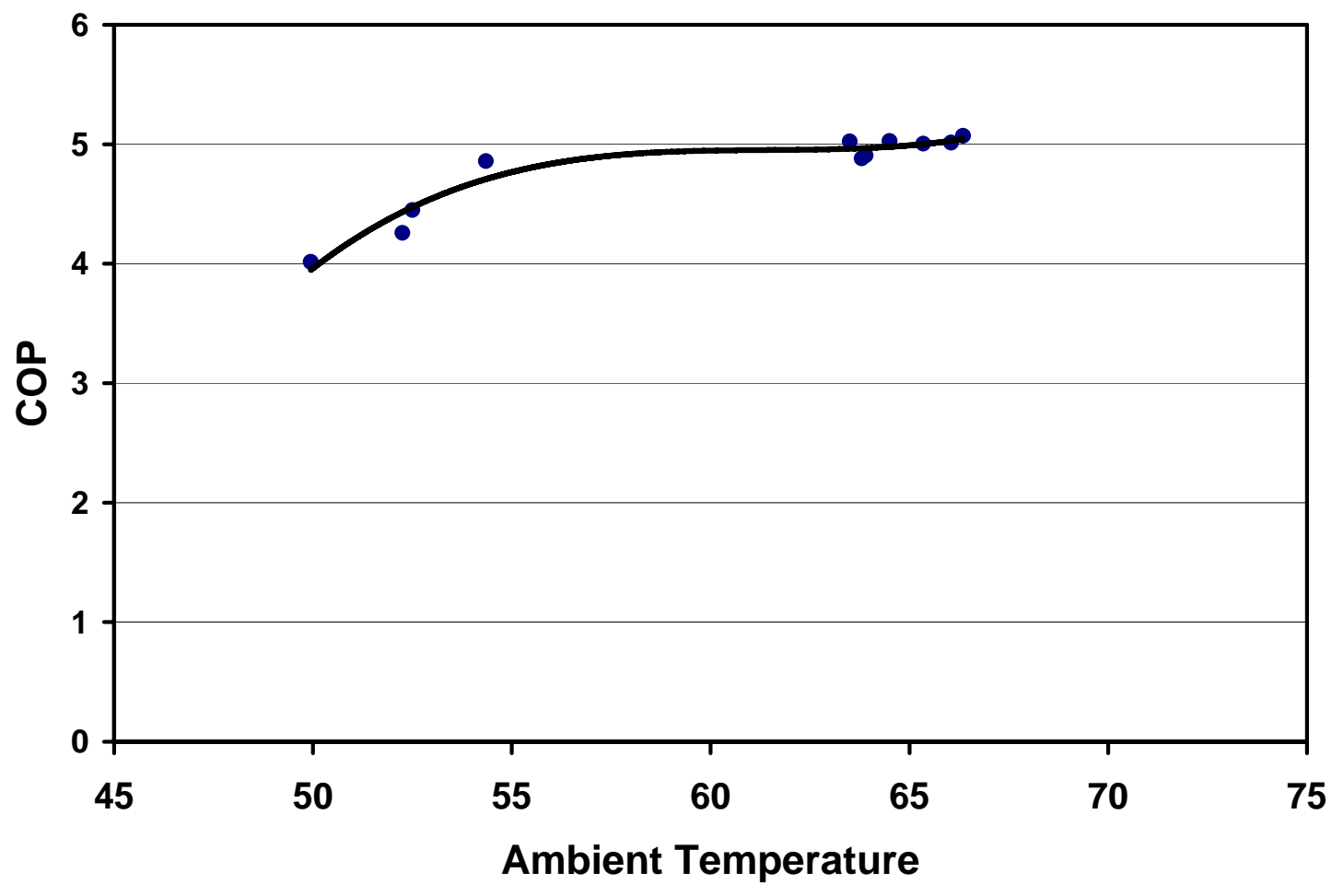

Figure 25 COP results for Rheem Model 8320ti electric heat pump

During testing of the first heat pump the lower range of temperatures had been constrained by the limited ability to chill the air with the laboratory's HVAC system. The second heat pump (Rheem) was tested during November. In these tests it was possible to 
include measurements under much cooler ambient temperatures. This provided performance measurement data over a much wider range of temperature conditions. In addition, the humidity levels were much lower and more consistent during this period. The test results with the second unit are much better with regard to consistency and reduced scatter in the data points plotted for the COP curve. These results indicate a much more distinct decline in performance as a function of the decreasing air temperature. This decline is what is expected given the lower energy content of the ambient air used as the heat source as the temperatures fall. From this data an average COP value of 5.0 can be seen at an ambient temperature of 65 degrees F.

\section{General Comments - All Heater Tests}

The flow rate for the circulating water of the pool simulator was in the range of 30-35 gallons per minute. This flow was supplied by using a $3 / 4$ horsepower pool pump and was set within the acceptable range of flow rates as specified by the installation manuals for the four different units evaluated in this project. The range for the temperature rise across the units varied only slightly and was dependent on operational conditions. One primary reason for selecting this very narrow flow range was to keep conditions as equal as possible to provide for a direct comparison of the results. Table 11 contains the average and range of flow rates along with the average and range of temperature rise for each of the four units tested.

Table 11 Water flow rate and temperature rise data for all units tested

\begin{tabular}{|l|c|c|c|c|c|c|}
\hline \multirow{2}{*}{\begin{tabular}{c} 
Test $\begin{array}{c}\text { Unit } \\
\text { Identification }\end{array}$ \\
\cline { 2 - 7 }
\end{tabular}} & Minimum & Maximum & Average & Minimum & Maximum & Average \\
\cline { 2 - 7 } & GPM & Glow & Flow & Temp. Delta & Temp. Delta & Temp. Delta \\
\hline H150 & 34.6 & 34.8 & 34.8 & 6.7 & 6.8 & 6.8 \\
\hline H150FD & 34.3 & 34.8 & 34.6 & 7.6 & 8 & 7.8 \\
\hline Heat Master & 30.2 & 30.8 & 30.5 & 5.6 & 6.8 & 6.4 \\
\hline Rheem & 31.4 & 31.6 & 31.5 & 5.5 & 6.6 & 6.2 \\
\hline
\end{tabular}

The tests of the four units occurred over a period of approximately five months from June until the first week of November. This generally allowed for fairly equal test conditions A few things were not possible to control. First the tap water used to refill the simulator progressively got warmer through the period. This resulted in slightly increased starting temperatures for each run as testing progressed. The difference was on the order of seven degrees from a low of 63 degrees $\mathrm{F}$ to a high of 80 degrees $\mathrm{F}$ in August and lower again towards the last test in the Fall. The testing of the first heat pump with the scatter in the results (as described earlier) along with the extremely low thermal capacity of the heat exchanger that was almost instantly purged of any heat by the high rate of water flow were combined in a decision. This was to only test the heat pumps under steady state operations. The results with the second heat pump were much more consistent. This appears to be a function of very slight humidity swings during the tests as compared to the rather wide range that occurred during the first heat pump's evaluation conducted in July. All tests were conducted under as close to identical conditions as possible lacking an environmental test chamber, which was well outside of the project's scope and budget. 


\section{Comparative Analysis of Costs, Energy Use and Environmental Emissions}

This study was designed to measure the performance factors associated with two specific types of swimming pool heaters in order to compare their relative energy, environmental and economic characteristics. This report compares the results obtained for both natural gas-fired units and electric powered heat pump units based on tests conducted under controlled conditions using a pool heat-load simulator and instrumented test facility at BNL. This section of the report will provide information on the relative energy, environmental and economic costs associated with the use of these two different pool heater options in order to and fulfill the main goal and objectives of the project.

\subsection{Initial Costs of Pool Heaters and Factors Associated with Sizing Capacity}

In order to obtain comparable results and match the facility load limits the units selected were all sized to be as close to 120,000 Btu per hour in output capacity. The gas-fired units were very close to this figure. The capacity of heat pumps is dependent on the ambient temperature. The largest capacity electric heat pumps available fell somewhat short of this size range at ambient air temperatures of 60-70 degrees $\mathrm{F}$ but they were capable of delivering about 100,000 Btu per hour. The warmer the air the higher is the output capacity of the heat pump. This highlights two issues associated with electric heat pumps. The first is the decreased capacity with decreasing temperature and the second is their relatively low capacity in general. Gas-fired units are available in sizes ranging form 120,000 to $320,000 \mathrm{Btu} / \mathrm{hr}$ in output heating capacity. The largest heat pump capacity just about matches the lowest capacity of any gas-fired unit.

These factors have two implications. First, as the temperature falls and the pool owner needs more heat the heating capacity with a heat pump unit will decrease. The second is that if the consumer wants to raise the pool water temperature from an initially low point it will require a much longer time to meet the load demand with the heat pump when compared to larger capacity gas-fired units. Again the option to buy a larger heat pump is currently nonexistent. The only option would be to install more than one heat pump and this requires additional capacity in terms of the electric circuit that supplies the electricity. As evident by the large amperage power circuit (60-amps) required for a single unit $(100,000 \mathrm{Btu} / \mathrm{hr})$ this may not even be within the capacity of some homes. Many older homes only have a 100-amp service for the whole house. Even given the available capacity it would entail a larger investment in providing the additional electrical circuit. In homes with only a 100-amps service a larger service panel would be needed to install for multiple heat pump units.

Heat pumps also likely need to be operated 24 hours a day at a fixed set point so the pool will not cool off excessively. Alternately the pool owner would need to wait a considerably longer time (and much longer during cold weather conditions) to have the pool reach a desired temperature. The pool's pump must be turned on when ever the pool heater is in operation or else the heater's control system will not allow it to operate for safety reasons. So by running the heater longer additional costs are incurred by the pool pump’s constant use. 
As an example, even though the two homeowners visited during the initial field study had gas-fired heaters they both preferred to normally operate the pool pump for only 8-12 hours per day. It should also be also noted that both homeowners only used their heaters on rare and infrequent special occasions. They both had large 320,000 Btu per hour output capacity heaters. One said that it still required a significant period of operation to raise the pool to the set point. A large electric heat pump (108,000 Btu per hour) would have required a period of time equal to three times that amount required for by the gasfired unit to satisfy the same load demand.

This discussion obviously has not addressed the actual costs of operation or associated environmental impacts. However, it does highlight an important area to consider related to the customer's initial sizing decision and the associated satisfaction or lack of satisfaction with the heater actually once installed.

Based on the survey conducted, the purchase costs for the gas-fired heaters range from about $\$ 1,200$ to $\$ 2,550$ per unit depending on features and capacity $(120,000-320,00$ Btu per hour). The one exception was the condensing ultra-high efficiency unit, which costs around \$5,000 and is only available with an output capacity of 315,000 Btu per hour. The cost for the electric heat pumps will range form $\$ 2,900$ to $\$ 4,600$ depending on features and capacity. The output capacity ranges from 100,000 to 120,000 Btu/hr for the heat pumps. The installation cost for either type would be similar but highly variable depending on the location and effort involved in running either a gas line and a 15-amp power line or a high amperage (60-amp) electric service for the heat pump option. It would also vary a lot based on the home's location, the site's physical terrain and the labor skills required. As a result this study will not attempt to address a comparison of the installation costs.

\subsection{Emissions Comparison}

The emissions from the gas-fired heaters will be compared to those associated with the power consumption of heat pump heaters. The data for the gas-fired heaters was measured in terms of concentration, either in percentage for carbon dioxide $\left(\mathrm{CO}_{2}\right)$ or in parts per million for nitrogen oxides $\left(\mathrm{NO}_{\mathrm{x}}\right)$, carbon monoxide $(\mathrm{CO})$ and sulfur dioxide $\left(\mathrm{SO}_{2}\right)$. These can be converted to pounds of pollutant per pound of fuel burned for any given fuel. This formula can be derived and is specific to the compositional gas analysis of the fuel including the various volume percentages of combustible and inert constituents to calculate the volume of dry combustion products at $3 \%$ oxygen. Table 12 presents the gas composition by volume and total sulfur by weight percentage for all sulfur components including the mercaptan compounds used as odorants and any hydrogen sulfide.

Table 12 Analysis of natural gas constituents in volume percentage

\begin{tabular}{|l|l|l|l|l|l|l|}
\hline $\begin{array}{l}\text { Methane } \\
(\mathrm{CH} 4)\end{array}$ & $\begin{array}{l}\text { Ethane } \\
(\mathrm{C} 2 \mathrm{H} 6)\end{array}$ & $\begin{array}{l}\text { Propane } \\
\text { (C3H8) }\end{array}$ & $\begin{array}{l}\text { Butane } \\
\text { (C4H10) }\end{array}$ & $\begin{array}{l}\text { Carbon } \\
\text { Dioxide }\end{array}$ & Nitrogen & $\begin{array}{l}\text { Sulfur Components } \\
\text { (total sulfur by weight) }\end{array}$ \\
\hline 96.5592 & 1.2247 & 0.0679 & 0.0061 & 0.5943 & 1.5478 & $0.001045 \%$ \\
\hline
\end{tabular}


The formula to convert values measured in ppm at 3\% oxygen also depends on the molecular weight of the various pollutants. The molecular weights of the gaseous emissions are shown in Table 13 along with the conversion of the values measured for the two types of gas-fired heaters. The values given for $\mathrm{NO}$ and $\mathrm{NO}_{2}$ emissions are based on individual electrochemical detection cells. The total amount of $\mathrm{NO}_{\mathrm{x}}$ is simply the sum of the two values.

\section{Table 13 Pollutant emissions from gas heaters due to gas consumption}

\begin{tabular}{|c|c|c|c|c|c|c|c|}
\hline \multirow{2}{*}{\multicolumn{5}{|c|}{ Conventional Baseline Gas-fired Pool Heater }} & \multirow{3}{*}{\begin{tabular}{|c|} 
HHV \\
Input \\
Ibs/mmBtu
\end{tabular}} & \multirow{3}{*}{\begin{tabular}{|c|} 
HHV \\
Output \\
Ibs/mmBtu
\end{tabular}} & \\
\hline & & & & & & & \\
\hline & ppm @ 3\% O2 & MW & g/kg & Ibs/lb fuel & & & \\
\hline $\mathrm{CO} 2$ & 100,723 & 44 & 2639 & 2.64 & 115.5 & 143.8 & \\
\hline $\mathrm{CO}$ & 16 & 28 & 0.267 & 0.00027 & 0.0117 & 0.0145 & \\
\hline NO & 114 & 30 & 2.036 & 0.00204 & 0.0891 & 0.1110 & \\
\hline NO2 & 23.5 & 46 & 0.644 & 0.00064 & 0.0282 & 0.0351 & \\
\hline NOx ${ }^{2}$ & 137 & 32.85 & 2.680 & 0.00268 & 0.1173 & 0.1460 & Correct With \\
\hline SO2 & 0 & 32 & ND & ND & None & None & Electric Use \\
\hline & L w NOx Forced Dra & Gas-firec & Pool Hea & & HHV & HHV & HHV \\
\hline & Low iNox forcea Dra & Gas-inec & Poor Hea & & Input & Output & Output \\
\hline & ppm @ 3\% 02 & MW & $\mathrm{g} / \mathrm{kg}$ & Ibs/lb fuel & Ibs/mmBtu & Ibs/mmBtu & Ibs/mmBtu \\
\hline $\mathrm{CO}$ & 100,723 & 44 & 2638.612 & 2.64 & 115.5 & 134.4 & 136.1 \\
\hline $\mathrm{CO}$ & 13 & 28 & \begin{tabular}{|l|}
0.217 \\
\end{tabular} & 0.00022 & 0.0095 & 0.0110 & No Data \\
\hline NO & 13.6 & 30 & 0.243 & 0.00024 & 0.0106 & 0.0124 & No Data \\
\hline NO2 & 5.9 & 46 & 0.162 & 0.00016 & 0.0071 & 0.0082 & No Data \\
\hline NOx ${ }^{2}$ & 19.5 & 34.84 & 0.4045 & 0.00040 & 0.0177 & 0.0206 & 0.0224 \\
\hline $\mathrm{SO} 2$ & 1 & 32 & 0.019 & 0.00002 & 0.0008 & 0.0010 & 0.0050 \\
\hline $\begin{array}{l}\text { Notes: } \\
{ }^{1} \text { Molecula } \\
{ }^{2} \text { Effective }\end{array}$ & $\begin{array}{l}\text { ar Weight }=\text { MW } \\
\text { MW of NOx is based }\end{array}$ & on weight & ed percent & 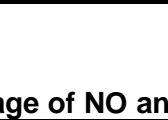 & 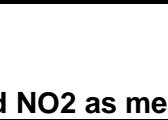 & & \\
\hline${ }^{3}$ Higher & r Heating Value HHV) & ${ }^{4}$ Effic & iency & ${ }^{5} \mathrm{ppm}$ & Conversion & $\mathrm{og} / \mathrm{kg}$ & \\
\hline $\begin{array}{r}22,851 \\
43.76\end{array}$ & $\begin{array}{l}\mathrm{Btu} / \mathrm{lb} \\
\mathrm{lbs} / \mathrm{mmBtu}\end{array}$ & $\begin{array}{c}\text { Baseline } \\
80.3 \%\end{array}$ & $\begin{array}{c}\text { Low NOx } \\
85.9 \%\end{array}$ & & & & \\
\hline
\end{tabular}

In the case of the baseline unit, the emissions indicated in Table 13 account for all energy used by the pool heater. In the case of the Low $\mathrm{NO}_{\mathrm{x}}$ forced draft unit there is also a small amount of electric power consumed by the combustion system. The emissions from generating that power consumption were added as a correction to the analysis as indicated on the right hand column. The foundation for the correction is based on available data for emissions related to power generation and will be discussed next.

The emissions related to electric power generation are based on reported 2005 values supplied by National Grid to the Federal Environmental Protection Agency (EPA) and available on the EPA eGRIDweb database. The average annual values provided and used in this report are specific for the NYLI-NPCC Long Island Sub-region and based on specific year, 2005 being the most recent data available. The values vary from year to year depending on the mix of fuels used to generate the power for any given year. Price and availability of fuels are major factors that can affect the annual mix of fuel used. 
The output emission rates for 2005 are 1,536.80 for $\mathrm{CO}_{2}, 1.6385$ for $\mathrm{NO}_{\mathrm{x}}$ and 3.7516 for $\mathrm{SO}_{2}$ all provided in units of pound per megawatt hour (MWh) equal to one million watthours of electric power generation. The output emissions rates are converted to pounds of pollutant per million Btu (MMBtu) (by dividing by 3.41214 MMBtu per MWh) and are then 450.39 pounds of $\mathrm{CO}_{2}, 0.4802$ pounds of $\mathrm{NO}_{\mathrm{x}}$ and 1.0995 pounds all per MMBtu of electric output. [The data provided on the EPA eGRID website also presents the data in terms of fuel input at the power plants and for 2005 the emissions from this is 150.36 pounds of $\mathrm{CO}_{2}, 0.1603$ pounds of $\mathrm{NO}_{\mathrm{x}}$ and 0.3671 pounds of $\mathrm{SO}_{2}$ all given per MMBtu. The efficiency of power generation can then be determined from these and was about 33.4 percent averaged over 2005.]

Knowing the emissions associated with electric power generation for the electric heat pumps as well as the emissions from the gas-fired units allows for a comparison to be made as presented in Table 14. The emissions of carbon monoxide and the break down of nitrogen oxides to $\mathrm{NO}_{2}$ and $\mathrm{NO}$ were not given in this table as no data was available in the eGRID website, only $\mathrm{NO}_{\mathrm{x}}$.

Table 14 Pollutant emissions in pounds per million Btu as delivered to the load

\begin{tabular}{|c|c|c|c|c|}
\hline \multirow{2}{*}{ Pollutant } & \multicolumn{2}{|c|}{ Gas-fired Units } & \multicolumn{2}{c|}{ Heat Pump Units } \\
\cline { 2 - 5 } Emitted & Hayward & Hayward & Hayward & Rheem \\
\cline { 2 - 5 } & H-150 & H-150HD & HML125L & $8320 t i$ \\
\cline { 2 - 5 } & Lbs/MMBtu & Lbs/MMBtu & Lbs/MMBtu & Lbs/MMBtu \\
\hline Carbon Dioxide & 143.8 & 136.1 & 99.8 & 90.0 \\
\hline Nitrogen Oxides & 0.1460 & 0.0224 & 0.1064 & 0.0960 \\
\hline Sulfur Dioxide & None Detected & 0.0050 & 0.2435 & 0.2198 \\
\hline
\end{tabular}

The emission rates in Table 14 are based on the performance data and energy use measured in this study and calculated per million Btu input to the heating load of the swimming pool. The emission factors for the heat pumps are based on ambient temperatures of 65-70 degrees F. These were calculated on a steady state basis due to the difficulty of defining a "typical operational pattern." As has been discussed the gas-fired units are available in much larger capacities and thus the cyclic on-off patterns associated with their use would also vary widely. This has no effect on the Low-NOx emissions rate as it only produces emissions during the burner operation. The baseline unit however has a pilot light that consumes 1,080 Btu per hour. This will contribute to the emissions over 24 hours per day. The portion of emissions from the pilot flame when the main burners are off can be considered somewhat comparable to the extra emissions associated with the extra operating time required for a heat pump unit to satisfy an identical heating load. Since the longer running periods require the pool's water pump to operate longer the emissions associated with the generation of the electric power for the pool pump would need to be included in a direct comparison. The pilot light used with the gas-fired units and the extra pool pump usage for heat pump units are much too variable from one installation to the next. In the calculations for Table 14 they can't be clearly defined. To some extent they would tend to cancel each other out and were omitted in this analysis. 


\subsection{Operating Cost Comparison}

The operating direct cost comparison is presented in Table 15. This comparison is based on delivering one million Btu of heat to pool. To provide a concept of the amount of heat energy that 1,000,000 Btu represents; an example is calculated for a large pool. In this example the dimensions are 40 foot long by 18 feet wide and eight foot deep for half the length and an average of four feet for the other half. The volume would be approximately 32,000 gallons of water and the weight of the water would be about 269,000 pounds. The water temperature in this pool would increase by 3.7 degrees $\mathrm{F}$ assuming no thermal losses to the ambient air or the ground occur.

Table 15 Comparison of operating cost per MMBtu of heat supplied to load

\begin{tabular}{|l|c|c|c|c|c|}
\hline \multirow{2}{*}{ Operating Cost Anaysis Results } & \multicolumn{2}{|c|}{ Gas-fired Units } & \multicolumn{3}{c|}{ Heat Pump Units } \\
\cline { 2 - 6 } & Hayward & Hayward & Hayward & Rheem & Rheem \\
\cline { 2 - 6 } & $\mathrm{H}-150$ & $\mathrm{H}-150 \mathrm{HD}$ & HML125L & $8320 \mathrm{ti}$ & $8320 \mathrm{ti}$ \\
\hline Thermal Efficiency & $80.3 \%$ & $85.9 \%$ & {$[450 \%]$} & {$[500 \%]$} & {$[425]$} \\
\hline Thermal COP & {$[0.803]$} & {$[0.859]$} & 4.5 & 5.0 & 4.25 \\
\hline Average Ambient Temperature & $65 \mathrm{~F}$ & $65 \mathrm{~F}$ & $70 \mathrm{~F}$ & $65 \mathrm{~F}$ & $52 \mathrm{~F}$ \\
\hline Btu Output Per Hour & 117,472 & 129,176 & 96,174 & 101,470 & 84,199 \\
\hline Hours to Output 1,000,000 Btu & 8.51 & 7.74 & 10.40 & 9.86 & 11.88 \\
\hline Energy Consumed Gas - Btu & $1,245,240$ & $1,163,940$ & 0 & 0 & 0 \\
\hline Natural Gas - Therms Used & 12.452 & 11.639 & 0 & 0 & 0 \\
\hline Btu Thermal Equivalent of Electric Used & 0 & 3,698 & 221,506 & 199,884 & 236,162 \\
\hline Electric Power Consumption KWh & 0 & 1.08 & 64.92 & 58.58 & 69.2 \\
\hline Natural gas \$ Cost Per Therm & $\$ 1.65$ & $\$ 1.65$ & $\$ 0.00$ & $\$ 0.00$ & $\$ 0.00$ \\
\hline Electric Power Cost \$Per KWh & & $\$ 0.22$ & $\$ 0.22$ & $\$ 0.22$ & $\$ 0.22$ \\
\hline Total Cost Per MMBtu Pool Heat & $\$ 20.55$ & $\$ 19.44$ & $\$ 14.28$ & $\$ 12.89$ & $\$ 15.22$ \\
\hline
\end{tabular}

The gas-fired and electric heat pump units tested in this study had output rates that ranged from 96,129 to 117,472 Btu per hour as seen in the table. To heat approximately 32,000 gallons of water by 3.7 degrees F it would require about 7.7 to 10.4 hours of operation for the specific units tested in this study. This is also based on ambient temperatures in the range of 65-70 degrees $\mathrm{F}$ for the heat pumps included. If the ambient temperature were lower the output rate for the heat pumps would also be reduced as seen in Figure 25. In addition, a pool would certainly have thermal losses whenever heat is required. These could be to the ambient air by convection or to the ground soil from the buried pool piping (assuming the ground temperature is less than the circulating water) by conduction or by means of radiant losses from the water surface to the night sky. The resulting losses would require an even longer period of heater operation to make up the difference. This is why when selecting a pool heater the unit is sized with sufficient capacity for the job. There are many large capacity gas-fired units available on the market but as stated the heat pump units selected for testing in this project are among the largest available.

Table 15 does highlight the considerably lower operating costs associated with electric heat pumps in comparison to gas-fired units. The better of the two heat pumps operating 
at 65 degrees $\mathrm{F}$ would cost $33 \%$ less to operate. If the temperature were to drop, for example to 52 degrees $\mathrm{F}$ the unit would still cost less to operate but at a reduced savings of about 22\%. This temperature condition is very low but would be representative of various days during the early spring or late fall swimming season.

Table 16 presents another set of computational results using the same basic data but in this case the cost figures are calculated based on delivering 2,700,00 Btu in order to raise the temperature of the water by 10 degrees $\mathrm{F}$. It assumes the use of larger capacity 300,000 Btu per hour gas-fired units manufactured in the same product lines that are available for sale and use. It is assumed that these larger units will perform at the same level of efficiency as found with the smaller 150,000 Btu units of the same design.

To avoid damage from over heating, a pool heater cannot operate without water circulation. Table 16 illustrates the additional cost that is associated with the operation of a swimming pool's water circulation pump during the use of a pool heater. A reasonable power consumption estimate for an average sized pump with a two horsepower pump is 1,500 watts and this was used in these calculations. In this case the pump was assumed to run only as long as it took to meet the heating demands. As can be seen the better heat pump unit will still operate at a cost advantage but the cost saving is now reduced to 21 $\%$ at an ambient temperatures of 65 degrees $\mathrm{F}$. This cost advantage drops even further to $6.5 \%$ at an ambient temperature of 52 degrees $\mathrm{F}$. It also points out the length of time that could be required to raise a sizeable pool's temperature by 10 degrees F even when ignoring normal heat loss mechanisms that would add to the load. These losses are variable based on many factors but are significant for most of the year.

Table 16 Comparison of cost per 2.7 MMBtu supplied to load, rise of $10 \mathrm{deg}$. F

\begin{tabular}{|l|c|c|c|c|c|}
\hline \multirow{2}{*}{\multicolumn{1}{c}{ Operating Cost Anaysis Results }} & \multicolumn{2}{c|}{ Gas-fired Units } & \multicolumn{3}{c|}{ Heat Pump Units } \\
\cline { 2 - 6 } & Hayward & Hayward & Hayward & Rheem & Rheem \\
\cline { 2 - 6 } & $\mathrm{H}-300$ & $\mathrm{H}-300 \mathrm{HD}$ & HML125L & 8320 ti & $8320 \mathrm{ti}$ \\
\hline Thermal Efficiency & $80.3 \%$ & $85.9 \%$ & {$[450 \%]$} & {$[500 \%]$} & {$[425]$} \\
\hline Thermal COP & {$[0.803]$} & {$[0.859]$} & 4.5 & 5.0 & 4.25 \\
\hline Average Ambient Temperature & $65 \mathrm{~F}$ & $65 \mathrm{~F}$ & $70 \mathrm{~F}$ & $65 \mathrm{~F}$ & $52 \mathrm{~F}$ \\
\hline Btu Output Per Hour & 234,944 & 258,352 & 96,174 & 101,470 & 84,199 \\
\hline Hours to Output 2,700,000 Btu & 11.49 & 10.45 & 28.07 & 26.61 & 32.07 \\
\hline Energy Consumed Gas - Btu & $3,362,148$ & $3,142,638$ & 0 & 0 & 0 \\
\hline Natural Gas - Therms Used & 33.62 & 31.43 & 0 & 0 & 0 \\
\hline Btu Thermal Equivalent of Electric Used & 0 & 9,985 & 598,066 & 539,687 & 637,637 \\
\hline Electric Power Consumption KWh & 0 & 2.93 & 175.28 & 158.17 & 186.84 \\
\hline Natural gas \$ Cost Per Therm & $\$ 1.65$ & $\$ 1.65$ & $\$ 0.00$ & $\$ 0.00$ & $\$ 0.00$ \\
\hline Electric Power Cost \$ Per KWh & $\$ 0.00$ & $\$ 0.22$ & $\$ 0.22$ & $\$ 0.22$ & $\$ 0.22$ \\
\hline Cost to Output 2,700,000 & $\$ 55.48$ & $\$ 52.50$ & $\$ 38.56$ & $\$ 34.80$ & $\$ 41.10$ \\
\hline Additional Pump Operating Cost & $\$ 3.79$ & $\$ 3.45$ & $\$ 9.26$ & $\$ 8.78$ & $\$ 10.58$ \\
\hline Total Cost Per MMBtu Pool Heat & $\$ 59.27$ & $\$ 55.30$ & $\$ 47.83$ & $\$ 43.58$ & $\$ 51.69$ \\
\hline
\end{tabular}

It is fairly obvious from the numbers in Table 16 that the capacity of an electric heat pump needs to be considered. Installing a larger heat pump is not an option as the largest units manufactured only have capacities of 120,000 to 140,000 Btu per hour even at the best of operating conditions (80 degrees F). As discussed the capacity drops measurably as the ambient outdoor temperature drops to levels that might be experienced on the front 
end or the back of the pool use season (60-70 degrees F). The only other option is to install multiple heat pump units at additional expense. This would double the purchase price and in all likelihood drastically increasing the electrician's installation bill to provide the electric power required. If the home's power distribution panel doesn't have the extra capacity to allow for multiple heat pumps to be installed this requires considerable extra costs to install a lager capacity electric service including at least a 200amp distribution circuit breaker panel.

\section{Summary}

This study has presented data on the performance of two generic types of swimming pool heaters, natural gas-fired and electric heat pump units. It has illustrated the measurable operating energy cost reductions with the use of heat pumps in comparison to gas-fired units. In general the use of a heat pump also provides environmental reduction advantages with regard to $\mathrm{CO}_{2}$ and $\mathrm{NO}_{\mathrm{x}}$ emissions. Sulfur dioxide emissions with electric heat pump use are actually higher due to the mix of fuel used to produce the electric power, largely due to the use of oil in some of the power generation units. Measurements of fine particulate mater (PM 2.5) were not included in this study. However, the use of some fossil fuels like residual oil for power generation produces significant levels of primary PM 2.5 emissions. This is difficult to quantify absent any specific data for the mix of fuels used by National Grid. This mix also changes from year to year. Natural gas combustion produces almost insignificant amounts of primary PM 2.5. This report has also pointed out the limitations of heat pump pool heaters. These include the lack of available product lines with medium to large heating capacities. This can limit electric heat pump use to small and medium sized pool applications. It also precludes their use with larger sized pool loads useless multiple units are purchased and a very large investment is made to supply power to the units. The lower capacity limits the ability to satisfy the thermal demand in a timely fashion. The availability of larger capacity gasfired pool heaters can easily satisfy the demand for rapid heating of a pool. This presents tradeoff decisions that the consumer and the pool heater installer need to address.

The heat pump option can provide lower operating costs and with modestly sized pools this may be a very reasonable choice. When the load is significantly larger, the heat pump units with their smaller capacity will require a much longer time to satisfy the demand for heat. These longer periods of operation increase the ancillary costs associated with operating the water filtration-circulation pump, which is required for any heater to function. The operating cost advantage would still favor the heat pump option but its relative savings is reduced. This is an option if the homeowner is willing to accept the much slower response to increasing the heater's set point for pool temperature. If the load is just too large and/or the consumer desires a more rapid response to increases in set point temperature, the heat pump option will not have sufficient capacity to meet these demands. In addition, as the ambient temperature gets colder the load increases just as the heat pump's performance (COP) is decreasing making it less able to satisfy the load demand and/or response time. In comparison the capacity of the gas-fired heater will remain nearly the same regardless of changes in the ambient temperature. The availability of large capacity gas-fired heaters allows for satisfying larger loads and provides a much more rapid response to an increased temperature demand. 